\title{
A Critical Assessment of Power Transformers Reliability in the Nigerian Electricity Supply Industry (A Case Study)
}

\author{
Engr. Isaac Ojochogwu Onuh, Engr. Dr. Stephen Oodo, Engr. Dr. Abubakar Sadiq Umar \\ Electrical Electronics Engineering Department, \\ Faculty of Engineering, University of Abuja \\ Abuja, Nigeria
}

\begin{abstract}
Electricity is a deterministic factor in the development of any nation; the same is the case for Nigeria which constitutes a more complex network of power transmission. Hence, there must be a keen assessment approach to ensure better services. The main aim of this thesis is to qualitatively analyze the practical fault statistics and reliability of power transformer systems in Nigeria (a case study of the Transmission Company of Nigeria, Abuja sub-region) based on Fault Tree Analysis and Statistical Package for Social Sciences, and to demonstrate how this new practical study technique can transform the Nigerian electricity industry through improving the power transformers failures assessment, and hence, enhancing the reliability. The thesis used the qualitative analysis method in the process of gathering data needed to study the problem. The justification for this research work is based on the fact that the techniques of power transformer diagnostic and monitoring have been expanded over the years from inception of this electrical machine in power system; and numerous apparatus abound for the assessment of the state of electrical power transformer, nonetheless there remains a craving necessity for improved diagnostic and monitoring apparatus to assess power transformer state. The causes for the collapses of transformers were practically investigated by the qualitative approach while considering all of the technical and environmental variables, and the assessment yielded the failure statistics of 1196 auto power transformers failures within the period of 6 year in the Transmission Company of Nigeria, Abuja Sub-Region as case study, as well as minimum cut-sets and qualitative importance. The conclusion revealed the main strength and the weakness points of power transformer were core sub-system and coil sub-system, respectively. Summarily, this thesis contributed that the qualitative fault tree technique with practical statistical tool is effortless approach to apply on the power transformer structure, and recommend same to the Electricity Services Providers as a choice technique poised to improving the reliability issue assessment of power transformer to guarantee the functionality and quality of electrical supply of the Nigerian Electricity supply Industry.
\end{abstract}

Keywords - Critical; assessment; power transformers; reliability; Nigeria

\section{INTRODUCTION}

\section{A. Background}

Electricity has been both a tool and a major limitation to the growth of the Nigerian economy since the first power plant was set up in Lagos in 1896. Since then the country has made incredible progress in electrifying rural areas. However, there are still major areas of the grid in need of improvement. Additionally, an unstable electric grid has reduced public trust in electricity and led to the preference towards natural gas, as well as an underutilization of electricity on the whole [1].

Today, the modern electric power system has become very large and complex network like it has never before. In fact, this ranges from a cost of generators, power transformers, distribution lines, and transmission lines to mention but a few. The power transformer remains one of the most essential electrical equipment as far as power system is concerned. More so, power transformer plays an important role especially in transmission and distribution system while transferring the electricity energy [2]. In this case, it is always important to maintain better conditions of power transformer because of its electricity function [3], [4], and [5]. As the energy system continues to become complex, there has been an increasing need for better and tested practical analytical tools that can help in assessing the conditions of power transformer faults [6], [7]. 


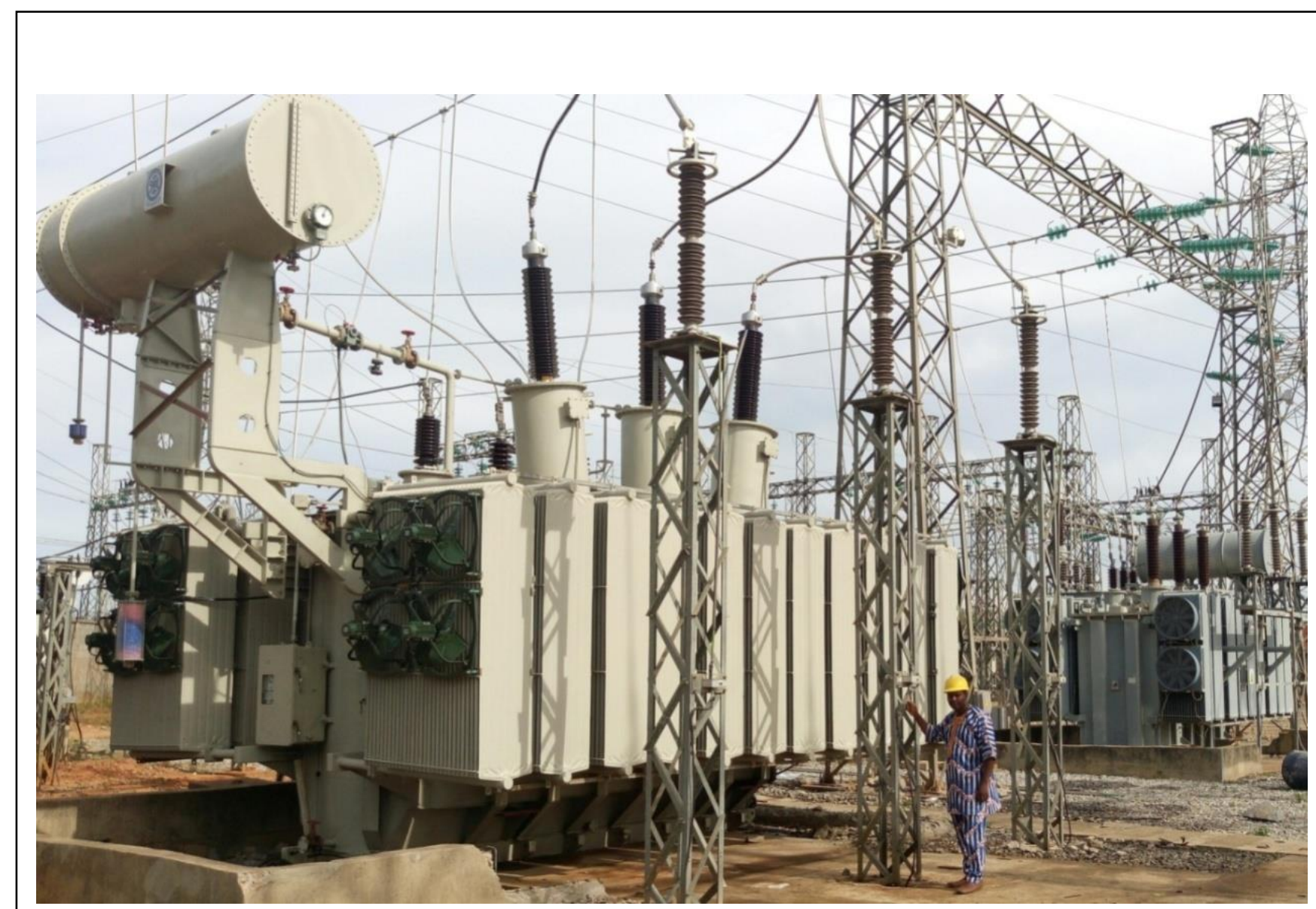

Fig. 1.1: 2 x 60MVA, 132/33KV Auto Power Transformer in 132KV Transmission Station at Katampe, Abuja, Nigeria

\section{B. Statement of the problem}

Not only in Nigeria are power transformers failures usually devastating and costly, it is also applicable to all countries across the globe [8], [9]. The government of Nigeria aims specifically to improve the functioning of its power grid. [10] Ideally, it would function without pause except for scheduled maintenance outages. The problem at hand is that the repetitive failures of the power transformers in Nigeria, and in Abuja specifically, prevent them from achieving that aim. These transformers cost millions in lost productivity when they fail and often lead to continuing infrastructure problems. [11]
However, despite copious amounts of investment and multiple stages of problem-solving research, no solution has been reached as to a consistent cause of power transformer failure. This makes it difficult to enact the sweeping changes necessary to resurrect Nigeria's power transformer systems, and subsequently provide power to its citizens. Should this gap in the knowledge proceed it might prove impossible to ever conclusively repair the challenges that are currently being faced in the country's electrical grid network.

Summarily, in Nigeria [12], [13] and [14] it is an unfortunate fact that rigorous reliability assessments, as well as maintenance programs, has not done much in limiting power transformer faults from happening. In a bid to prepare a comprehensive study, the recommendations to reduce recurrence are necessary for Nigeria to improve in the electricity industry. 


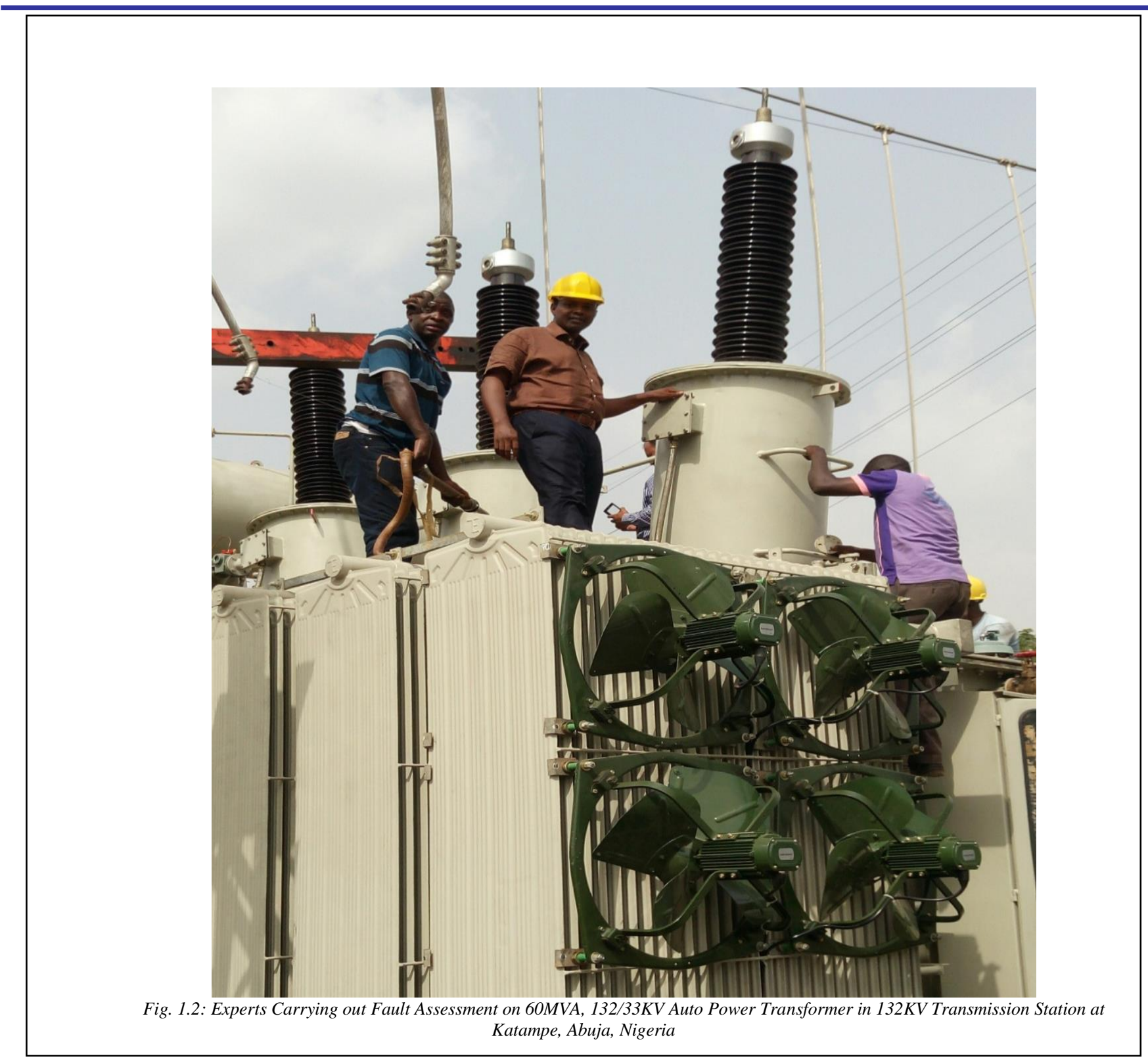

\section{Research Hypotheses}

With the aim of getting to the core of power transformer reliability issues in the Nigerian Electricity Industry - a case study of Transmission Company of Nigerian, Abuja SubRegion, the following hypotheses were presented for validations.

Hypothesis No. 1

The recurrence of power transformer failures in the Nigerian transmission grid network is alarming.

Hypothesis No. 2

There are main causes and effects of power transformer failures that usually contribute to unreliability of the power transmission grid system in Nigeria.

\section{Hypothesis No. 3}

Power transformers reliability in the Nigerian transmission grid system can be improved upon by appliance of a brand new assessment approach

\section{Aims and Objectives}

\section{1) Aim of the Proposed Thesis}

The main aim of this thesis is to qualitatively analyze the practical fault statistics and reliability of power transformer systems in Nigeria (a case study of the Transmission Company of Nigeria, Abuja sub-region) based on Fault Tree Analysis and Statistical Package for Social Sciences, and to demonstrate how this new practical study technique can transform the Nigerian electricity industry through improving the power transformers failures assessment, and hence, enhancing the reliability.

\section{2) Objectives of the proposed Thesis}

i. $\quad$ To apply the SPSS to practically analyze the failure statistics, and to establish the main causes and effects of power transformer faults/failures that usually contribute to its unreliability in the Nigerian power transmission grid system, 
ii.

To apply the qualitative FTA to assess the reliability of power transformer system in the Nigerian Power Transmission Grid System:

a) To qualitatively deduce minimal cut sets; and qualitative importance. The qualitative deduction will aid to concentrate on critical component/subsystem of power transformer that impairs its reliability,

b) To document the causes and effect relationship between failures at various subsystem levels, to spot the key failures and weakness points in power transformers.

iii. To proffer a simple and better approach of improving power transformers reliability, as well as safety tips during operation and transmission in the Nigerian transmission grid system by focusing attention on main apparatus of power transformer that contributed to the unreliability of the system.

\section{E. Motivation}

Our motivation to perform proposed investigation is based on the facts that failures of power transformers on the Nigerian Transmission grid network is usually devastating and costly [12], [15]; and there is a rising recurrence of power transformers failures in the Nigerian transmission grid network [16], [17], and [18]. Hence, it can be regarded as a trial to make available a brand new realistic technique to mitigate reliability assessment of power transformer in the transmission grid system of developing country like Nigeria.

\section{F. Justification}

The justification for this research work is based on the fact that the techniques of power transformer diagnostic and monitoring have been expanded over the years from inception of this electrical machine in power system; and numerous apparatus abound for the assessment of the state of electrical power transformer, nonetheless there remains a craving necessity for improved diagnostic and monitoring apparatus to assess power transformer state.

In this thesis, we proposed a brand new technique for the assessment of power transformer state by the imposition of a combination of the qualitative fault tree analysis (FTA) and statistical package for social sciences (SPSS) kits.

\section{G. Contribution of the Thesis}

This brand new practical assessment technique is captivating for reason that it does not need laborious theoretical work; as well as being a practical apparatus that can effortlessly be used by any engineer. The cause and effect relationship between failures at eight power transformer subsystems levels are documented by this assessment, to spot the weakness points and most important failures in the subsystems.
Summarily, conclusion and recommendation are proffered to allow for contribution for mitigating the challenge of reliability assessment of a realistic electrical power transformer to ensure quality transmission of power and safety of operation of grid network of the Transmission Company of Nigeria.

\section{H. Technical Standards}

1) Power transformer system standards

For the aim of this thesis, the subsequent definitions shall relate [19].

1. Power transformer : a static piece of equipment with 2 or a lot of coils that,by electromagnetic induction changes a system of alternating current and voltage into different system of current and voltage typically of various values and at constant frequency for the aim of transmission of electric power.

2. Auto-transformer: a power transformer that has a minimum of 2 coils which have a typical part.

3. Oil-immersed type power transformer: a transformer of which the magnetic circuit and coils are immersed in oil.

4. Cistern: The component part which serves to shield the operating portions of a transformer from the outside environment. It also houses several other integral structures.

5. Bushing: the component part of power transformer that functions to insulate the electrical mechanisms like coil device components as they transmit information through the apparatus.

6. Coil: the collection of turns making an electrical circuit related with one of the voltages allotted to the power transformer.

7. Core: The ferrous center part of a transformer or inductor used to increase the strength of the magnetic field. It carries the flux and forms the magnetic coupling between primary and secondary.

8. Oil insulation: The oil component of the insulation system serves a dual purpose. It simultaneously insulates and chills specific components of the power transformer to great effect.

9. Chiller: The component part of a power transformer that functions to keep it running at an optimal temperature. This integral system usually comprises of oil pump, cooler and fan.

10. On-load tap-changer: a device for changing the tapping connections of a coil, suitable for operation while the transformer is energized or on load.

11. Casing: It is an integral part that provides the physical barrier of insulation to various internal components of the power transformer.

\section{2) Reliability Assessment Standards}

The following definitions are provided to ensure a standardized perception of chosen terminologies as they are 
distinctively applied in this thesis based on Reliability Assessment Standards for Nuclear Power Plant Application [20].

1. Critical: a paradigm shift or new method that a proposal relies upon to accomplish thriving improvement on the functionality of a system/component.

2. Assessment: the revision and estimation of a brand new technique systematically applied to resolving previously active power transformer issues by spotting its strong point, and area of improvement for further studies, as well as preventing prospective dent caused by the unsuspecting appliance and the trading of the method.

3. Reliability: the capacity of the transformer to accomplish the task as desired under specific situations under which the transformer is subjected to in a specified period of time.

4. Unreliability: The inability of a system/component to meet the requirement external to it and upon which its function depends and is associated with dependent events that are determined by, influenced by, or correlated to other events or occurrences.

5. Availability: The infinitesimal fraction of time that a system/component is competent of handling its role including, but not limited to, the instant is incapacitated for test or maintenance.

6. Unavailability: the tiny proportion of time that a system or component is not competent of sustaining its function including, but not limited to, the instant it is immobilized for test or repairs.

7. System: a deciding unit comprising an interacting assortment of distinct parts.

8. System failure: termination of the ability of a system to execute any one of itsvital intended purpose.

9. Diagnosis: assessment and estimation of data to determine the state of either structures, systems, elements or the cause of the state.

10. Failure : an intolerable departure from the design tolerance or in the expected service delivery, an erroneous output, the powerlessness to execute the desired task

11. Fault: a deficiency, blemish, error or imperfection of varying severity that arises within some hardware or software component or system. "Fault" is a universal terminology and can range from a minor defect to a crash or failure.

12. Dependency : requirement external to an item and upon which its function depends and is associated with dependent events that are determined by, influenced by, or correlated to other events or occurrences.

13. Transient fault: a fault of restricted interval that causes no lasting hardware injury. Transient faults can be originated by undue heat, power outages, timing issues or environmental control, for instance. It is often feasible to recuperate from a transient fault without eliminating the affected component or system.

14. Permanent fault: a fault with durable effects. The failed component or system must be substituted.

15. Failure rate: projected number of failures per unit time, estimated for instance, by the ratio of the number of failures in a population of elements to the total time observed for that population.

16. Failure probability: the chance that any systems, components and structures fail to operate upon command or fail to operate for an exact assignment time.

17. "State of system" fault: a fault with a systemlevel effect that is not essentially restricted at a given component.

18. "State of component" fault: a fault of a component owing to either the failure of the component or the failure of a control signal to the component.

19. Safety system: systems which are planned to prevent or mitigate a blueprint centered accident.

20. Component: a basic event in a power transformer fault tree mold.

21. Fault tree: a deductive logic figure that represent how a particular undesired event can arise as a logical combination of other undesired events.

22. Event tree: a logic figure that starts with an instigating event or state and progresses through a sequence of branches that signify projected system or operator performance that either thrives or fails and arrives at either a successful or failed end condition.

23. Basic event: an event in a fault tree mold that has need of no extra expansion, because the suitable limit of decision has been attained.

24. Undesired event: the peak event of the fault tree.

25. Top event: the opening event of a fault tree or success tree that is also called the undesired event in lieu of a fault tree.

26. Minimal cut set: a least combination of basic events whose incidence results in the incidence of the peak event of a fault tree.

Common cause failure: manifold component faults which arise at the same instance or that arise in a relatively minute instance gap and that are owing to a common cause.

\section{Structure of the Thesis}

This research is dedicated to the appliance of statistical package for social sciences (SPSS) and fault tree analysis (FTA) in power transformer structure. The design of the thesis is structured into four parts which are briefly described below.

In the first part being Chapter two of the thesis, we highlighted the significance of assessment of power transformers, including accelerated yield of electric power demand, installation of refurbished transformer and the ageing factor, software and computer errors, colossal cost of 
handling and replacement and power system collapse. Furthermore in this chapter, we highlighted the IEE guide to failure investigation; recent development in lieu of power transformer failure assessment; the daunting challenges of the Nigerian electricity supply industry; 2020 vision and electricity power outage; equipment for diagnosis and prognosis including FTA and SPSS software and the causes of the power transformer fault relating to FTA. Other issues described are the reliability of the power transformer, and the proposed method.

In the second part being Chapter three of the thesis, we unveiled the technique of the statistical analysis of the failure of power transformers based on SPSS. We also described the method of creating and building the power transformer fault tree method using a case study of the Transmission Company of Nigeria, Abuja Sub-Region. The fault tree structure was built in the order of a hierarchy with a top event, and subsequently, the qualitative FTA of power transformer subsystems. Finally, statistical analysis and FTA analysis were conducted to assess the causes of power transformers operational failures. Minimal cut sets and qualitative component importance were qualitatively deduced. In all, both the SPSS and FTA assessment revealed the weakness point of the power transformer system to be the coil subsystem.

In the third part being Chapter Fourof the thesis, we presented analysis of results and discussion of the research work, which included but not limited to practical assessment of power transformers failures statistics with the aid of SPSS tool, and then power transformer reliability assessment based on the qualitative fault tree analysis (FTA).

In the fourth part which is Chapter five of the thesis, we made presentation of our summary, conclusion and recommendation for future research works.

\section{POWER TRANSFORMER ASSESSMENT}

\section{A. Overview}

The objective of this review is to provide a context in which to view the subsequent investigation into the primary causes of power transformer failure in the Transmission Company of Nigeria, Abuja Sub-Region as case study. It will cover the generally accepted terms discussed in the study, as well as previous attempts to quantify power transformer failure around the world. It will deal specifically with previous investigations into the causes of power grid failure in Nigeria, and the proposed solutions put forth by the various authors of the studies. It will also briefly touch upon the Nigerian government's goals to become a fully industrialized nation by the year 2020, and how the power grid poses a major obstacle to that goal.

Generating plant, power transformers, transmission circuit, distribution circuit and other auxiliary apparatus all constitute the bogus and complex network of a contemporary electric power system. The power system is also referred to the grid system which is subdivided into three groups, namely, the generating station that creates electricity from fossil fuel, solar and hydro sources; the transmission station that step up/step down from extra-high to high levels and vice-visa for the purpose of conveyance to the bulk energy consumers or to the distribution injection stations; and the distribution station that steps down voltage from high to medium levels for the necessity of delivery of power supply to the end users distribution transformers.

A well built power grid system delivers best quality of electrical energy to the end users steadily, reliably and safely in the quantity that is required. Consequently, the grid system and their associated elements require appropriate protection from device collapses and natural hazards, in addition to human errors. The aims of any electric power utility are to sustain network reliability and stability at all time, and to propagate better dependability of power supply to consumers with no outages [21].

Imperativeness of power transformers in the contemporary interconnected power grid system is non-negotiable. According to IEEE/ANSI definition, power transformer is a static electric machine that has no rotating component, engaged in electric power systems to transmit electric energy in any component of the circuits between the generating plant and the distribution primary circuits via electromagnetism principle [22].

The terminology power transformer in the power transmission grid context refers to any transformer connected between the generation station and the distribution station, which are often rated in ranges of 500KVA to several hundreds of MVAs, and with corresponding primary voltage level ranging between $132 \mathrm{KV}$ and $330 \mathrm{KV}$ as in the case of the current status of transmission power grid network in Nigeria.

Being an integral part of power grids around the world since its invention in 1885, the power transformer has played an indispensable role in the modernization and rapid onset of the electrical grid as we know it today. In another definition the power transformer is a device which, in its simplest form, transmits electricity of differing voltages between multiple conductors [23]. The reliability of power transformers is associated with a 20-40 years design life[24]. With adequate maintenance power transformer age can be extended up to 60 years while in service. The internal state of power transformers degenerates with age, which escalates the danger of potential collapses. Incidents such as short circuits, transient switching, lightning strikes, and sabotages, amongst others are responsible for power transformer failures. Of note, a brand new power transformer has adequate mechanical, chemical and electrical strength to oppose harsh system condition. But as power transformer grows old, the insulation can weaken to the extent that they will no longer be able to cope with inimical system events like transient over voltages or short circuit faults [21].

Moreover, power transformers are notably prone to failure, due primarily to the nature of their wiring. Because of this, much work has been done on the subject of determining the causes of power grid failures across the globe. Bushing is generally considered the primary source of power transformer failure [21].

B. The Significance of Assessment of Power Transformers. Power transformer being one of the most essential apparatus in power grid system plays a vital function by transforming the electrical energy from one level of voltage to another by the principle of electromagnetic induction. In [25] the Electric Power research Institute (EPRI) submitted that the 
meaningful life span of power transformer is unilaterally the most vital technique for a corresponding expansion of the life of power grid infrastructures.

In another study, CIGRE Working group 12/05 under the team lead of Bossi in 1983 published a report reviewing the outcome of an assessment of data pulled together on failures of titanic power transformers below twenty years of age that happened between the year 1968 and 1978, associated with 1000 failures in an overall population of beyond 47000 unityears that matches with a universal failure rate number, not particular of the role of the units and classification of voltage, of the ranking of $2 \%$ [26]. However, it appears that the failure rate skyrockets with voltage if voltage classifications are considered. Assessment of available data was carried out in correlation with foremost component failure involved and of the anticipated cause. The statistically valid outcomes are the ones associated with substation transformers with on-load tap changer. It was highlighted that about $33 \%$ of failure resulted coils [27].

Itemized below is the significance of the assessment of power transformer status.

\section{1) Accelerated yield of electric power demand}

The global electric energy requirement is forecasted to double amid years 2000 and 2030 respectively at a yearly escalation rate of $2.4 \%$. Electric energy demand escalation has the most muscular inclination in countries under development, where above $4 \%$ per annum over the forecasted time demand rise anticipated, above tripling by the calendar year 2030 [28]. Resultantly, a brand new vehicle of electric grid system, particularly power transformer, necessitates a remodeling. The loads expansion and the rise in bulk energy management hasten the material ageing development of power transformer because of corresponding rise of the running traumas.

factor

\section{2) Installation of refurbished transformer and the aging}

Globally, age strata of the power transformers is philosophical of power grid network components with astronomical proportion of power transformers in excess of 20 calendar years, as depicted pictorially in figure 2.1 [29]. Saying it in another way, ancient or refurbished power transformers similarly occupy pertinent nodes on the power grid system. In [30], [31], and [32] the average step-up power transformer life is regarded as 20-29 years, whereas, practically the lifespan of power transformers can extend to about 60 years with adequate handling. Implementing appropriate assessment and handling techniques will elongate the power transformer lifespan.

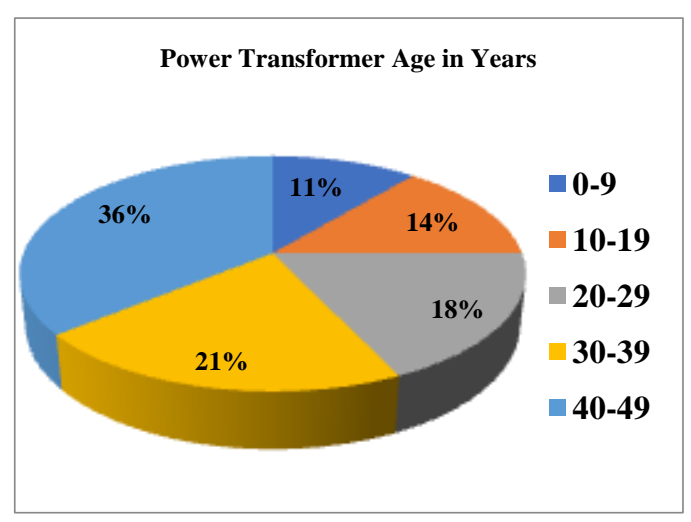

Fig. 2.1: Age Circulation for Power Transformers [29].

\section{3) Software and computer errors}

The functionality of power transformer control and protection systems is determined by Programmable Logic Controller (PLC) in the contemporary period. The protection system is designed to instantly trigger in the event of any atypical status of the power transformer, to absorb its subsystems from avertable injuries. Logical malfunction like software design errors give important contribution to system unforeseen causes of event based on the fact that the reliability of hardware system improves with progression of technology. Human errors are also major reasons for accident in the power grid system. For power transformers, the dependability of smart control and protection systems requires logical assessment for integrity of safety of system [33].

\section{4) Colossal cost of handling and replacement}

Power transformer being a vital organ in the electric power grid network requires lifespan improvement to circumvent colossal cost of its replacement. Poor handling of power transformer leads to its failure. To evade the colossal power transformer repair and handling expenses, the facility for its assessment requires modification without compromising its reliability.

\section{5) Power system collapses}

Without controversy, failures of power transformer impair the power grid network reliability. Whereas it may be complicated to expressly evaluate the effect of a failure for the dependability of power grid network, it is doable to assess it by appliance of some techniques. For example, power transformer failure with excessive loading is far weightier than with minimal loading [34]. Power transformer quality and security of operation is very vital because unwarranted collapse of the machine may cause accident that yields to penalty in lost end product cost, in particular in an everescalating viable atmosphere.

\section{IEEE Guide to Failure Investigation}

The Institute of Electrical and Electronics Engineers (IEEE) sets the standards worldwide for many forms of investigation as well as industries and professional organizations, not 
precluding investigations into power transformer failures. In 1992, the IEEE published the seminal guide for all subsequent investigations into power transformer failures. In it, they recommend a system of data collection designed to be as routine as possible and come to consistent conclusions as to the cause of power transformer system failures such as in [35]. See Fig. 2.2.

\section{Power Transformer Components Failures}

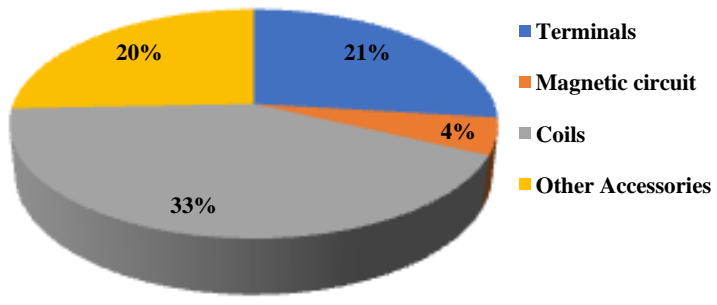

Fig. 2.2: Characteristic Collapse Circulation for Power Transformers [35].

Their recommendations inform this investigation.

D. Recent Work Done

In most cases, a power transformer can fail from different combinations of electrical, thermal causes or even mechanical. In other words, a power transformer fault can be caused by more than one factor [8], [9].
In Nigeria it is important to understand why there is still an increase of power transformer faults despite the government's efforts [12]. Power transformer core problems have been attributed to core insulation fault, an open ground strap, or shorted laminators. Other miscellaneous faults have been caused by current power transformers, oil leakage owing to inadequate cistern welds, oil contamination from metal particles, overloads and over voltage. The factors responsible for faults and accelerated deterioration can be categorized as follows:

i. Operating Environment (Electrical): Load current, short circuits, lightening and switching surges;

ii. Operating Environment (Physical): Temperature, wind, rain, pollution;

iii. Operating Time: Time in service and time under abnormal conditions;

iv. Number of operations of tap changer;

v. Vibration effect: sound and material fatigue;

vi. Contaminants: moisture, presence of oxygen and particles in oil.

A relationship between the causes and the effects produced at the flaw is presented in Table 2.1 [36]. Usually, one fault type may have more than one cause. Example: arching and/or overheating of solid insulation may have as cause, coil turnto-turn short-circuits; arching and corona discharges may have as cause, free water or excessive moisture in oil, etc. This makes fault location very complex. Nevertheless, fault diagnosis is good enough to provide information to a maintenance program, and serve as the basis of a preventive maintenance strategy.

Table 2.1: [36] Relationship between Power Transformer Internal Faults and Causes.

\begin{tabular}{|c|c|c|c|c|}
\hline \multirow[t]{2}{*}{ Causes of the internal faults } & \multicolumn{4}{|c|}{ Description of the internal faults developed } \\
\hline & Arcing & Corona & $\begin{array}{l}\text { Overheating of } \\
\text { cellulose }\end{array}$ & $\begin{array}{l}\text { Overheating of } \\
\text { oil }\end{array}$ \\
\hline Short-circuited coil & 1 & & 1 & \\
\hline Open circuited coil & 1 & & 1 & \\
\hline 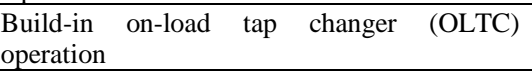 & 1 & & & \\
\hline Displacement or distortion of coil & & 1 & 1 & \\
\hline Displacement or distortion of lead & & 1 & 1 & \\
\hline $\begin{array}{l}\text { Slack connection at the bushing terminals, } \\
\text { terminal board, and tap leads }\end{array}$ & 1 & 1 & 1 & \\
\hline Excessive foreign liquids in oil & 1 & 1 & & \\
\hline Floating metallic detritus & 1 & 1 & & \\
\hline Wobbly bond to corona shields & & 1 & & \\
\hline $\begin{array}{l}\text { Unfastened core ground, spacers, collars, } \\
\text { straps, core hold down angle (braces) }\end{array}$ & & 1 & & \\
\hline Through fault & & & 1 & \\
\hline Excessive loading & & & 1 & 1 \\
\hline Yoke bolt insulation injury & & & & 1 \\
\hline Rust or other injuries on the core & & & & 1 \\
\hline Injured shunt packs of cistern & & & & 1 \\
\hline Blocked oil pipe & & & & 1 \\
\hline Chiller Subsystem collapse & & & & 1 \\
\hline
\end{tabular}


In another studies [37] a detailed analysis of Power transformers faults conducted by a major electrical equipment insurer breaks down the causes of Power transformers faults based on the power transformers they insure. Table 2.2 shows the insurer's breakdown of the causes of faults, included approximately 8,000 insured power transformers. One of the insurer's conclusions is that whatever the cause of faults, age compounds the problem. Therefore, the proper detection and isolation of aging power transformers warrants careful attention from industrial facility engineers.

\begin{tabular}{|l|c|}
\hline \multicolumn{2}{|c|}{ Table 2.2: [37] Causes of Power Transformer Faults } \\
\hline \multicolumn{1}{|c|}{ Cault } & $\begin{array}{c}\text { \% of faults } \\
\text { developed }\end{array}$ \\
\hline Insulation collapse & 26 \\
\hline Manufacturing issues & 24 \\
\hline Unknown effect & 16 \\
\hline Slack connections & 7 \\
\hline Through Faults & 5 \\
\hline Careless handling & 5 \\
\hline Foreign particles in oil & 4 \\
\hline Excess loading & 4 \\
\hline Fire/outburst & 3 \\
\hline Lighting spikes & 3 \\
\hline Flooding issues & 2 \\
\hline Foreign liquids & 1 \\
\hline
\end{tabular}

In 2015 Ambuj Kumar and his fellow researchers at the National Institute of Technology in Hamirpur, India attempted to conclusively determine the cause of power transformer failures in the substations of the Gujarat state of India. They gathered information about the various power transformers to utilize as a baseline and conducted testing and investigation to ascertain whether the failure was due to electrical breakdown, mechanical breakdown or thermal breakdown. They concluded with a list of recommendations to avoid further power transformer failures, include stricter regulation and regular maintenance work [38].

Kumar et al. conducted their study in an environment similar to the one in Abuja. Both the Abuja transmission sub-region and the Gujarat state of India are both highly unregulated areas in terms of power transformer activity, and both tend to overload the capacity of their respective power grids with increased demands that the grids are ill-equipped to handle. It is interesting to note that at the end of their study, Kumar et al. recommended as is noted here that more care should be taken with the coils of the many power transformers in the region as to prevent power transformer failures.

\section{E. The Daunting Challenges of the Nigerian Electricity Supply Industry}

The work in [8] attempted to quantify the relative condition and reliability of the Nigerian electrical grid alongside the social and economic ramifications of its current status that rated below international standards of quality. The researchers travelled throughout Nigeria in an attempt to gather data through interviews and observation. They conclude that the major factors negatively impacting Nigeria's electricity grid are an underutilization of resources like natural gas, of which the country has copious amounts, aging infrastructure of the grid itself, much of which was erected in the mid-20th century, an inaccurate metering system and signification, grid outages. These outages were said to occur frequently and caused something of a regional emergency every time they occurred [39].The authors of the study offer no concrete solutions at the finish of their work on how to improve Nigeria's power grid, except that swift and effective action must be taken by both government and private entities to overcome the challenges the grid faces. Their work however underscores the urgency with which power grid problems must be addressed in Nigeria, so as not to pose a further impediment to the country's development. Concerned about the issues of erratic electric power supply in Nigeria, in [40] Study work was executed on detailing the underutilization of electricity; primarily due to the unstable nature of the grid itself paints a telling portrait of the current electric situation in Nigeria. The author through a metaanalysis of sort distils the major causes as he sees them of Nigeria's electrical grid failures. He concurs with previous works on the subject in saying that the causes of the grid failures in the region centre around aging infrastructure and the lack of a clear action plan on the subject. While noting the huge role power transformers play in the region, he also goes a step further, naming power transmission infrastructure as a specific area in need of improvement. Somefun also sees vandalism and poor regulation as negatively impacting the sector on the whole. His recommendations as to solutions on the topic are limited, even as he decries the government for the same "ad-hoc" approach [40]. He proposes diversifying energy sources, and leaning further into wind and solar energy, rather than continue to rely on an irregular electric network. His solutions as to infrastructure requirements include, as this work does, consistent maintenance of the systems of the grid. He adds that this may incur extra costs; however the benefits far outweigh any temporary budget constraints. This work adds more contexts to the general understanding of the Nigerian power grid. Specifically, where the challenges are and what is being done, as of now, to address them.

\section{F. 2020 Vision and Electrical Power Outages}

"Electrical Power Outage in Nigeria: History, Causes, and Possible Solutions" details many of the same grid issues lamented by the authors of the previous studies; however it details them from the interesting position of government reaction and potential interventions. It terms the outages "embarrassing" and notes that they do not spare the president when they occur, as when in 2009 they caused failures even to the presidential mansion in the wake of a particularly sweeping power outage. The study details the government's efforts to industrialize the nation by the year 2020; the administration's 20-2020 vision. (The first twenty denotes the number of fully "industrialized" countries there are currently in the world.) The article points out the poor maintenance transformers suffer resulting in voltage drops and poor performance. In fact, one of the author's strongest recommendations surrounds the regular maintenance of power transformers [41].

\section{G. Equipment for Power Transformer Prognostics and Diagnostics}

Since the creation of power transformer several prognostic and diagnostic methods have been invented. The term "Prognostic" expresses a basic factor measurement with threshold alarms, whereas, the term "Diagnostics" 
illustrates the extra of complicated analysis, such a proficient system capable of delivering an assessment of apparatus state and recommended actions [42], [26].

Diversity of equipment is presented for the assessment of the condition of power transformer [43] - [53]. Often used diagnostic techniques are based on: electrical, optical, chemical, thermal and mechanical diagnostic techniques respectively. As well they can be grouped into traditional diagnostic techniques that have been employed in widespread use for numerous years and non-traditional techniques that vary from techniques which implementation just commenced to those that are still being incubated in the research stage [54]. Thermograph, power factor testing, dissolved gasses analysis, coil resistance and insulating oil quality testing constitute traditional diagnostic techniques. Whereas, recovery voltage measurement, tap changer/motor monitoring, dielectric spectroscopy, in service testing, coil insulation oil testing, coil movement detection, on-line power factor measurement, internal temperature measurement, expert system and software diagnostics respectively, all constitute non-traditional techniques for which a great deal of the new developed methods have been used for transformers. [21].

1) Fault Tree Analysis (FTA) and Statistical Package for Social Sciences (SPSS) Software.

The FTA and SPSS facilitate precise statistical analysis of the transformer failure, and identification of the qualitative deductions and minimum cut sets.

In this instance, one of the analysis tool used is SPSS. The software app facilitates statistical, batched and interactive analysis. Also, it facilitates file reshaping, case selection, formulation of derived data and information documentation. The software handles a variety of functions, including geospatial simulation, factor or cluster prediction; linear regression, correlation and t-tests; and detailed calculations. In this case, the SPSS avails options for data analysis in the pull-down menu; an example is the command syntax programming [55]. The concept allows researchers to handle complex data related to the electric power system in Abuja; identify the patterns and manipulate the information. Also, it helps to estimate the reliability of transformers, their causes of failure and effects of damage.

Another analysis employed in this thesis is the fault tree analysis (FTA). The FTA is a visual representation of the direction of failure from the smallest component [3]. The technique helps professionals to determine the estimate the reliability of a unit and cause of a fault. In FTA, the Boolean logic used to review the undesired state of a system. The logic data includes using instructions such as "OR", "AND", "NOR", "EXLUSIVE-OR" and "EXCLUSIVE-NOR" on low-level events. In most cases, FTA used in reliability and safety engineering; that is, the technique helps formulate a risk management plan; or mitigate effects of a science problem. In this case, the analysis involves dividing the power transformer system into several vital sub-units and using logic gate symbols to represent the flow of events [14]. The cut set symbol is the collection of activities such as component failures causing a fault in the entire system.
Ideally, the minimum cut set is the number of events which cannot eliminate without affecting the top function; that is, power supply. Research has also utilized the event trees as an analysis tool. The strategy helps to identify the initiator that is power transformer failure and the series of system activities affected by the fault. Each event is a new node with the probability of several split branches. For instance, the transformer level has departments such as "operational" and "not functioning." The event symbols in FTA include the conditioning; undeveloped; external and essential events. The primary activity is an error in a unit; in this case, it is the failure of transformer parts such as the core, insulation, casing, or bushings. The external event is an operation that usually happens. An example is the operation of the Buchholz relay in transformers. On the other hand, the undeveloped event is an activity which the researcher has insufficient data concerning it. Also, the game lacks any consequence; in this case, the business is transmission cables connecting the electric grid. The conditioning activity is the event which influences or restricts the logic gates; an example is the optimum mode of operation for transformers. The Boolean gates play a pivotal role in FTA analysis. The construction of a realistic qualitative fault tree (FTA) of power transformer subsystems cannot be achieved without knowledge on the prevalent faults on the vital subsystems of the power transformers.

A combination of both SPSS and FTA tools creates the cause-effect relationship between the highlighted power transformer subsystems, including Coil, Bushing, Core, and On-load Tap Changer (OLTC), amongst others respectively; this allows researchers to formulate simple and better approaches to improving the reliability assessment of power transformers.

2) Causes of the power transformer faults relating FTA The various reasons for the failure of transformers include the insulation failures, errors during manufacturing, contamination of oil, overloading of the transformer, connections that are loose, natural causes as well as human causes.

The qualitative FTA technique is used for the investigation of the various faults to identifying the unwelcoming form of the structure in a particular manner. This is a model that uses graphics that are arranged in form of sequential and parallel combinations of faults. The faults are arising from the occurrence of a redefined event that was not desired. For this specific proposal, the faults that we are dealing with are the power transformer faults [56]. The cause of the faults is human errors, failure of the parts of the transformer or occurrence of any other pertinent event. Scientists and engineers have used fault tree analysis to show the relationship in between the basic events that are noted to cause the undesired event. The undesired event is found at the top of the fault tree [57]. In this specific case, the undesired event is the malfunction of the power transformer. The attractive feature of using FTA is that it starts from the topmost event and then identifying the root causes of the main event [57]. Most transformers have been constructed such that they can be adjusted by reducing on increasing the number of turns of their coils. 
3) Chief incident offpower transformer malfunction Main causes of the failure consist of Mechanical, Thermal, Electrical, Chemical, and Electromagnetic stresses respectively. The five are the main causes of failure of transformers combination or non-combinational state. The five are as a result of various factors that include age, manufacturing errors, human factors and the environment conditions subjected to the transformers [58]. The leading cause of failures of transformers is line disturbance and it includes voltages spikes, line fault, switching surges as well as other abnormalities. The following are the electrical factors that can cause a transformer to fail.

A. Electrical Faults: A transformer can fail when it has been operated in transient or sustained overvoltage conditions. Such an activity results in overstressing the insulation and the overheating of the core.

i. A transformer can fail when it has been operated in transient or sustained overvoltage conditions. Such an activity results in overstressing the insulation and the overheating of the core.

ii. Disclosure to switching and lightning surges. The two are noted to be the main cause of both mechanical and electrical damages, hence compromising the integrity of the power transformers [57]. The surges are characterized by large magnitude travelling waves that have the speed of light. The basic Impulse level is incorporated into the design of the transformer to detect the level of lighting and switching surge voltages and then determines the level at which the transformer can tolerate without being damaged. In addition to this, there is a need to install surge arresters than need a careful selection to ensure the desired performance will be arrived at. A transformer that has failed due to lighting and switching surges shows damages that are localized at the line-end terminals.

iii. Partial discharge. The problem is caused by contamination of the insulation system, manufacturing defects, and poor design of the insulation system[59]. It is mainly connected to the low-intensity arching. In turn, it causes localized damage to the insulation and the conductor.

iv. Static electrification is the other fact that is noted to cause electrical faults of a transformer [59]. The phenomenon takes place whenever the insulation oil has low temperature and the thickened oil is circulating in a rapid manner. Basically, the static charge develops in between the oil and the metal components of the transformer.
NB: The above electrical factors are discovered to cause failure of the power transformer in combination with other thermal or mechanical evidence.

B. Thermal Factors: The factors mainly cause degrading of the physical strength of the insulation, hence unable to withstand the mechanical duty imposed on it by mechanical or vibration means inside of the transformer

a. Blocked oil duct. The blockage prevents the flow of cooling oil in the Coils.

b. Overloading: The overloads go beyond the design specifications.

c. Chiller Subsystem failure: This can be as a result of the failure of pumps, blockages of coolers or radiators and failure of the directed flow oil distribution.

d. Exposing and making the transformer to operate in an overexcited condition. The conditions include low frequency or overvoltage. The effect of these is that they cause excessive stray magnetic flux that leads to overheating of the insulation that has close remoteness to the core and other structural members.

e. Operating transformers under excessive temperature conditions is the other form of thermal failure of a transformer.

C. Mechanical Induced Factors: The mechanical factors cause deformations of the Coils which lead to the rupturing of the cellulose insulation [60]. In an extreme situation, the transformer fails the electricity. The rupturing of the Coils takes place in two forms. One of the forms is through electromechanical forces and the other is the shipping damage. The various mechanical factors include:

a) Conductor tipping. This specific problem is mainly connected to the helical Coils. The damage of the insulation due to conductor tipping usually leads to electrical failure almost abrupt.

b) Hoop buckling of the innermost Coil. The conductor is noted to buckle inwards towards the core. Extreme cases are characterized by the fact of the buckling resulting in the damage of the paper insulation. Basically, the magnitude of damage dictates whether the damage will take place or not in an abrupt manner.

c) Telescoping of the conductor. This happens in the case where the conductors that have layer Coils are exposed to excessive axial forces[60]. The result of the conductor telescoping includes making the layer of the conductor being mechanically unstable as well as causing damage to the insulation of the paper. 
d) Tightening of the spiral. The same case as in the problem of conductor telescoping, tightening of the spiral involves layer Coils but in this case, the forces that are in action are radial forces.

e) Crushing of the end ring. The failure results whenever the axial forces on the Coils are beyond the capabilities of the hoop.

f) Coil clamping system failure. This is a system whose purpose is to ensure a relentless clamping force on the coils all the time. The abrupt rise in the flow of current in transformers leads to the formation of electromechanical forces that distribute in the Coil coils except in the axial direction. Basically, the system prevents the movements of the coils. The implication of this is that failure of the coil clamping system causes deformation of coils as well as damage to the cellulose insulation, a scenario that causes an immediate electrical failure.

g) Outgoing and incoming leads disarticulation: This takes place when supports of the leads breaks or space formed where the leads originate from the Coils [60].

Power transformer fault tree is made include sub-trees such as the cooling system, core, cistern, and bushing sub-trees. The sub-trees are combined to form the main power transformer fault tree.

\section{H. Reliability of Power Transformers}

Reliability is the capacity of the transformer to accomplish the task as desired under specific situations under which the transformer is subjected to in a specified period of time. The reliability-centered maintenance is the other aspect that needs to consider when dealing with the power transformer reliability assessment [26]. It is a fact that any physical asset should be maintained and assessed from time to time and it may also require modifications. It is much of importance to put into considerations the cost of maintenance of the physical assets; in this case, the physical asset is the power transformer [61]. The efficiency of the electric power transmission is highly dependent on the maintenance and assessment of the various components of the power transformer. Power transformers are designed to perform a number of passive and active functions [62]. This being the case, the reliability of the power transformers is assessed by focusing on the required functionality on being able to operate with minimal failures.

\section{Proposed Method}

As per the current status, there is the application of Power Transformer assessment techniques. The approach is replacing the conventional assessment techniques. The qualitative FTA with SPSS coloration makes use of eight power transformer subsystems/components. These are the critical components of the power transformer system as they are the ones that measure the reliability of the power transformer [61].

In this perspective, the thesis proposed among others things a brand new approach of assessing power transformer failures related and reliability issues. More so, the study aimed at employing the qualitative analysis methods in investigating power transformer failures in Transmission System of the Nigerian Electricity Industry - using Abuja Transmission Sub-Region as a case study. According to the research, the failure of a transmission power transformer has always affected people in Nigeria by leaving them without heat and light. In fact, the fault of a step up power transformer in most of the power generation plants usually causes the shutdown of different attached generation units [36], [63], and [64]. This qualitative investigation has helped focus the attention on the main cause of power transformer failures that usually contribute to the unreliability of the transmission system in Nigeria [65]. The study highlights the shift from the conventional assessment approach to the current methods like practical analytical approaches based on qualitative fault tree analysis (FTA) and statistical package (SPSS) tools to improve reliability assessment.

The statistical analysis with the qualitative FTA reliability assessment of power transformer system is characterized by a higher level of efficiency [66]. This implies that use of the SPSS analysis with the qualitative FTA reliability assessment coloration on power transformer system will make the supply of electricity in Abuja region to be of better quality and characterized by lower costs.

\section{1) Reliability of power transformers based on SPSS and}

\section{FTA}

Reliability is the capacity of the transformer to accomplish the task as desired under specific situations under which the transformer is subjected to in a specified period of time. A combination of the qualitative SPSS and FTA approach was used to analyze failures of transformers in Abuja Transmission Sub-region. This approach is important as weaknesses in the overall system were identified and necessary steps were taken to elevate the level of reliability assessment of the power transformers. The application of this combination technique for the achievement of the chance of component failure resulting power transformer failure is the basic inspiration of the proposed power transformer reliability assessment analysis. Power transformer reliability is being assessed with this technique to establish a guiding principle of operation and maintenance. The finest management of the system, security, dependability and maintenance of the power transformer safety with minimal fund is a component of foremost motivation of measuring reliability issues. Usually, any proposed reliability of power transformer protection is easily compared with the application of fault tree analysis tool by the protection engineers.

Finally, the application of the combination technique of analysis is not only restricted to an existing system but also to the one under design stage. The SPSS and FTA is the approach that is used analyzing faults of transformers in Abuja region. This approach is important as weaknesses in the overall system will be identified and necessary steps are 
taken to elevate the level of reliability of the power transformers. Power transformers are designed to perform a number of passive and active functions [67]. This being the case, the reliability of the power transformers will be assessed by focusing on the required functionality on being able to operate with minimal faults. In this case, the proposed thesis presents new simple and better methods based on SPSS and FTA of assessing power transformer failures, recommendations that may establish reliability on the system as well as safety tips during operation and distribution.

\section{MATERIALS AND METHODS}

\section{A. Overview}

The Transmission Company of Nigeria Abuja Sub-Regional office located on the Apo District of the Abuja Municipal Area Council (AMAC) in Nigeria is made up of thirty-two (32) auto power transformers installed on eleven (11) 132/33KV Transmission Stations and two (2) 330/132KV Area Control Centers (ACC), with the power transformers apparent power rated capacities ranging from 7.5MVA to 150MVA respectively, and the choice of the installed capacity in each of the distributed transmission station locations depends on the connected consumers' load demands - see appendixes A \& B. The consumers include industries who are major consumers of the Nigeria electric power - the population reliability model. The types of power transformers in this research, namely auto-power transformers have the following standard specifications:

i. All equipped with basic accessories which include but not limited to conservator cistern, bushing, silica gel, pressure relief machine, temperature indicator, buchholz relay device, sudden pressure relay system, and oil level indicator.

ii. Chiller system configuration: oil natural air natural (ONAN), oil natural - air forced (ONAF), and oil forced - air forced (OFAF), equipped with circulatory system, fans and oil pumps.

iii. Also furnished with on-load tap changer and other optimal components.

Power transformer reliability relies on the states of its vital subsystems, and defect in one of these subsystems can result to failure. Moreover, other factors such as aging of the insulation materials and lifespan of the subsystems have great control on the operation of power transformers. In this thesis the primary components include: Coil, Bushing, Core, Oil Insulation, Cooler, On-load Tap Changer (OLTC), Cistern and Casing Subsystems respectively.

\section{B. Method of Data Collection}

The collection of data required in this thesis was based on gathering general information on power transformer failures - of within the past six years' period (2013 to 2018) - in the Transmission Company of Nigeria, Abuja Sub-Region while using the qualitative method. More so, interviews with various departmental heads, as well as heads of stations, of the Transmission Company of Nigeria, Abuja Sub-region were carried out. In this case, the researcher made some study visits to power transformer locations (various Transmission Stations within Abuja Sub-Region of the Transmission Company of Nigeria) to study the power transformers conditions. Consequently, all the records of 1196 power transformer failures that were made available to the researcher by the interviewees were inputted into the laptop computer system and were further analysis by appliance of SPSS. The SPSS result outputs complimented the qualitative FTA power transformer reliability assessment; and they were also documented in the hope to facilitating their future appliance on the quantitative fault tree analysis technique on power transformer reliability studies - refer to appendices A, $\mathrm{B} \& \mathrm{C}$ respectively.

\section{Fault Tree Analysis (FTA) and Statistical Package for Social Sciences (SPSS) Software}

The study included two analysis tools; the fault tree analysis (FTA) and Statistical Package for Social Sciences (SPSS). However, the research also entailed reviewing findings from the interviews and qualitative study. In this case, the FTA and SPSS facilitated precise analysis of the transformer failure, identification of the qualitative deductions and minimum cut sets

\section{1) Statistical Package for Social Sciences (SPSS)}

\section{Software}

One of the analysis tool used is SPSS. The software app facilitates statistical, batched and interactive analysis. Also, it facilitates file reshaping, case selection, formulation of derived data and information documentation. The software handles a variety of functions, including geospatial simulation, factor or cluster prediction; linear regression, correlation and t-tests; and detailed calculations. In this case, the SPSS avails options for data analysis in the pull-down menu; an example is the command syntax programming [55]. The concept allows the researcher to handle complex data related to the electric power system in Abuja; identify the patterns and manipulate the information. Also, it helps to estimate the reliability of transformers, their causes of failure and effects of damage.

Consequently, the analysis tools create the cause-effect relationship between the highlighted eight (8) power transformer subsystems, including Coil, Bushing, Core, Oil Insulation, Cooler, On-load Tap Changer (OLTC), Cistern, and Casing respectively; this allows the researcher to formulate simple and better approaches to improving the reliability assessment of power transformers.

\section{2) Fault Tree Analysis (FTA) Software}

The fault tree analysis is a visual representation of the direction of failure from the smallest component [10]. The technique helps professionals to determine the estimate of the reliability of a unit and cause of a fault. In FTA, the Boolean logic is used to review the undesired state of a system. The logic data includes using instructions such as "OR", "AND", "NOR", "EXLUSIVE-OR" and "EXCLUSIVE-NOR" on low- 


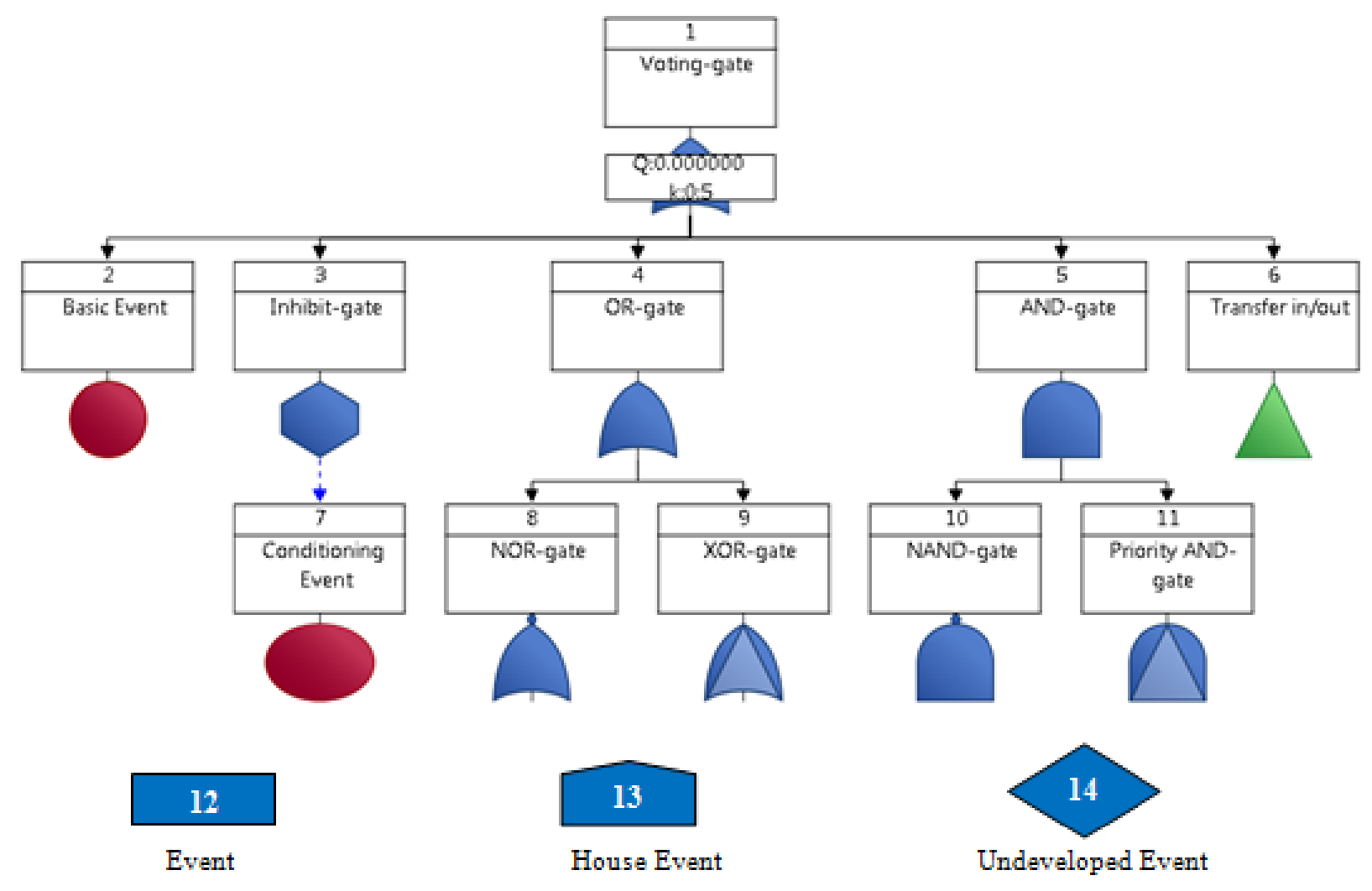

Fig. 3.00: Pictorial Listing of Fault Tree Analysis Symbols

level events as in Fig. 3.00. In most cases, FTA used in reliability and safety engineering; that is, the technique helps formulate a risk management plan; or mitigate effects of a science problem. In this case, the analysis involves dividing the power transformer system into eight (8) sub-units and using logic gate symbols to represent the flow of events [68]. The cut set symbol is the collection of activities such as component failures causing a fault in the entire system. Ideally, the minimum cut set is the number of events which cannot eliminate without affecting the top function; that is, power supply. The research also utilized the event trees as an analysis tool. In this case, the strategy helps to identify the initiator that is power transformer failure and the series of system activities affected by the fault. Each event is a new node with the probability of several split branches. For instance, the transformer level has departments such as "operational" and "not functioning." The event symbols in FTA include the conditioning; undeveloped; external and essential events. The primary activity is an error in a unit; in this case, it is the failure of transformer parts such as the coil, bushing, core, oil insulation, cooling system, on-load tap changer (OLTC), cistern, and casing. The external event is an operation that usually happens. An example is the operation of the Buchholz relay in transformers.
On the other hand, the undeveloped event is an activity which the researcher has insufficient data concerning it. Also, the game lacks any consequence; in this case, the business is transmission cables connecting the electric grid. The conditioning activity is the event which influences or restricts the logic gates; an example is the optimum mode of operation for transformers. The Boolean gates play a pivotal role in FTA analysis. 
Table 3.00: Definitive Description of Some Fault Tree Analysis Symbols [68]

\begin{tabular}{|c|c|c|}
\hline $\begin{array}{r}\text { ITEM } \\
\text { LABEL }\end{array}$ & NAME & DEFINITIVE DESCRIPTION \\
\hline 1 & Voting-gate & The Voting-gate depicts that the output event happens if $\mathrm{k}$ or no one of the input events happen. \\
\hline 2 & Basic Event & $\begin{array}{l}\text { The Basic Event represents the bottom or initiating event or event in a fault tree mold that has need of no } \\
\text { extra expansion, because the suitable limit of decision has been attained. }\end{array}$ \\
\hline 3 & Inhibit-gate & $\begin{array}{l}\text { The inhibit-gate shows that the output event occurs if the input event occurs under a possible state } \\
\text { identified by a conditioning event }\end{array}$ \\
\hline 4 & OR-gate & $\begin{array}{l}\text { The OR-gate depicts that the output event occurs if any or all of the input events occur. This means that } \\
\text { If all input events do not occur then the output event will not occur. }\end{array}$ \\
\hline 5 & AND-gate & $\begin{array}{l}\text { In AND-gate scenario, the output event occurs when all input events occur simultaneously. Otherwise, } \\
\text { the output event will not occur. }\end{array}$ \\
\hline 6 & Transfer-in/out & $\begin{array}{l}\text { Transfer-in/out symbols are employed to join the input event and output events of associated fault trees. } \\
\text { For example, connecting the fault tree of a subsystem to its system. }\end{array}$ \\
\hline 7 & Conditioning Event & $\begin{array}{l}\text { Conditioning Event is the event conditions that bar or influence logic gates, such as state of function in } \\
\text { effect. }\end{array}$ \\
\hline 8 & NOR-gate & $\begin{array}{l}\text { In NOR-gate its output event happens if all input events do not happen." Otherwise, the output event } \\
\text { does not happen" }\end{array}$ \\
\hline 9 & XOR-gate & $\begin{array}{l}\text { The XOR-gate shows that the output event occurrence is only possible either if anyone, but not more, of } \\
\text { the input events occurs." It means that the output event will not occur if all of the input events do not } \\
\text { occur" or if more than one or all of the input events occur simultaneously. }\end{array}$ \\
\hline 10 & NAND-gate & $\begin{array}{l}\text { In the case of NAND-gate the output event occurrence is determined by non-simultaneous occurrences of } \\
\text { all the input events. "Otherwise, the output event will not occur." }\end{array}$ \\
\hline 11 & Priority AND-gate & $\begin{array}{l}\text { In the Priority AND-gate the output occurs if the inputs occur in an exact order stated by a conditioning } \\
\text { event. }\end{array}$ \\
\hline 12 & Top Event & $\begin{array}{l}\text { Top event is a primary event or the opening event of a fault tree or success tree that is also called the } \\
\text { undesired event in lieu of a fault tree. }\end{array}$ \\
\hline 13 & House Event & It is an event which occurrence is usually anticipated. It is also known as an external event \\
\hline 14 & Undeveloped Event & It is an event about which scanty information is handy, or which occurrence is of no effect \\
\hline
\end{tabular}

D. Construction of Qualitative Fault Tree of Eight Power

Transformer Subsystems

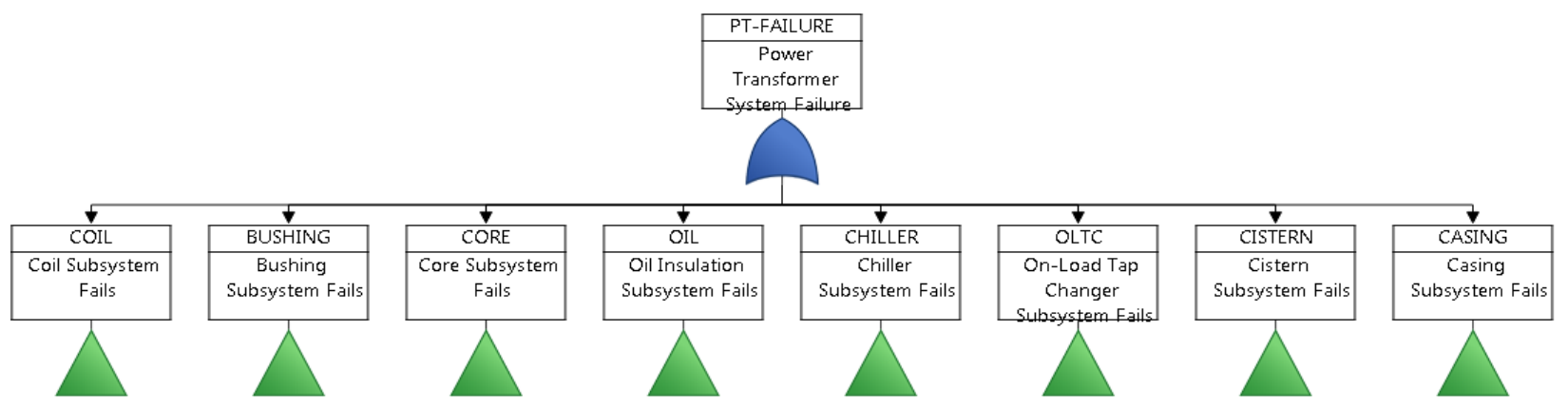

Fig. 3.10: Power Transformer System Fault Tree 


\section{1) Coil Subsystem Failure}

The coil apparatus provides a reliable way to estimate the amount of current flowing through the primary Coil of the power transformer [69]. When it fails, it generally happens for one of two primary reasons: coil failure and lead failure. Coil failure results generally from circuit breaker failures, internal short circuit errors and external short circuit errors. Circuit breaker failures in turn are cause by substandard construction and coil faults. Substandard construction might entail everything from shoddy materials used in the initial construction to poor welding practices that occurred later on in the process. Coil faults are sometimes cause by external short circuits which are not necessarily related to the machine itself, but which nevertheless impair the machine's ability to actively support the circuit breaker. Internal short circuit errors have as their causes: insulation detriment, the use of substandard materials in construction and external short circuit errors. Insulation can become damaged through years of wear and tear or rather rapidly, depending on the initial quality of the material used. The use of substandard materials can lead to issues such as frayed conducting wires, which in turn can cause major problems for the machine itself. Additionally, external circuit errors can also prove significant causes of coil failure, and in turn Coil failure. Lead failure has more to do with heat damage and emissions. Normally preceding heat damages are excessive spacing between joints and poor construction of the lead itself. Emissions on the other hand are caused by irritants in the machinery, pipe failure and insufficient insulation.

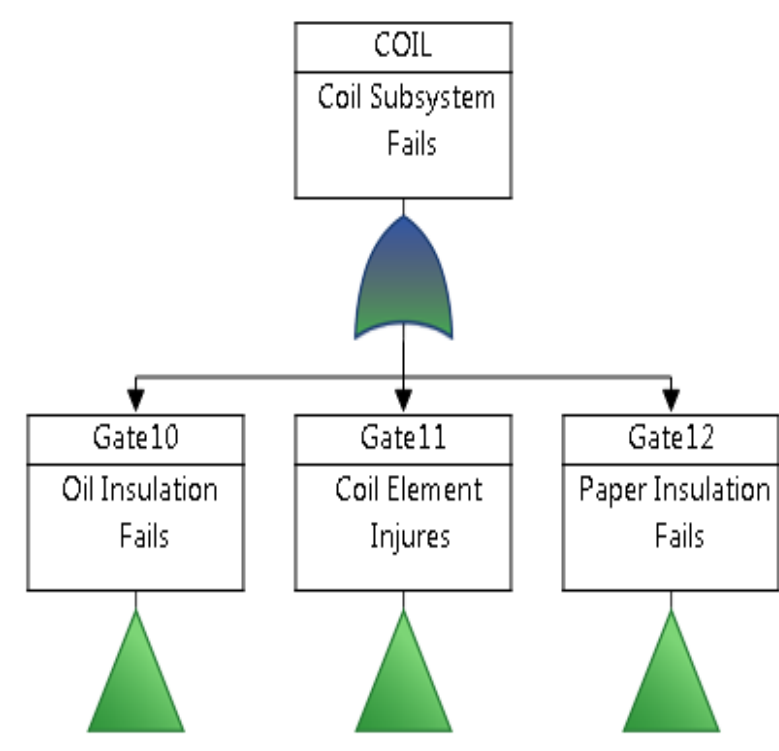

Fig. 3.20: Coil Subsystem Fault Tree 


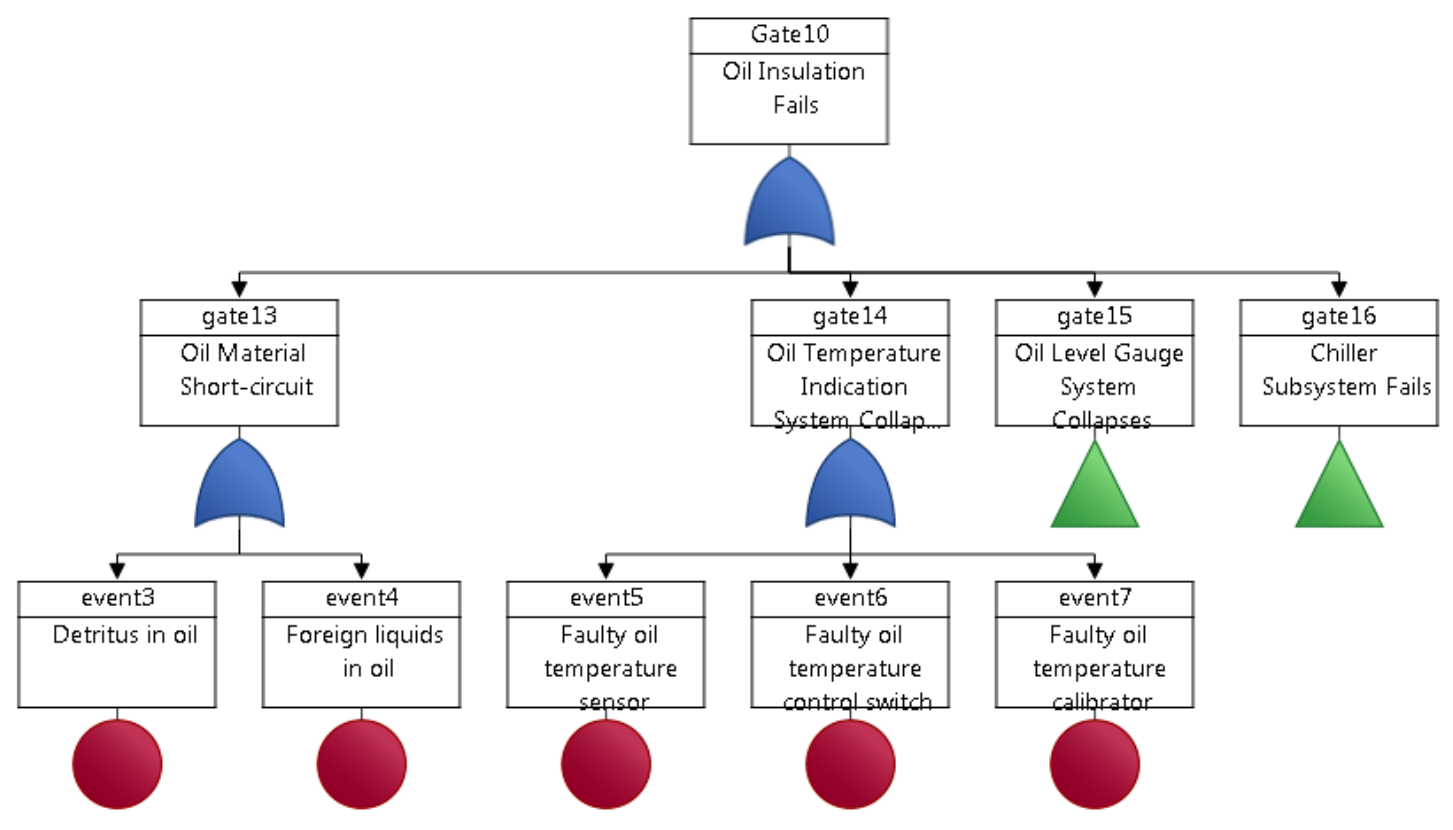

Fig. 3.21: Gate10 (Oil Insulation Fails)

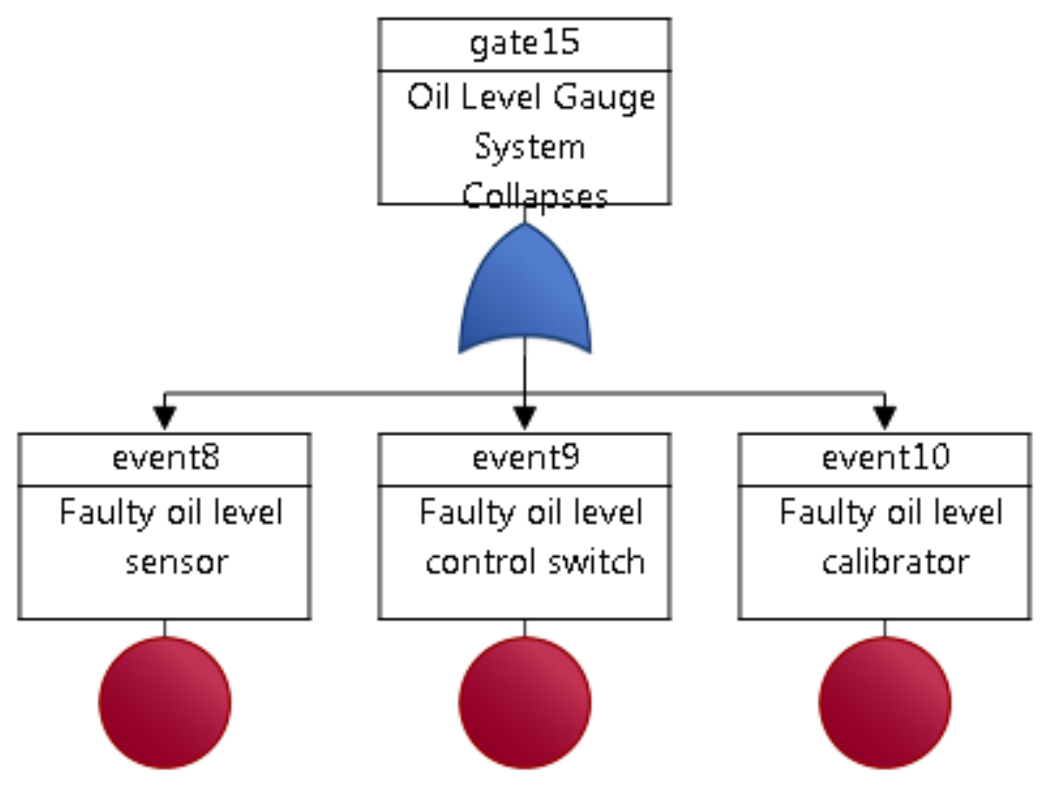

Fig. 3.21a: gate15 (Oil Level Gauge System Collapses) 


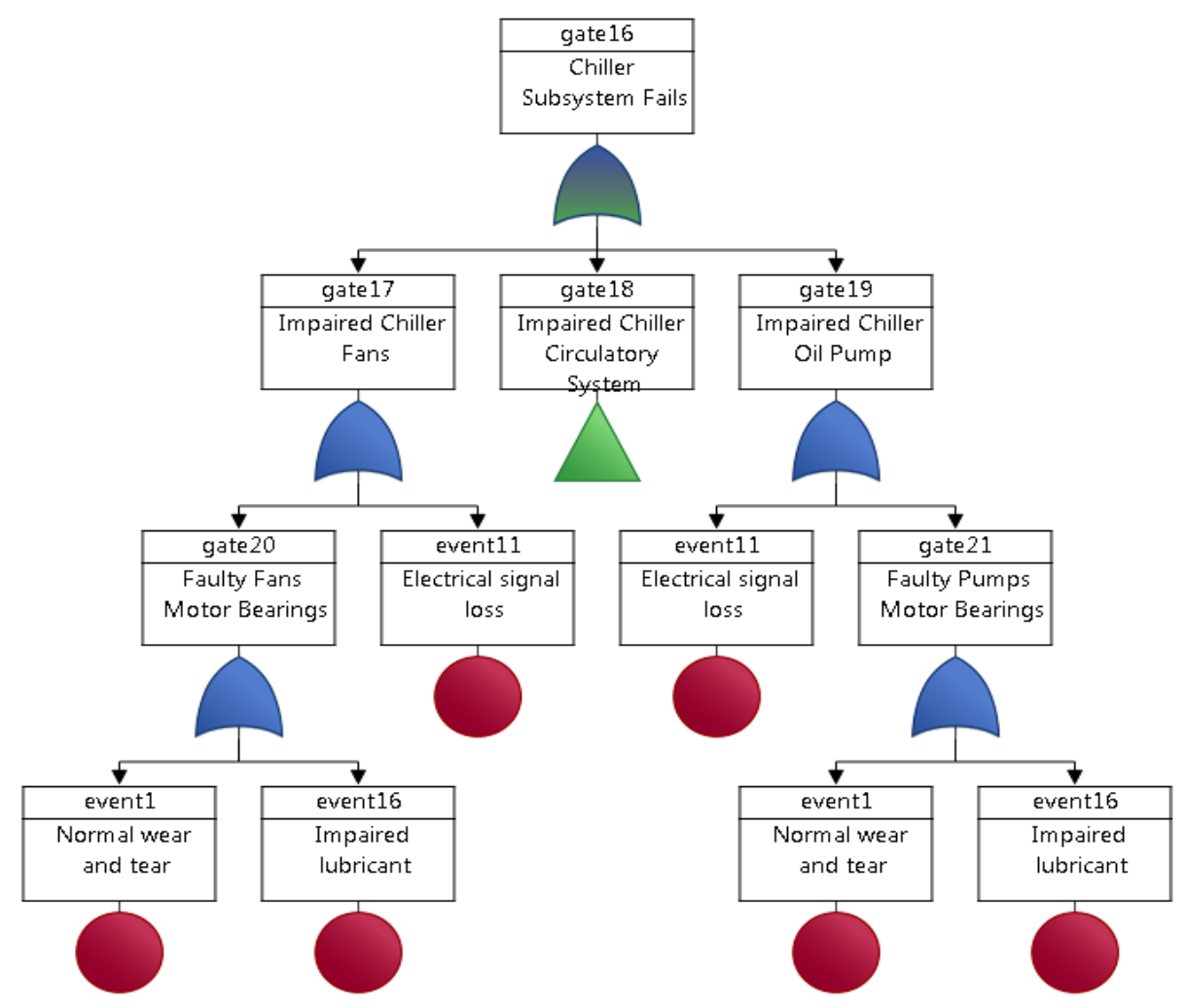

Fig. 3.21b: gate16 (Chiller Subsystem Fails)

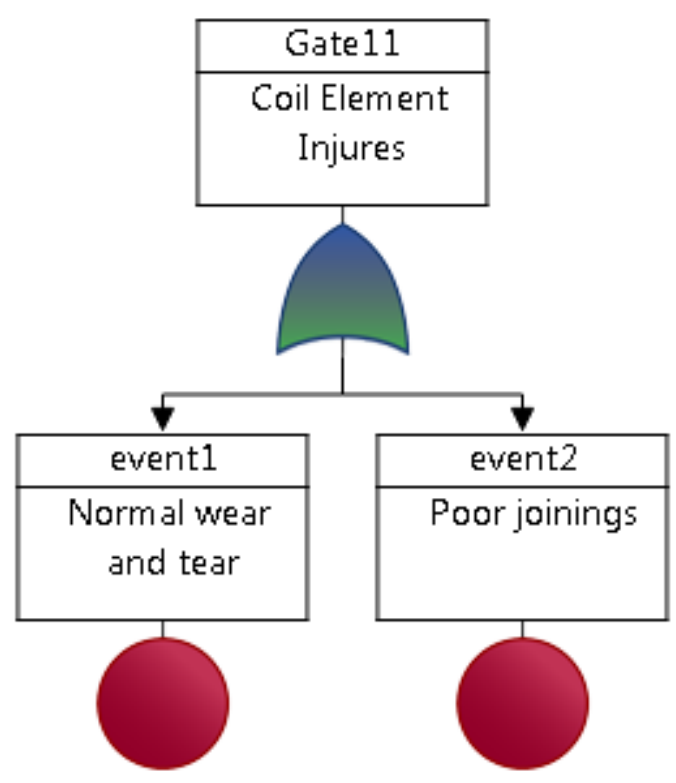

Fig. 3.22: Gate11 (Coil Element Fails) 


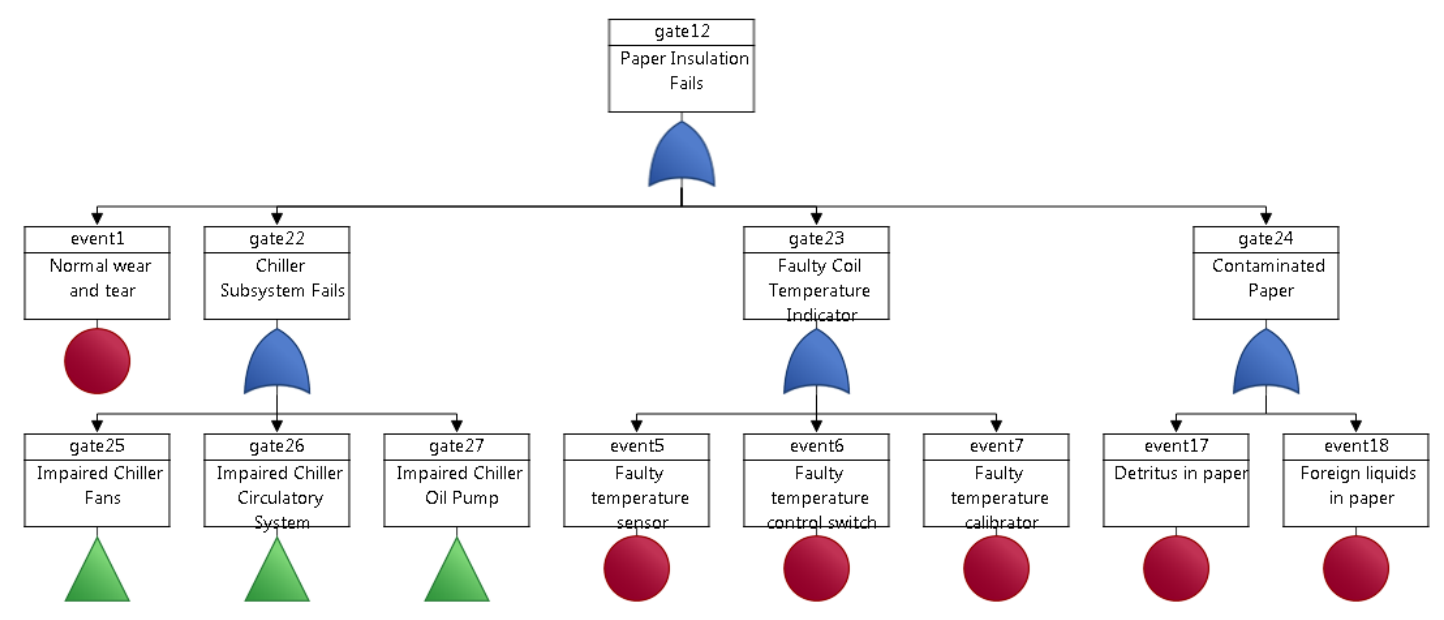

Fig. 3.23: gate12 (Paper Insulation Fails)

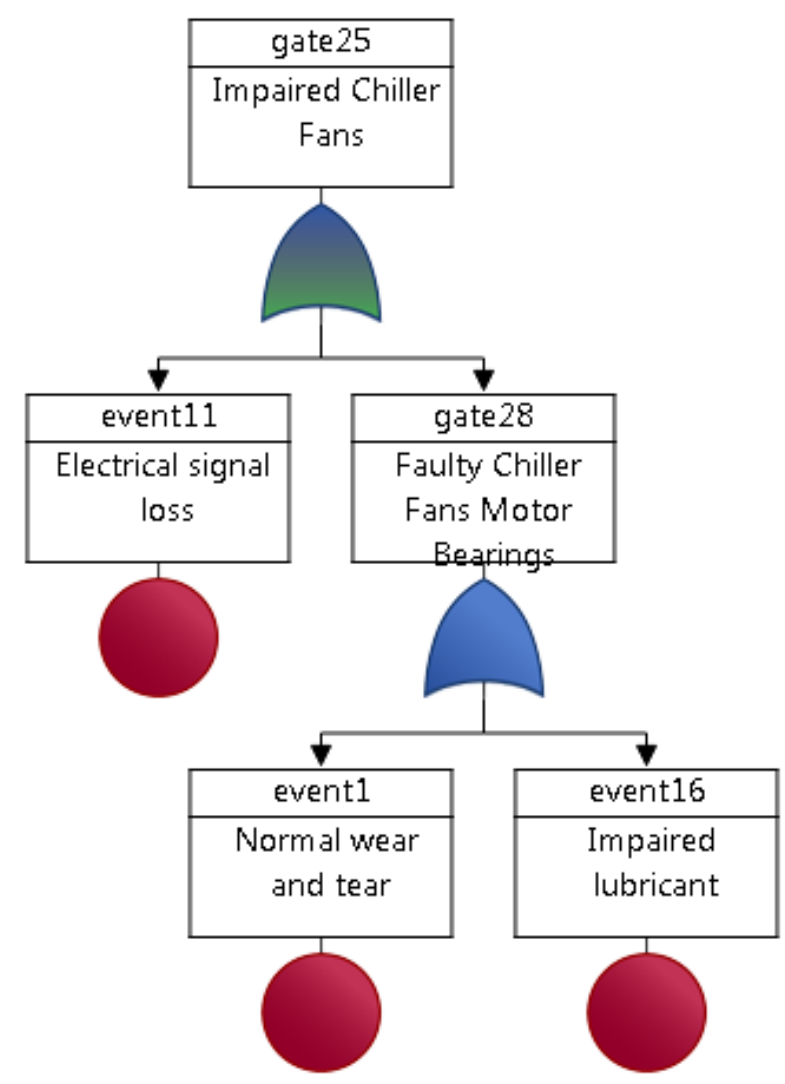

Fig. 3.23a: gate25 (Impaired Chiller Subsystem) 


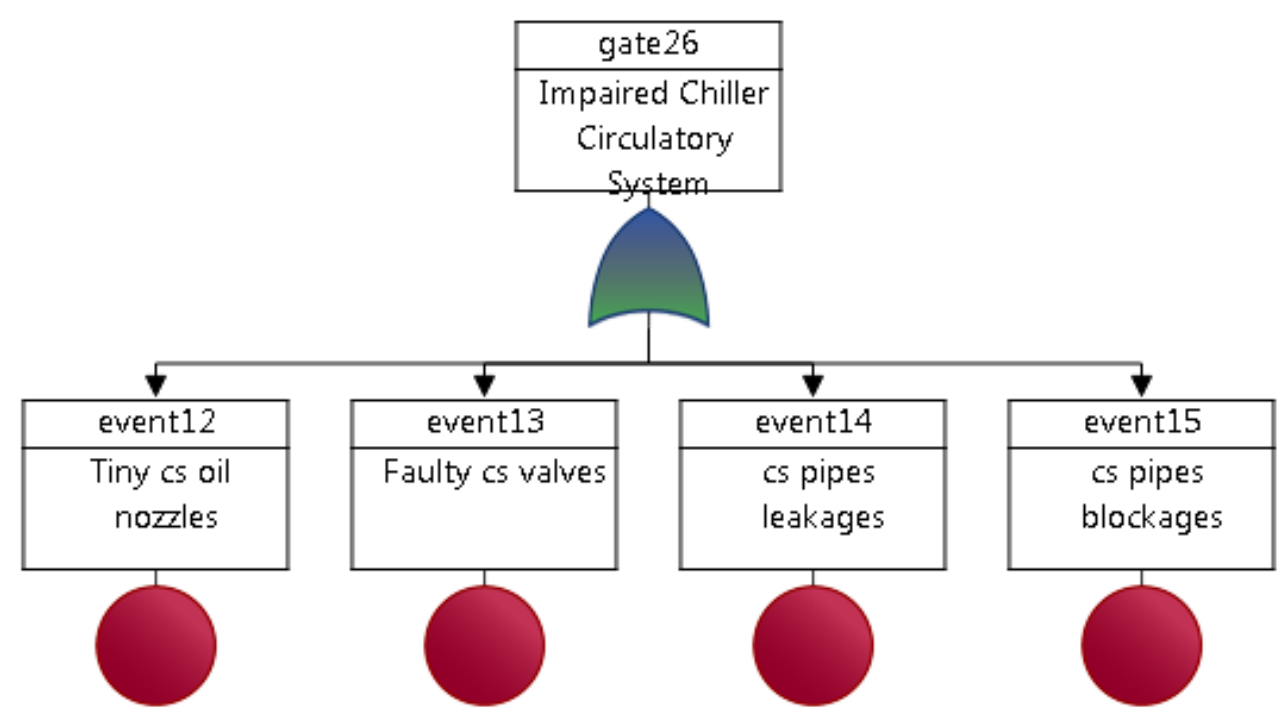

Fig. 3.23b: gate26 (Impaired Chiller Circulatory System)

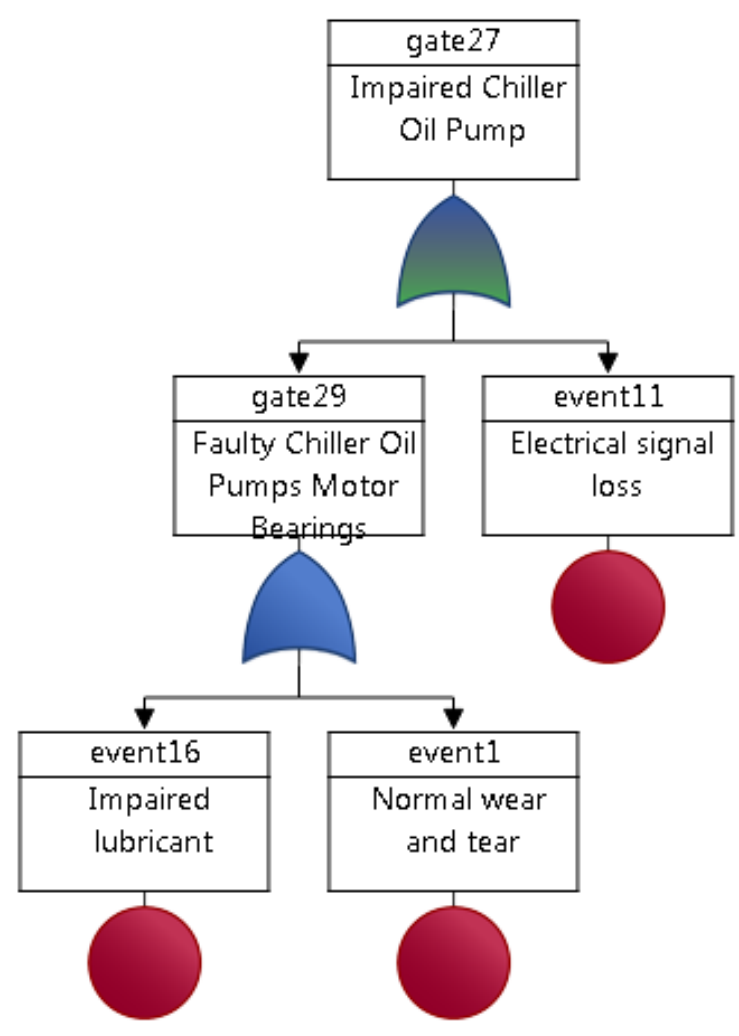

Fig. 3.23c: gate27 (Impaired Chiller Oil Pump) 
2) Bushings Subsystem Failure

Bushings function to insulate the electrical mechanisms like coil device components as they transmit electric signals through the apparatus [70]. When they fail, they primarily do so through short circuit failure. Short circuit failure results from impaired mediums of insulation and injured bushings. Insulation mediums can become impaired through water damage and filth. Water damage most often occurs as water seeps through failed gaskets, which generally fail due to normal wear and tear as they age. Filth accumulates in the gaskets as a direct result of irregular maintenance and is therefore highly preventable. Injured bushings come about in response to vandalism, which may occur if the power transmission systems are improperly secured and maintenance error. Maintenance errors most frequently take the form of improper handling of the bushings, which leads to damage not easily repaired.

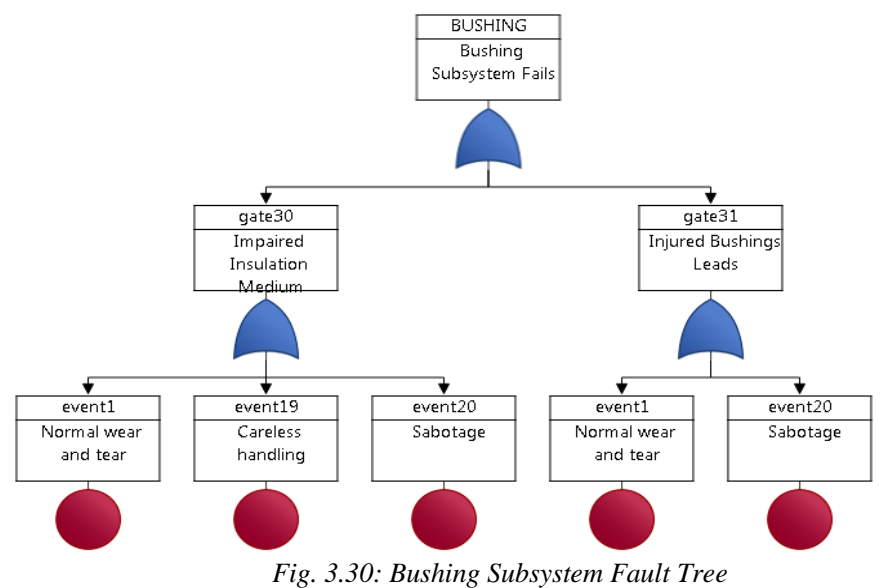

3) Core Subsystem Failure

The core works to transmit units of force in the form of magnetic flux. Core failure regularly takes the shape of eroded capability, which owes its presence to machine collapse. Machine collapse is most frequently due to DC magnetic induction failure.

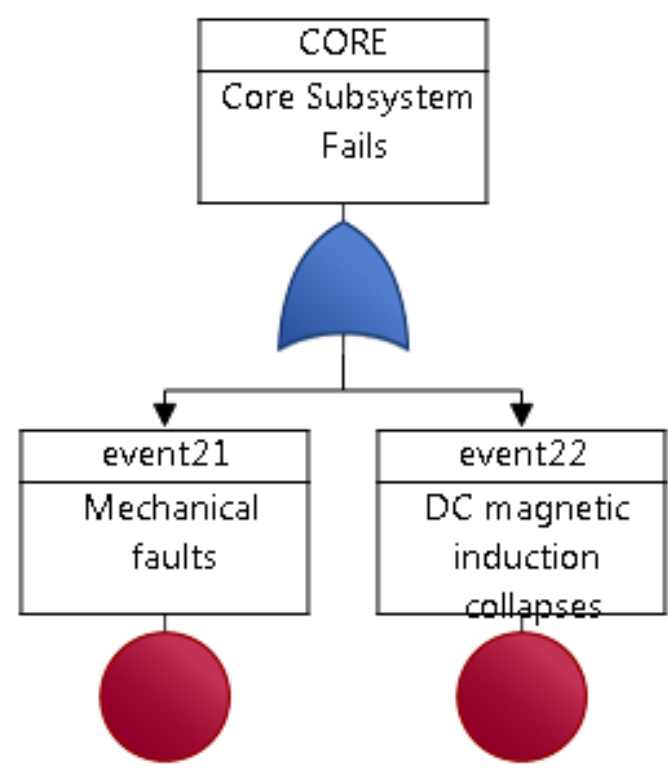

Fig. 3.40: Core Subsystem Fault Tree

4) Oil Insulation Subsystem Failure

The oil component of the insulation system serves a dual purpose. It simultaneously insulates and chills specific components of the power transformer to great effect. When it fails, it generally does so in one of two forms: short circuit failure and heat damage. Short circuit failure in the context of oil insulation failure often comes about as the result of fragments transmitted in the oil. These fragments originate as detritus pollutes the oil. The detritus itself comes from heat damage: as other components of the transformer's insulation network are damaged from excessive temperatures, bits and pieces of their various components flow through the oil, causing short circuit damage. Additionally, foreign liquids like water have been known to appear in the oil and can also prove themselves to be a cause of short circuit failure. These liquids result as normal wear and tear on the system progresses and various components are allowed to fall into disrepair. Heat damage comes about in response to insufficient oil cooling. As superheated water fails to cool the oil to the optimal temperature, heat damage to the infrastructure will result. Water that is too hot results from poor systems functioning, likely in due to circulation systems failure. Poor circulation also plays a role in heat damage to the oil insulation structure. It generally results from foreign detritus in the oil and pump failure. Pump failure is a single point of failure however foreign detritus in the oil can have several underlying causes including normal wear and tear, and, as previously discussed, heat damage. 


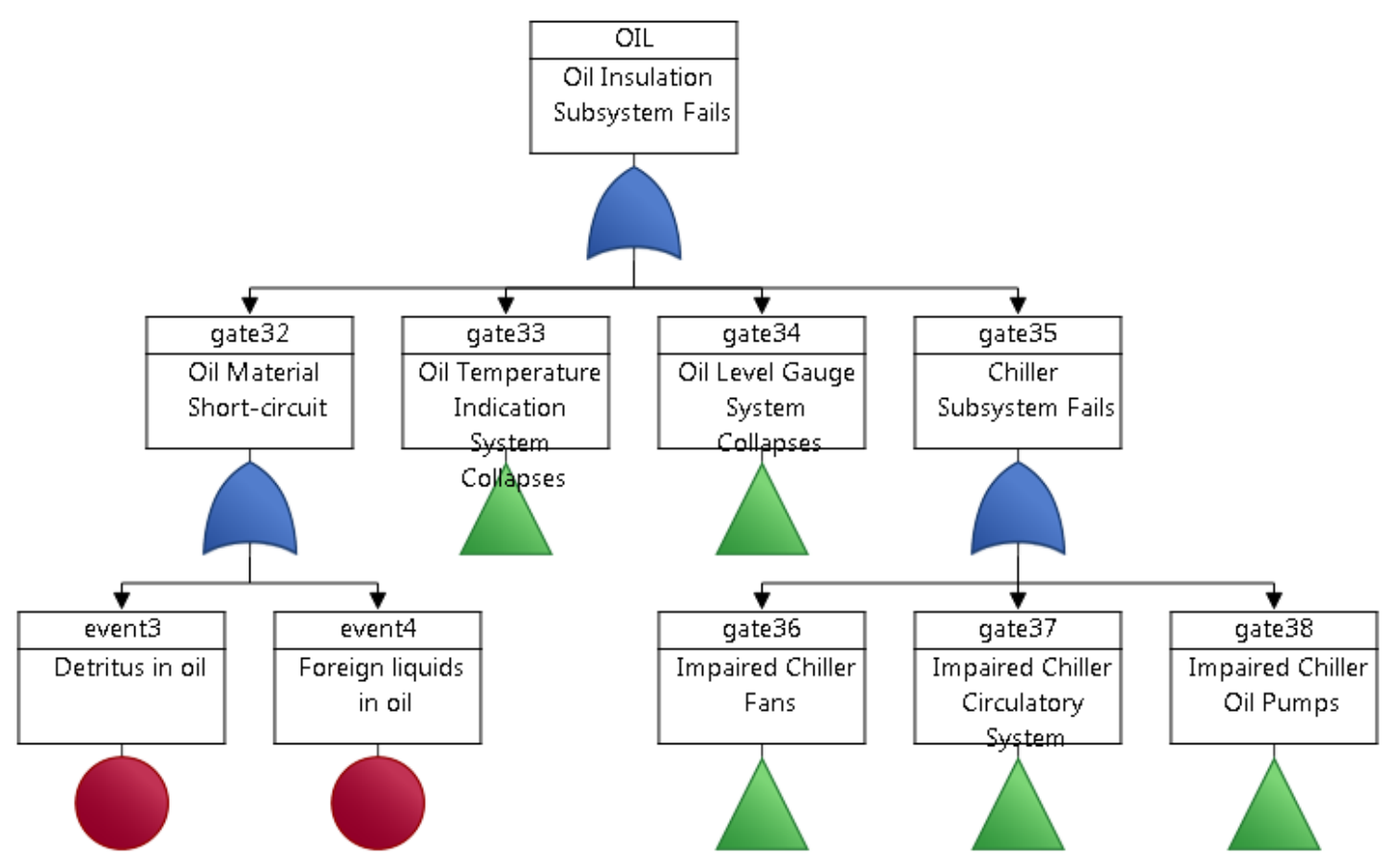

Fig. 3.50: Oil Insulation Subsystem Fault Tree

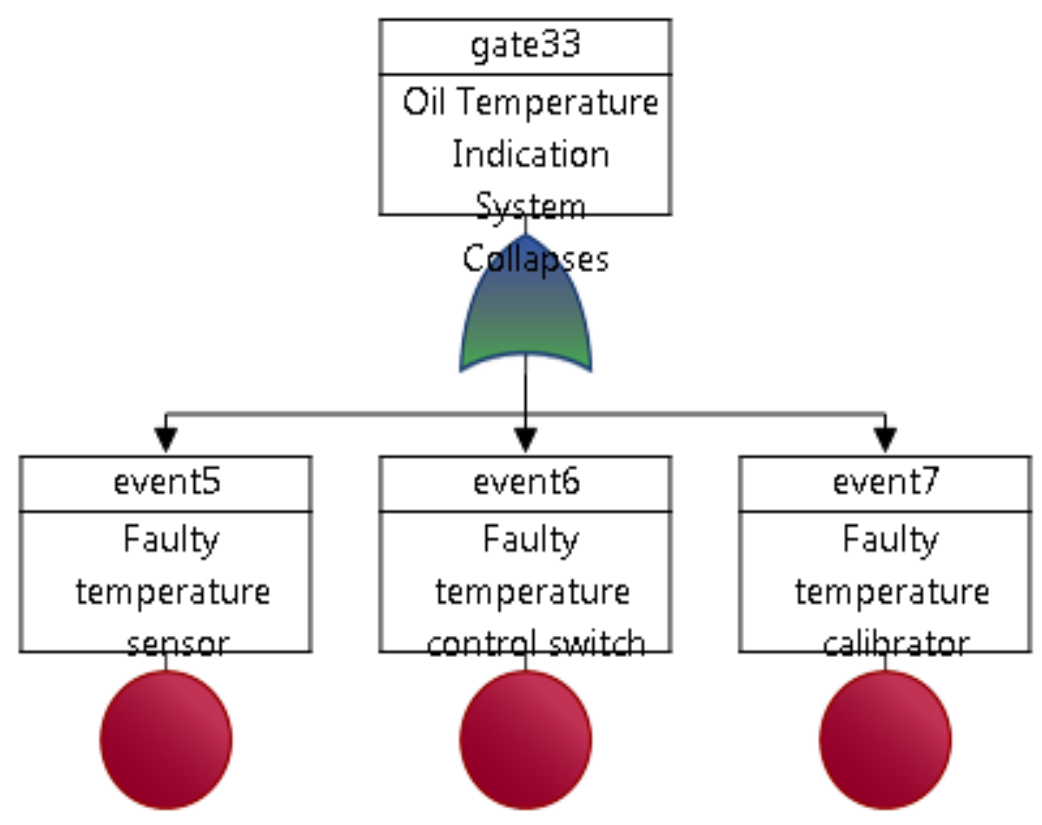

Fig. 3.51: gate33 (Oil Temperature Indication System Collapses) 


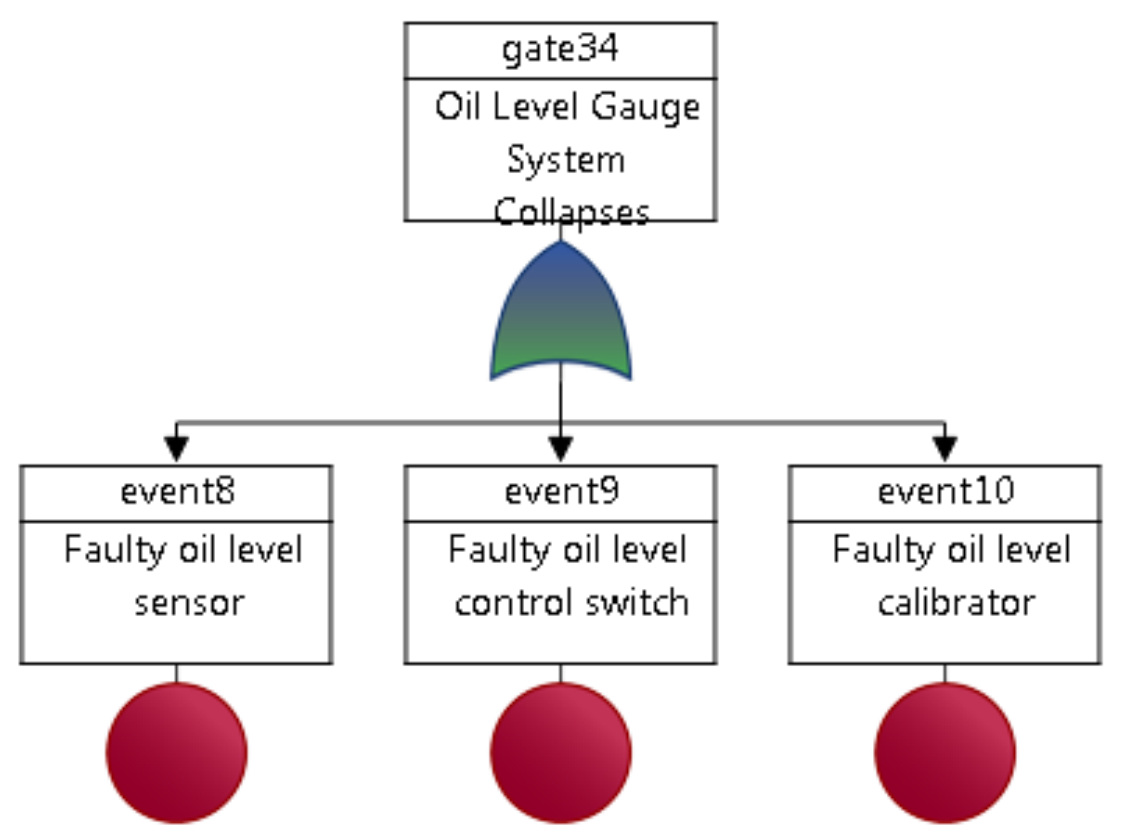

Fig. 3.52: gate34 (Oil Level Gauge System Collapses)

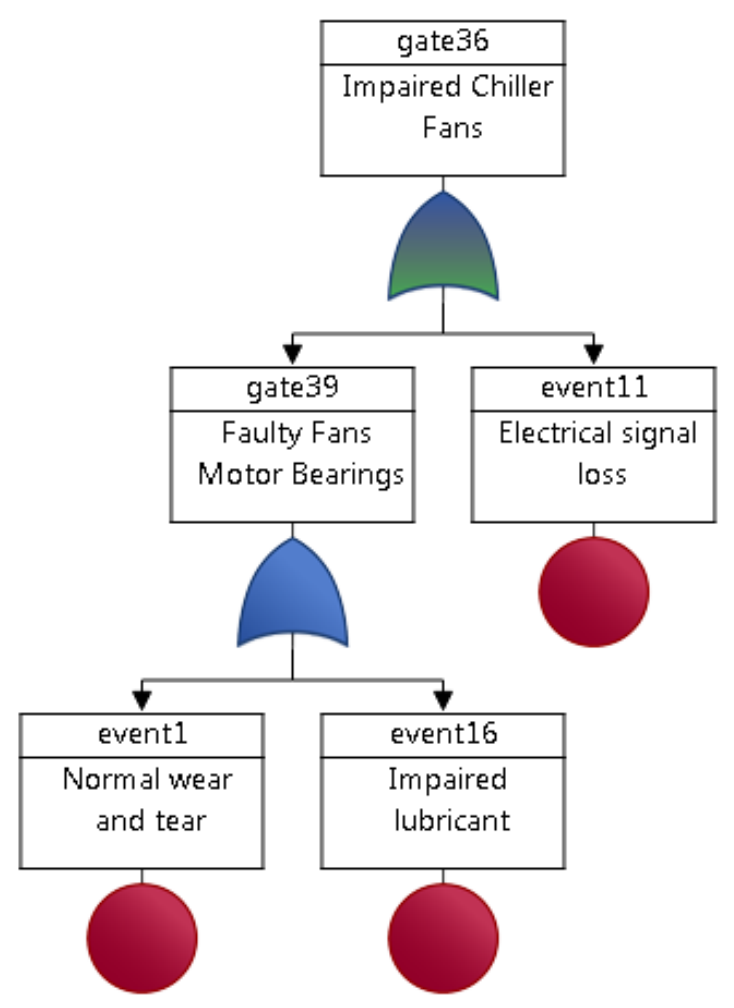

Fig. 3.53a: gate36 \{Impaired Chiller Fans) 


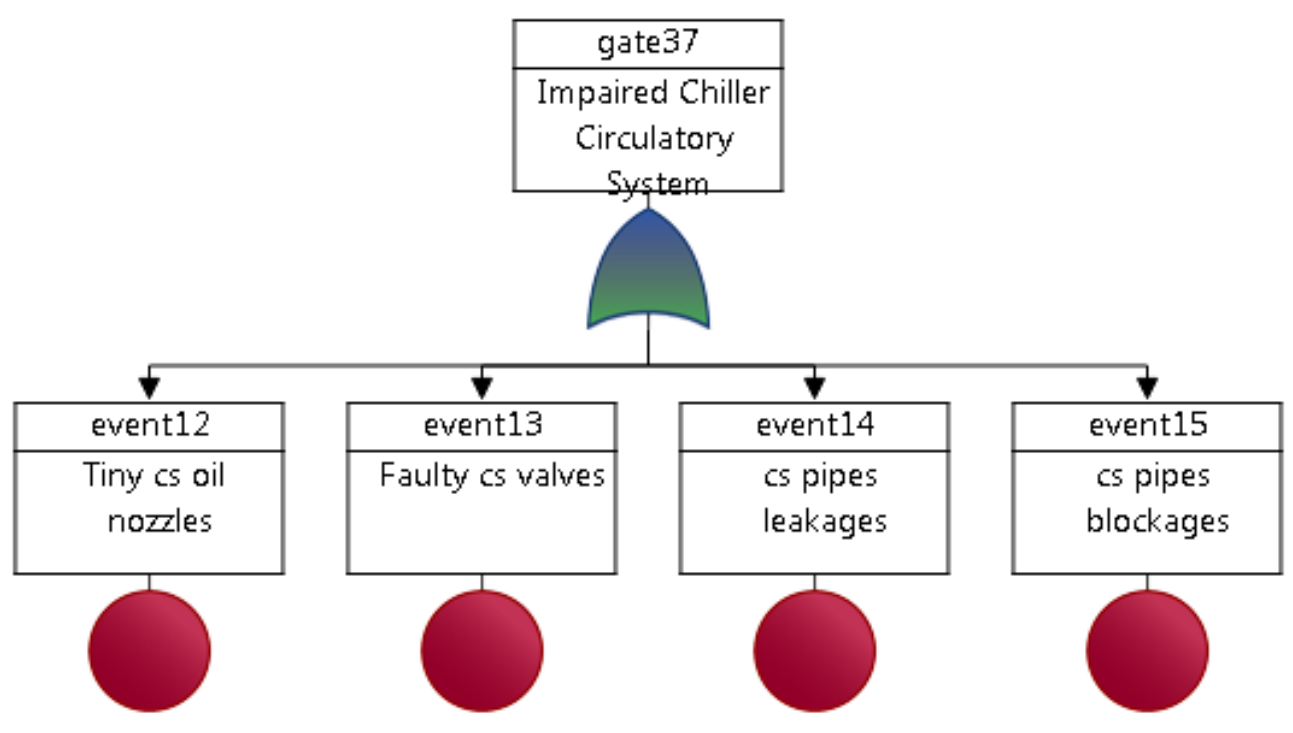

Fig. 3.53b: gate37 (Impaired Chiller Circulatory System)

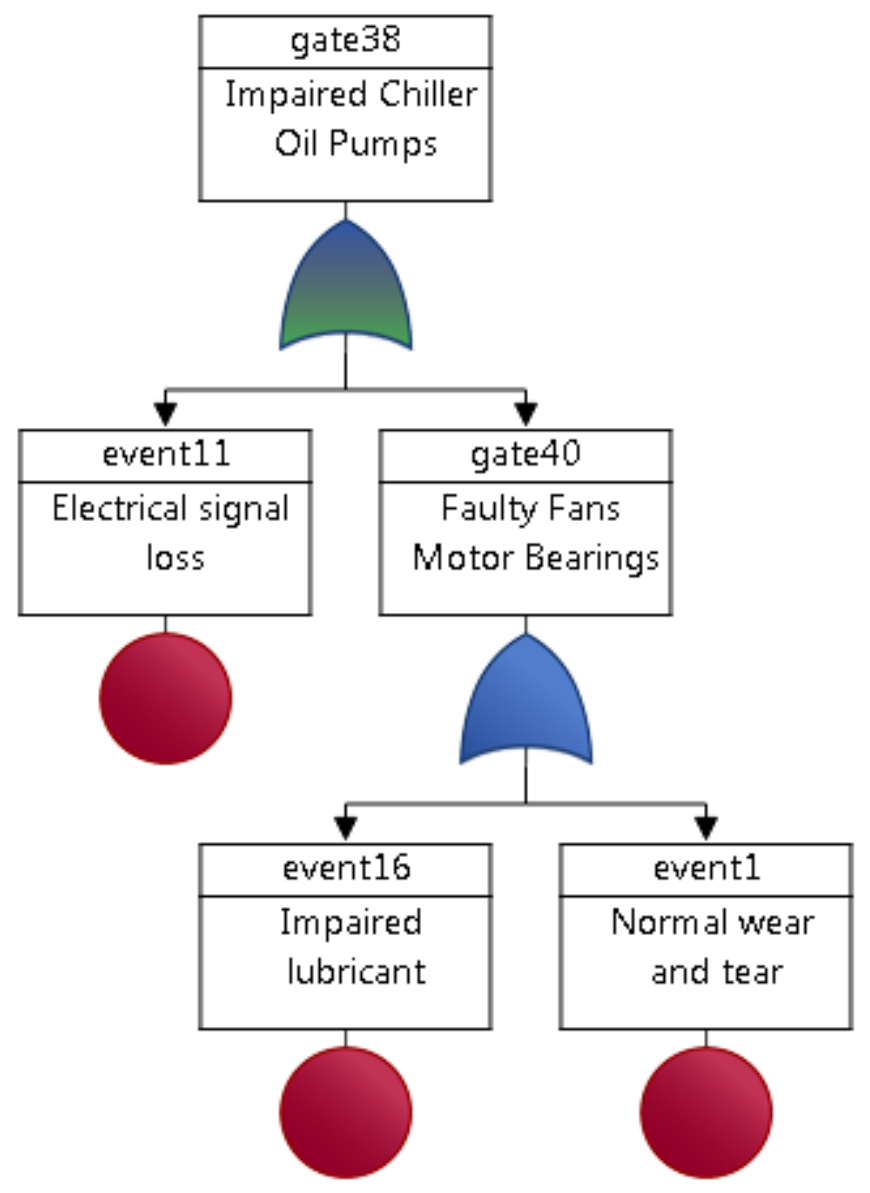

Fig. 3.53c: gate38 (Impaired Chiller Oil Pumps) 
5) Chiller SubsystemFailure

The Chiller Subsystem of a transformer functions to keep it running at an optimal temperature. When this integral system fails, it usually does so in one of three ways: oil pump failure, cooler failure and fan failure. Oil pump failure results from damage to the bearings and sealing failures. Damage to the bearings comes about as a result of insufficient lubrication and poor materials which were used in their construction. Insufficient lubrication can increase the friction on the bearings, causing premature wear. Poor materials utilized in construction can cause the bearings to be unable to withstand the mechanical pressure they are exposed to on a daily basis, and ultimately to fail frequently. Sealing failures, a secondary cause of oil pump failure can cause liquid to leak from various components and arrive in inopportune locations, resulting in oil pump failure. Chiller subsystem failure: the second primary cause of Chiller Subsystem failure - results, for its part, from detritus in the various heat ducts, as well as distributor impairment and duct rifts. Detritus in the heat ducts takes the form of small particles which originate outside the transformer and make their way inside. Distributor impairment results when various pipes become impaired in their ability to adequately transport water and air where they are needed. Duct rifts form a similar, but distinct problem and nevertheless result in acute cooler failure. Fan failure is a third cause of Chiller Subsystem failure. Fan failure can take the form of interrupted function as well as a loud dinning noise, which can bring about suboptimal working conditions as well as be indicative of significant damage to the fan itself. The loud dinning noise can result from one of two causes: insufficient lubrication and poorly constructed joining. Insufficient lubrication can cause excessive friction on the component parts of the fan, resulting in a loud noise. Poorly constructed joining can leave the fan too loosely set in critical locations, resulting in the indicative dinning noise. 


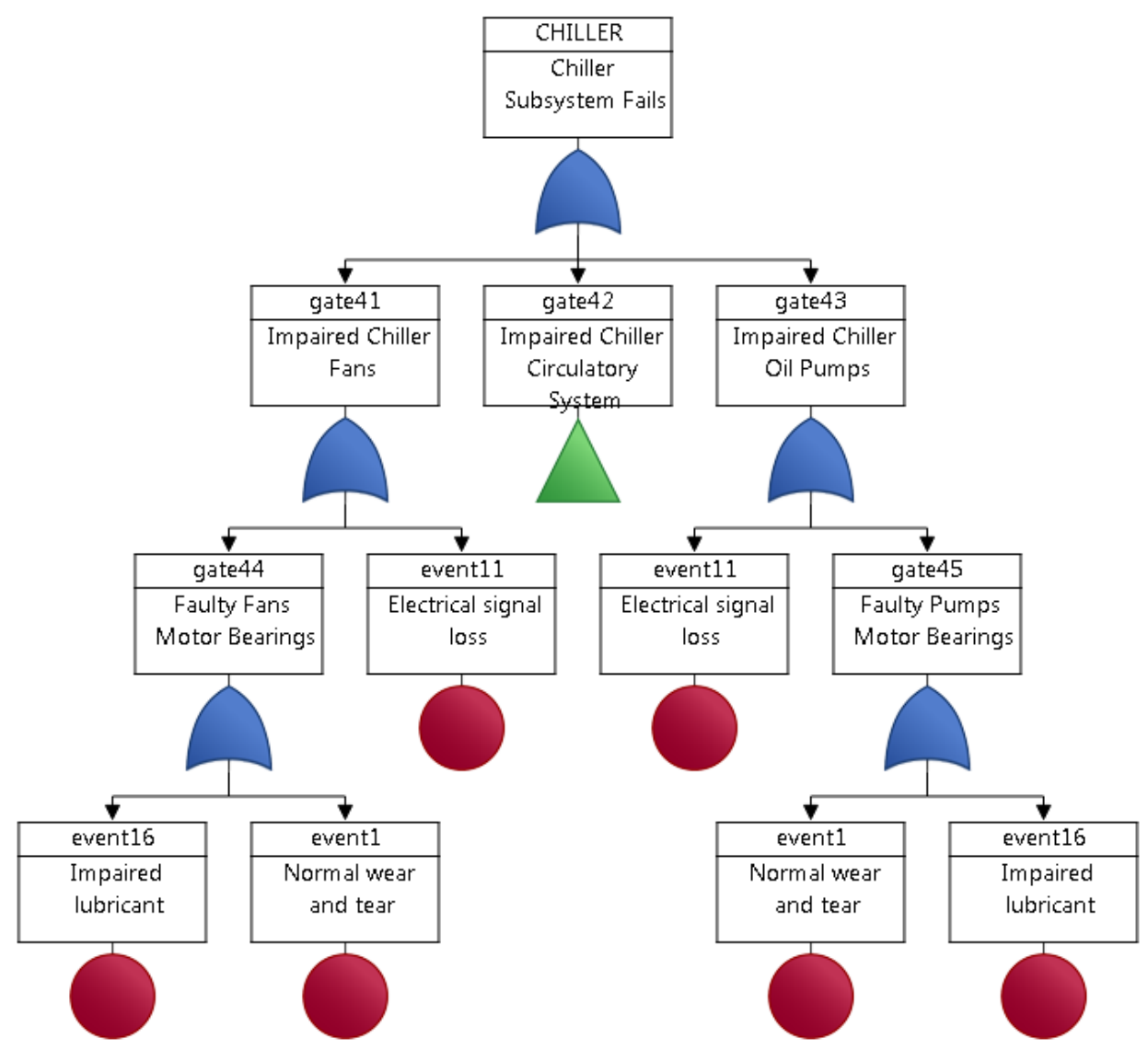

Fig. 3.60: Chiller Subsystem Fault Tree

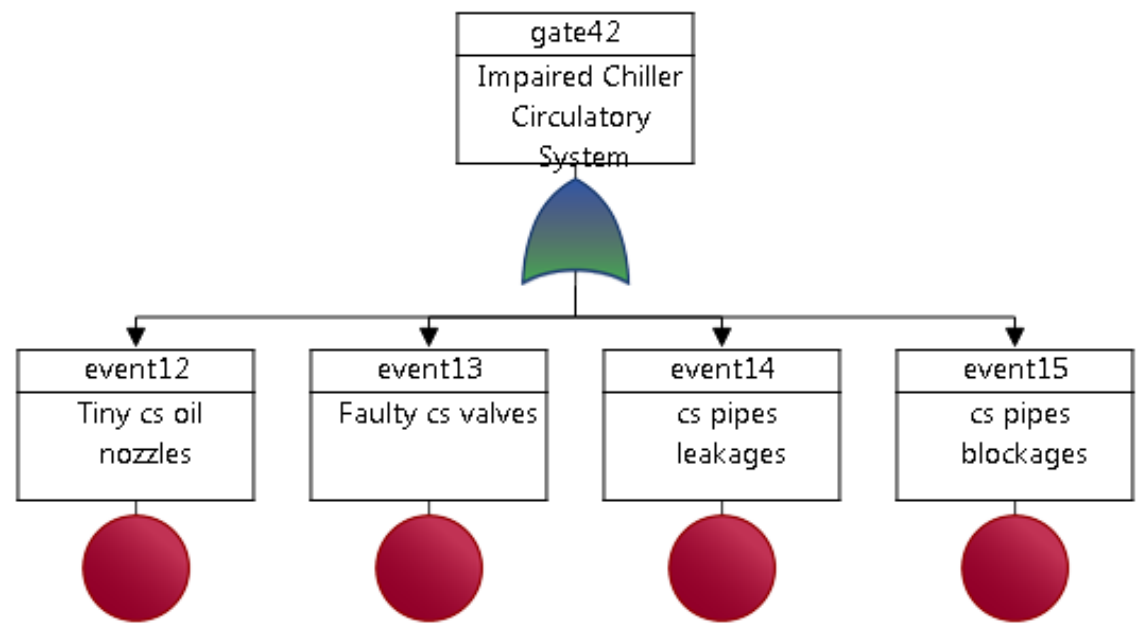

Fig. 3.61: gate42 (Impaired Chiller Circulatory System) 
6) On-Load Tap Changer (OLTC) Subsystem Failure

The tap changer works to maintain a level flow of voltage into the transformer coils. Failure generally results from and inability to control current. This inability to control current can take the form of the changer being unable to perform its crucial duty of managing the amount of current. This in turn is cause most frequently by machine failure due to normal wear and tear. Since this component so often has a single point of failure regular maintenance of its component parts is critical.

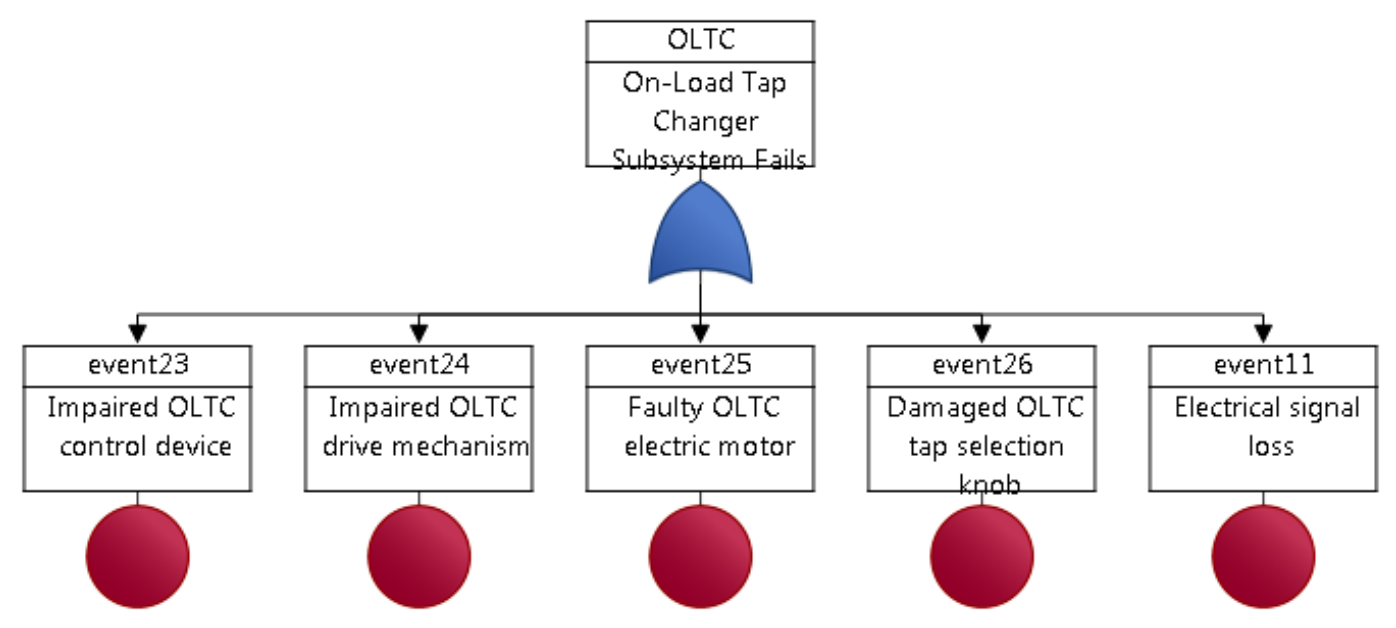

Fig. 3.70: OLTC Subsystem Fault Tree 


\section{7) Cistern Subsystem Failure}

The cistern, often referred to as Cistern serves to shield the operating portions of a transformer from the outside environment. It also houses several other integral structures. Its failures take the form of cistern outflow resulting from cistern impairment. Cistern impairment comes about from machine failure and material damage to the components, respectively. Machine failure is the result of maintenance error, a highly preventable point of failure, and overt pressurization, which may require advanced pressure sensors to keep in check. Material damage comes about in response

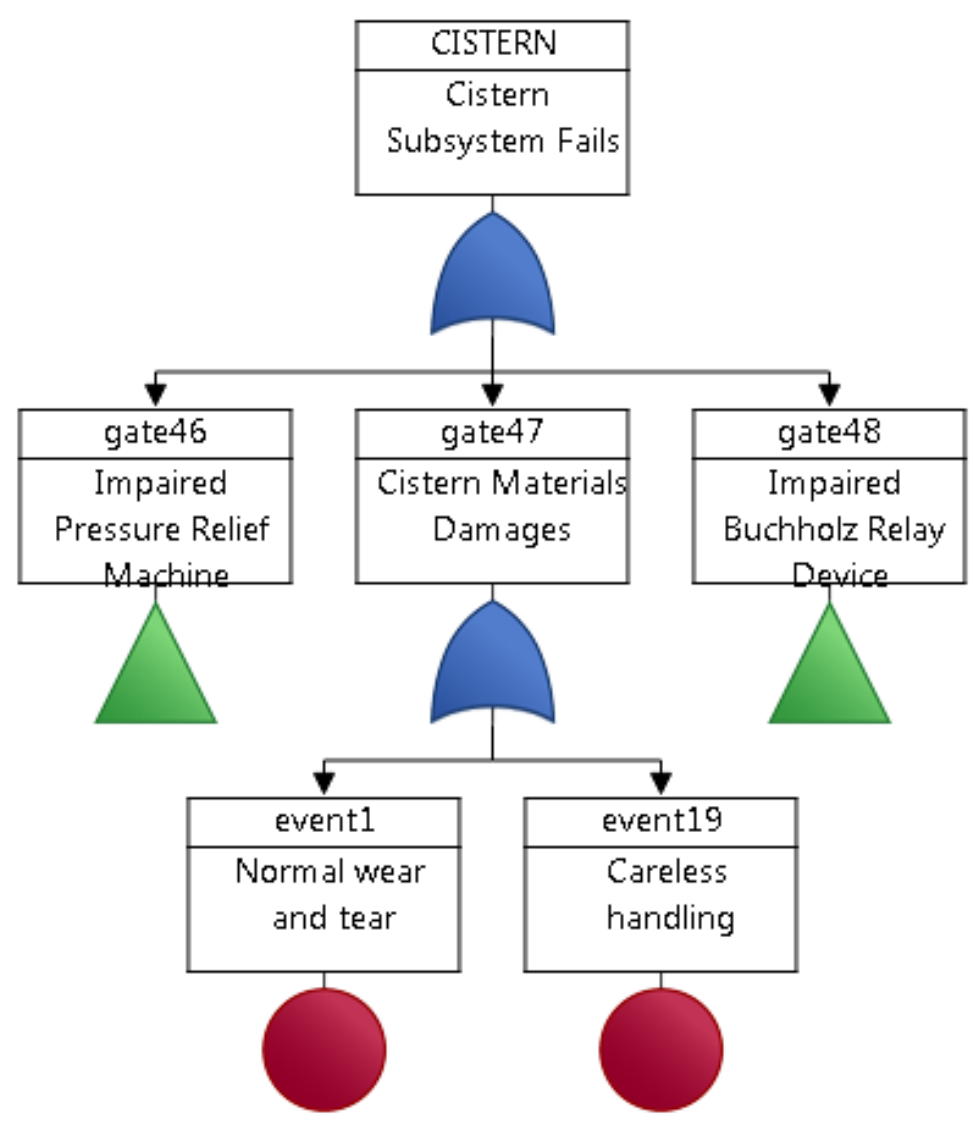

Fig. 3.80: Cistern Subsystem Fault Tree

to decay and gasket failure. Decay can result from irregular maintenance, which can lead to erosion and rust of the component parts. Gasket failure mostly results from normal wear and tear. 


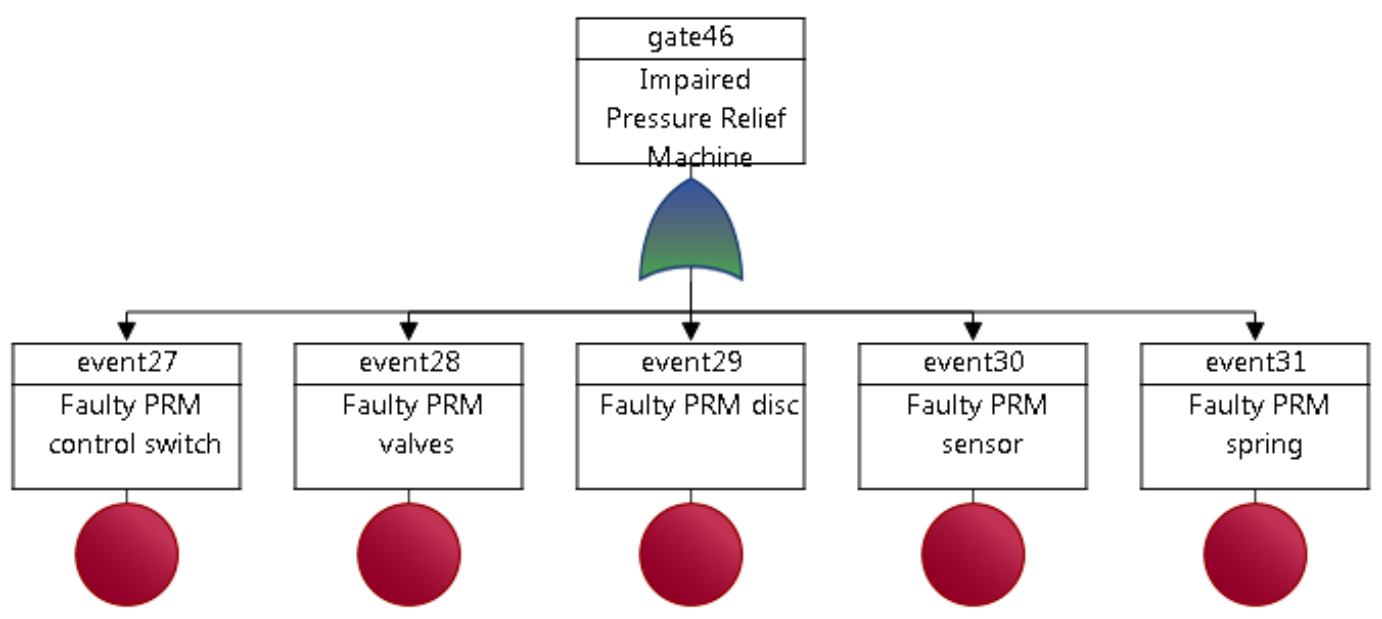

Fig. 3.81: gate46 (Impaired Pressure Relief Machine)

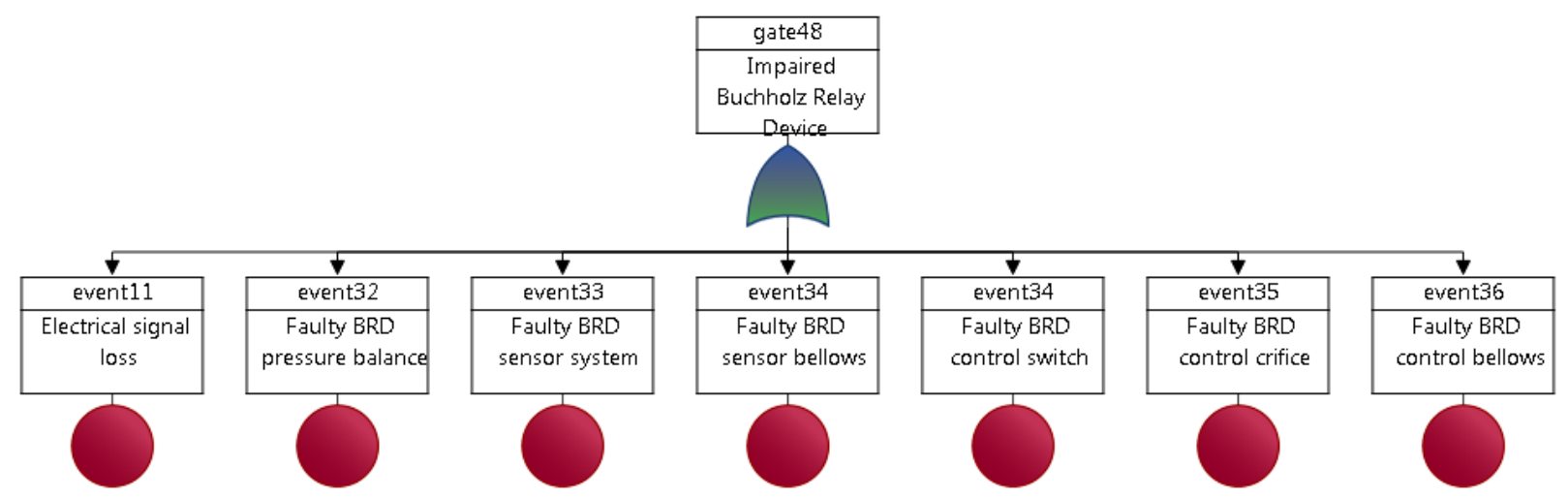

Fig. 3.82: gate48 (Impaired Buchholz Relay Device)

\section{8) Casing Subsystems Failure}

The casing subsystems provide the physical barrier of insulation to various internal components of the power transformer. Its failures come about in response to failures of the insulation systems. Machine-driven corrosion and impaired insulation materials prove most frequently to be the underlying cause of the insulation systems failure. Machinedriven corrosion comes about as the result of suboptimal transformer motions and circuitry issues. Suboptimal transformer motions exacerbate machine-driven corrosion. And circuitry issues most often appear in the form of a short circuit. Impaired insulation materials result from the normal lifecycle of internal components, a concentrated temperature increase and lowered efficiency. In the case of the normal wear and tear of the component parts of the insulation materials and how this impacts insulation systems failure, insulation is often derived from bio-materials such as cellulose, which has a short lifecycle. A concentrated temperature increase for its part can arise from contaminated oil and go on to severely damage the insulation materials. And lowered insulation efficiency can cause the materials themselves to overheat, causing insulation systems failure on another front. 


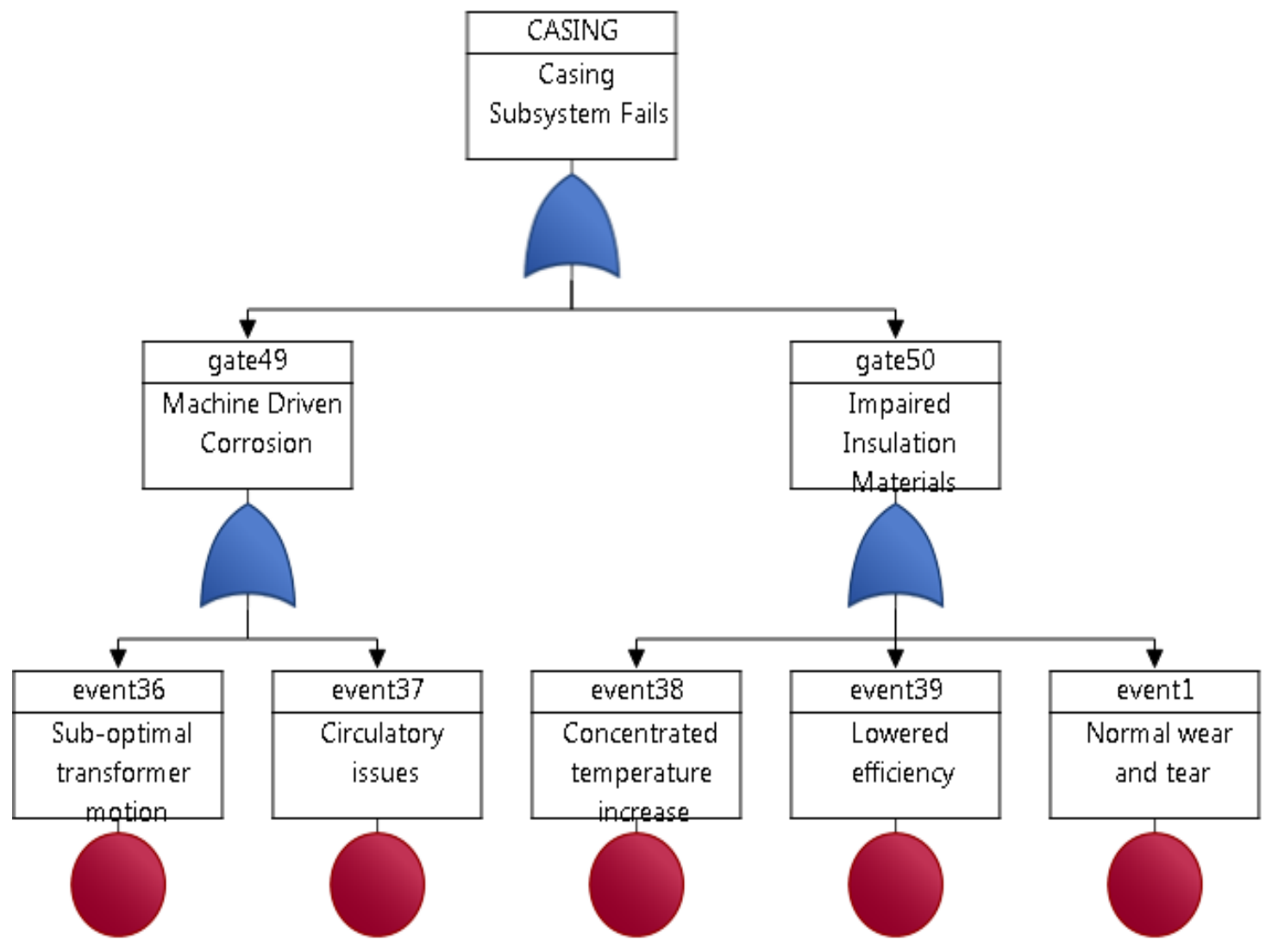

Fig. 3.90: Casing Subsystem Fault Tree

\section{RESULTS AND DISCUSSION}

Relating the proposed thesis hypothesis to the analysis of some related works, the test of hypothesis reveals expectedly that a paradigm shift from the conventional to the proposed brand new reliability assessment approach (A combination of

SPSS and FTA assessment tools) will positively impact the reliability of the Nigerian transmission grid system in the most

cost-effective manner by reducing power transformers faults/failure to the barest minimum.

A. Results of PracticalStatistical Analysis of Power Transformer Failure Based on SPSS

From table 4.1A, the Power Transformer Manufacture which equipment are most affected is $\mathrm{MBH}$ comprising of 23.6

\begin{tabular}{|l|l|l|l|l|}
\hline \multicolumn{6}{c|}{ Table 4.1A: The Power Transformer Manufacturer } \\
\hline ABB & Freq & $\%$ & Valid \% & Cum. \% \\
AREVA SHANGAI & 193 & 16.1 & 16.1 & 16.1 \\
CROMPTON & 25 & 2.1 & 2.1 & 18.2 \\
GREEVES & 15 & 1.3 & 1.3 & 19.5 \\
DIJAI & 80 & 6.7 & 6.7 & 26.2 \\
HYUNDAI & 40 & 3.3 & 3.3 & 29.5 \\
MBH & 282 & 23.6 & 23.6 & 53.1 \\
MOBITRA & 10 & .8 & .8 & 53.9 \\
SHAANSI & 74 & 6.2 & 6.2 & 60.1 \\
SHANDONG DACHI & 44 & 3.7 & 3.7 & 63.8 \\
SIEMENS & 178 & 14.9 & 14.9 & 78.7 \\
SKIPPER & 6 & .5 & .5 & 79.2 \\
SPECO & 40 & 3.3 & 3.3 & 82.5 \\
TBEA & 26 & 2.2 & 2.2 & 84.7 \\
TOSHIBA & 31 & 2.6 & 2.6 & 87.3 \\
TRAFO UNION & 137 & 11.5 & 11.5 & 98.7 \\
WOLONG ELECTRIC & 15 & 1.3 & 1.3 & 100.0 \\
Total & 1196 & 100.0 & 100.0 & \\
\hline
\end{tabular}

percent $(n=282)$, followed ABB with 16.1 percent. SIEMENS comes third with 14.9 percent, followed by TRAFO UNION comprising of 11.5 percent $(n=137)$. The 
next is DIJAI with 6.7 percent, followed by SHAANSI (6.2, 74). SHANDONG DACHI ranks $7^{\text {th }}$ with 3.7 percent $(n=$ 44), while HYUNDAI and SPECO rank $8^{\text {th }}$ comprising of 3.3 percent $(n=40)$ each. TOSHIBA has $(2.6,31)$. TBEA has $(2.2,26)$. AREVA SHANGAI follows with 2.1 percent. CROMPTON GREEVES and WOLONG ELECTRIC pear rank $13^{\text {th }}$ each comprising of 1.3 percent $(n=15)$ respectively. And MOBITRA and SKIPPER rank $15^{\text {th }}$ and $16^{\text {th }}$ with 0.8 percent and 0.5 percent respectively.

\begin{tabular}{|c|c|c|c|c|c|}
\hline & & Freq & $\%$ & Valid \% & Cum. $\%$ \\
\hline Valid & $\begin{array}{l}\text { 0-5 Years Old } \\
6-10 \text { Years Old } \\
\text { 11-15 Years Old } \\
\text { 16-20 Years Old } \\
\text { 21-25 Years Old } \\
\text { Above } 30 \text { Years } \\
\text { Old } \\
\text { Total } \\
\end{array}$ & $\begin{array}{l}171 \\
623 \\
36 \\
169 \\
13 \\
184 \\
1196 \\
\end{array}$ & $\begin{array}{l}14.3 \\
52.1 \\
3.0 \\
14.1 \\
1.1 \\
15.4 \\
100.0 \\
\end{array}$ & \begin{tabular}{|l}
14.3 \\
52.1 \\
3.0 \\
14.1 \\
1.1 \\
15.4 \\
100.0
\end{tabular} & $\begin{array}{l}14.3 \\
66.4 \\
69.4 \\
83.5 \\
84.6 \\
100.0\end{array}$ \\
\hline
\end{tabular}

From Table 4.1B above, the power transformer age grade that suffered the worst failure rate in descending ranking order is 6-10 Years Old comprising of 52.1 percent $(\mathrm{n}=623)$, which is distantly followed by Above 30 Years Old with 15.4 percent $(\mathrm{n}=184) .0-5$ Years Old having 14.3 percent $(\mathrm{n}=$ 171) places $3^{\text {rd }}$. The next is $16-20$ Years Old with 14.1 percent $(n=169)$, followed by 11-15 Years Old having 3.0 percent $(\mathrm{n}=36)$. And the last, 21-25 Years Old with 1.1 percent $(n=13)$.

\begin{tabular}{|c|c|c|c|c|c|}
\hline & & Freq. & $\%$ & Valid \% & $\begin{array}{l}\text { Cum. } \\
\%\end{array}$ \\
\hline \multirow{3}{*}{ Valid } & $\begin{array}{l}\text { Miscellaneous } \\
\text { failure }\end{array}$ & 308 & 25.8 & & \\
\hline & Forced failure & 888 & 74.2 & 74.2 & 100.0 \\
\hline & Total & 1196 & 100.0 & 100.0 & \\
\hline
\end{tabular}

From Table 4.1C it is observed that the most popular type of transformer failure is "Forced failure" comprising of 74.2 percent, followed by "Miscellaneous failure" with 25.8 percent.

Table 4.1D: The Power Transformer Failure Climatic Season

\begin{tabular}{|c|c|c|c|c|c|}
\hline & & Freq. & $\%$ & Valid \% & Cum. \% \\
\hline Valid & $\begin{array}{l}\text { Summer or Wet } \\
\text { Season } \\
\text { Covering from } \\
\text { the Month of } \\
\text { April to October } \\
\text { Winter or Dry } \\
\text { Season } \\
\text { Covering from } \\
\text { the Month of } \\
\text { January to } \\
\text { March; and } \\
\text { November to } \\
\text { December } \\
\text { Total }\end{array}$ & $\begin{array}{l}358 \\
\\
1196\end{array}$ & $\begin{array}{l}29.9 \\
100.0\end{array}$ & $\begin{array}{l}29.9 \\
100.0\end{array}$ & 70.1 \\
\hline
\end{tabular}

The table 4.1D above shows the Climatic Season of Power Transformer Failure occurrence. It can be glaringly observed that Summer or Wet Season Covering from the Month of April to October of the year most triggered the failure of power transformer at $70.1 \%(n=838)$, whereas, Winter or Dry Season Covering from the Month of January to March; and November to December of the year comes behind with $29.9 \%(\mathrm{n}=358)$.

\begin{tabular}{|c|c|c|c|c|c|}
\hline & & Freq. & $\%$ & $\begin{array}{l}\text { Valid } \\
\%\end{array}$ & $\begin{array}{l}\text { Cum. } \\
\%\end{array}$ \\
\hline \multirow{3}{*}{ Valid } & $\begin{array}{l}\text { External cause } \\
\text { factor including } \\
\text { but not limited to } \\
\text { natural and } \\
\text { artificial conditions }\end{array}$ & 968 & 80.9 & 80.9 & 80.9 \\
\hline & $\begin{array}{l}\text { Internal cause } \\
\text { factor such as } \\
\text { material aging \& } \\
\text { contaminations }\end{array}$ & 228 & 19.1 & 19.1 & 100.0 \\
\hline & Total & 1196 & 100.0 & 100.0 & \\
\hline
\end{tabular}

The table 4.1E indicates the causes of faults power transformers, whether they were external or internal. It is evident that 80.9 percent (968) of the transformers faulted due to external cause factors. Those transformers that experience an internal cause factors comprised of 19.1 percent (228).

Table 4.1F: Affected Subsystem Components of the Power Transformer

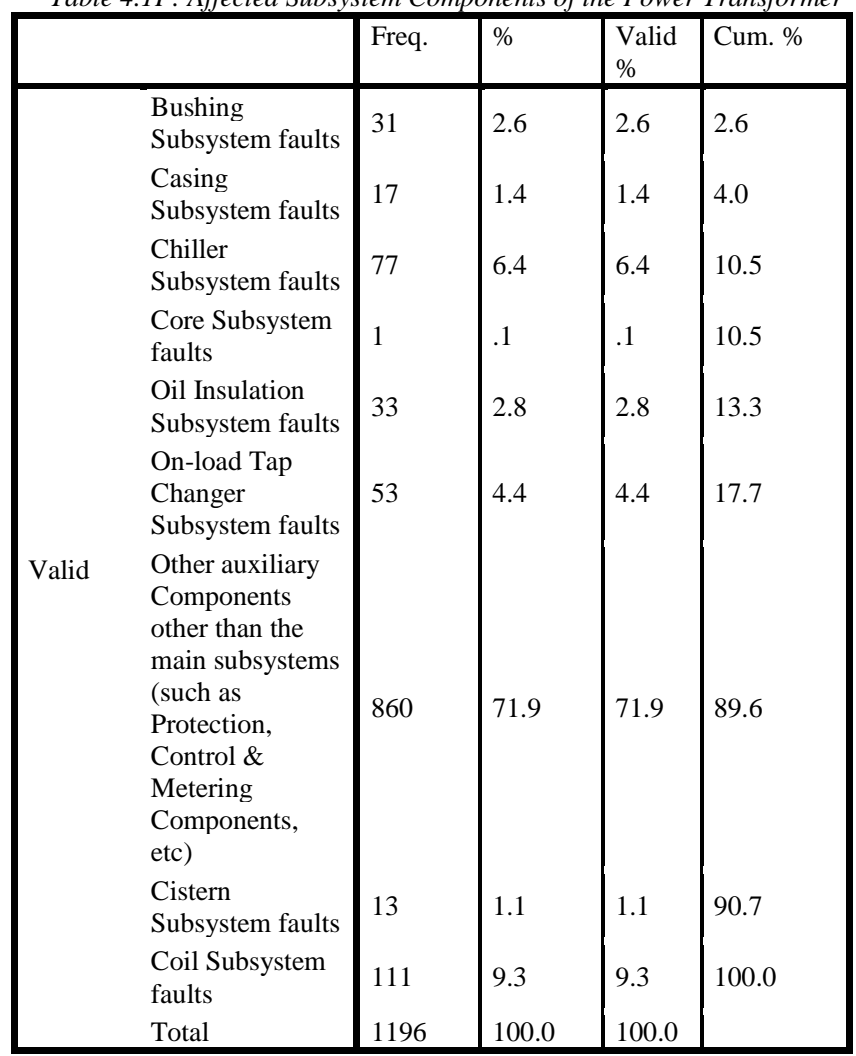

The table $4.1 \mathrm{~F}$ above indicates the subsystem components of the power transformer that failed. The subsystem component that most failed the transformers is "Other auxiliary Components other than the main subsystems (such as Protection, Control \& Metering Components, etc)" with 71.9 
$\%(\mathrm{n}=860)$, followed by Coil Subsystem faults with $9.3 \%$ (n = 111). The Chiller Subsystem faults had $6.4 \%$ (77), On-load Tap Changer Subsystem faults $(4.4 \%, \mathrm{n}=53)$. The Oil Insulation Subsystem faults $(2.8 \%, \mathrm{n}=33)$.Bushing Subsystem faults $(2.6 \%, \mathrm{n}=31)$. Casing Subsystem faults $(1.4 \%, \mathrm{n}=17)$. Cistern Subsystem faults $(1.1 \%, \mathrm{n}=13)$. And Core Subsystem faults $(0.1 \%, \mathrm{n}=1)$.

Table 4.1G: Methods Used In Carrying Out Repair Works on the Faulted Power Transformer

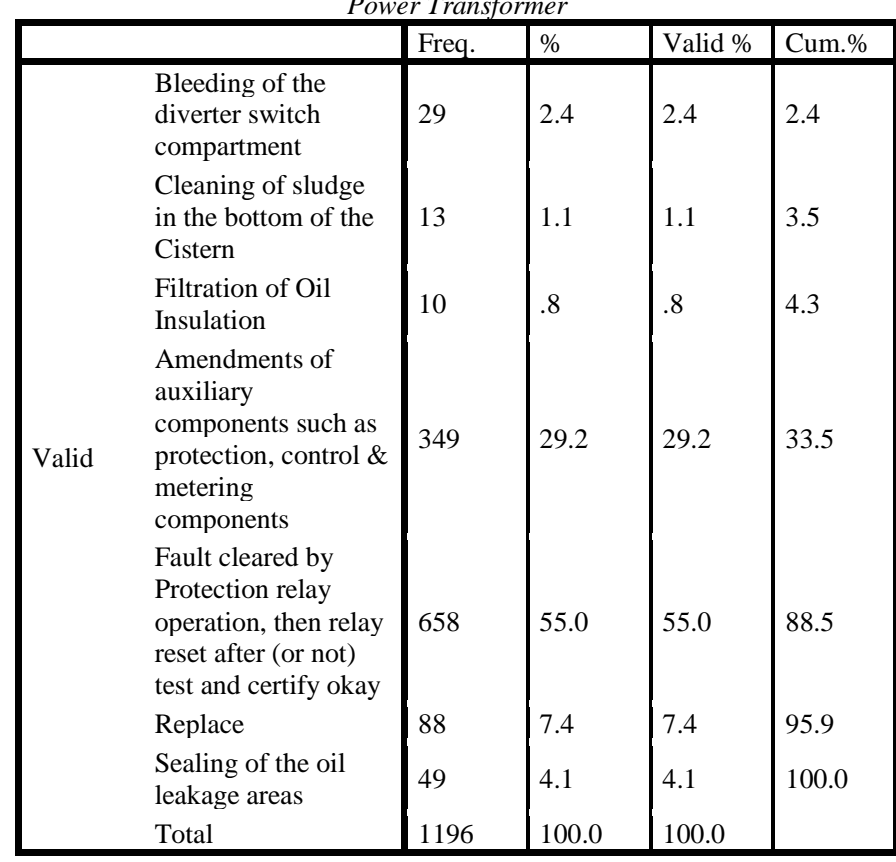

Table 4.1G shows the methods used to repair the faulted power transformers. The most preferred method of repair is Fault cleared by Protection relay operation, then relay reset after (or not) test and certify okay by 55.0 percent (658). Followed by Amendments of auxiliary components such as protection and control circuits with 29.2 percent, 7.4 percent is Replacement of defective components, 4.1 percent with Sealing of the oil leakage area. Then, $2.4 \%$ (29) is "Bleeding of the diverter switch compartment", Cleaning of sludge in the bottom of the Cistern with 1.1 percent and $0.8 \%$ with Filtration of Oil Insulation.

Table 4.1H: The Power Transformer Maintenance Trigger

\begin{tabular}{|c|c|c|c|c|c|}
\hline & & Freq. & $\%$ & $\begin{array}{l}\text { Valid } \\
\%\end{array}$ & $\begin{array}{l}\text { Cum. } \\
\%\end{array}$ \\
\hline Valid & $\begin{array}{l}\text { Annual } \\
\text { Maintenance } \\
\text { Break down } \\
\text { Periodic } \\
\text { Physical } \\
\text { inspection } \\
\text { Total }\end{array}$ & $\begin{array}{l}53 \\
863 \\
280 \\
1196\end{array}$ & $\begin{array}{l}4.4 \\
72.2 \\
23.4 \\
100.0\end{array}$ & $\begin{array}{l}4.4 \\
72.2 \\
23.4 \\
100.0\end{array}$ & $\begin{array}{l}4.4 \\
76.6 \\
100.0\end{array}$ \\
\hline
\end{tabular}

The table $4.1 \mathrm{H}$ above shows the factor that triggered the maintenance of the faulted power transformer. It is evident that the break down most triggered the maintenance of the faulted power transformer at $72.2 \%(\mathrm{n}=863)$, followed by
Periodic Physical inspection $(23.4 \%, \mathrm{n}=280)$ and Annual Maintenance $(4.4, \mathrm{n}=53)$.

Table 4.1I: The Existing Maintenance Practices that are in Use

\begin{tabular}{|c|c|c|c|c|c|}
\hline & & Freq. & $\%$ & Valid \% & $\begin{array}{l}\text { Cum. } \\
\%\end{array}$ \\
\hline Valid & $\begin{array}{l}\text { Periodic } \\
\text { Preventive } \\
\text { Maintenance } \\
\text { and } \\
\text { Breakdown } \\
\text { Maintenance }\end{array}$ & 1196 & 100.0 & 100.0 & 100.0 \\
\hline
\end{tabular}

The table 4.1I above reveals the existing maintenance practices that are in use currently as solely "Preventive Maintenance and Breakdown Maintenance" practice at 100 percent $(n=1196)$

Table 4.1J: The Effects of the Failure

\begin{tabular}{|c|c|c|c|c|c|}
\hline & & Freq. & $\%$ & $\begin{array}{l}\text { Valid } \\
\%\end{array}$ & $\begin{array}{l}\text { Cum. } \\
\%\end{array}$ \\
\hline \multirow{4}{*}{ Valid } & $\begin{array}{l}\text { Blackout (Consumers } \\
\text { subjected to total blackout } \\
\text { and the consequent repair } \\
\text { or replacement of } \\
\text { components) }\end{array}$ & 1140 & 95.3 & 95.3 & 95.3 \\
\hline & $\begin{array}{l}\text { None (Transfer of load to } \\
\text { other existing } \\
\text { transformers with no load } \\
\text { loss) }\end{array}$ & 50 & 4.2 & 4.2 & 99.5 \\
\hline & $\begin{array}{l}\text { Catastrophic } \\
\text { (Irrecoverable loss of } \\
\text { Power Transformer } \\
\text { with/without either/both } \\
\text { internal or/and external } \\
\text { fatal accident) }\end{array}$ & 6 & .5 & .5 & 100.0 \\
\hline & Total & 1196 & 100.0 & 100.0 & \\
\hline
\end{tabular}

From table $4.1 \mathrm{~J}$ above, the main effect of the failure is the blackout (Consumers subjected to total blackout and the consequent repair or replacement of components) with 95.3 percent. Followed by None (Transfer of load to other existing transformers with no load loss) by 4.2 percent and Catastrophic (Irrecoverable loss of Power Transformer with/without either/both internal or/and external fatal accident) 0.5 percent.

Table 4.1K: Suggested Better Methods Perceived could have averted the Failure?

\begin{tabular}{|c|c|c|c|c|c|}
\hline & & Freq. & $\%$ & $\begin{array}{l}\text { Valid } \\
\%\end{array}$ & $\begin{array}{l}\text { Cum. } \\
\%\end{array}$ \\
\hline Valid & $\begin{array}{l}\text { Online } \\
\text { Condition } \\
\text { Based } \\
\text { Monitoring }\end{array}$ & 1196 & 100.0 & 100.0 & 100.0 \\
\hline
\end{tabular}

The table $4.1 \mathrm{~K}$ above shows that there is only one suggestive better method perceived for averting the power transformers failures, which is Online Condition Based Monitoring. 
1) Summary of Practical Study Results of Power Transformer Failure Based on SPSS

The results of the study to determining the primary cause of 1196 power transformers failures in the Abuja sub-region of Transmission Company of Nigeria within the period of 6 years (from January 2013 to December 2018) summarily, revealed the Power Transformer Manufacture which equipment are most affected is MBH India comprising of 23.6 percent $(n=282)$, the power transformer age grade that suffered the worst failure rate is 6-10 Years Old comprising of 52.1 percent $(n=623)$, the most popular type of transformer failure is "Forced failure" comprising of 74.2 percent $(n=888)$, the Summer or Wet Season Covering from the Month of April to October of the year most triggered the failure of power transformer at $70.1 \%(n=838), 80.9$ percent $(n=968)$ of the transformers faulted due to external cause factors, the subsystem component that most failed the transformers is "Other auxiliary Components other than the main subsystems (such as Protection, Control \& Metering Components, etc)" with $71.9 \%(\mathrm{n}=860)$, This is due to a lack of data on the specific failure components of each instance of power transformer failure. "Other" proved the largest category with respect to failure components, featuring in 860 of the 1196 cases researched in the study. Failures in the "Other" category could not prove conclusively useful in this study; however they may be examined further at a later date. Despite this, much was learned about the secondary and tertiary causes of failure most prevalent in the region.

For cases for which we have specific data, or which were caused by a single failure component, by far the most common failed component was the coil. The coil was the component designated as causing the failure in 111 of 1196 instances of power transformer faults in the region, putting it as causing just over $9 \%$ of the failures in the region. The third largest cause of failure, after the nonspecific "Others" category and "Coil" was "Cooling Subsystem". The Chiller Subsystem failed in 77 out of 1196 cases of failure, or just over $6 \%$ of failures. The fourth largest cause of failure in terms of pure numbers was the On-load Tap Changer or OLTC, which accounted for $4 \%$ of the region's failures or 53 of 1196. After that, failures in the oil insulation system took fifth place, cause 33 of 1196 instances of failure and coming in as responsible for 3\% of the region's power transformer failures rounded. Bushing failures were not far behind accounting for $2.6 \%$ of the failures, 31 of 1196 cases specifically. Following that were casing failures, with $1.4 \%$ of instances caused by them, cistern failures, with $1 \%$ of instances caused by it and a single instance of failure due to a core failure.

Finally, going by the assumption that the critical components for which we have data can be safely extrapolated to the rest of the instances for which the data is nonspecific, it makes sense to assume that coils cause the largest number of power transformer faults and failures in the sub-region. If that is the case, the underlying causes of coil failure must be further examined. As extrapolated in earlier sections, the coil component of a transformer works in conjunction with the OLTC component of the power transformer in order to modulate and transport current. The coil component proves most prone to circuitry error, which is in turn caused by machine-driven wear and tear and defective insulation mediums. Machine- driven wear and tear can result in serious corrosive damage to the wiring. It is caused by shoddy construction, voltages which are regularly pushed past their upper limit of capacity and the gradual shifting of the internal components of the transformer itself. Shoddy construction results when either the material or method employed during the assembly of the coils was substandard, which inevitably brings about problems down the road. Voltages can be pushed past capacity in cases of connection errors and extreme weather events. In the case of connection errors, which are generally man-made, a simple miscalculation can result in notable impairment of the coils. Extreme weather events are harder to predict and may be irregular in their occurrence however they also damage the coil. As the transformers shift over the normal lifespan of their composite materials like cellulose, damage to the coils can also result. Defective insulation medium is the secondary cause of circuitry error as it relates to coil failure. Defective insulation mediums can come about as the result of a concentrated temperature increase, which can form hot spots. Concentrated temperature increases are the result of contaminated oil. Oil becomes contaminated when particles from other components become damaged by heat and are allowed to flow through the machine oil, a problem exacerbated by poor choice of materials during construction. Defective insulation mediums can also result from a build-up of copper sulfide.

B. Results of the Qualitative FTA Assessment of Power Transformer Reliability

1) Determination of the Minimal Cut Sets (MCS's) 


\begin{tabular}{|c|c|c|c|c|c|c|c|c|c|}
\hline S/No. & Code & Description & Type & Probability & S/No. & Code & Description & Type & Probability \\
\hline 1 & $\begin{array}{l}\text { PT- } \\
\text { FAILURE }\end{array}$ & & OR & $9.50 \mathrm{E}-02$ & 26 & gate26 & $\begin{array}{l}\text { Impaired Chiller } \\
\text { Circulatory System }\end{array}$ & OR & 4.00E-03 \\
\hline 2 & COIL & Coil Subsystem Fails & OR & $3.60 \mathrm{E}-02$ & 27 & gate27 & $\begin{array}{l}\text { Impaired Chiller Oil } \\
\text { Pump }\end{array}$ & OR & $3.00 \mathrm{E}-03$ \\
\hline 3 & BUSHING & Bushing Subsystem Fails & OR & $5.00 \mathrm{E}-03$ & 28 & gate28 & $\begin{array}{l}\text { Faulty Chiller Fans Motor } \\
\text { Bearings }\end{array}$ & OR & $2.00 \mathrm{E}-03$ \\
\hline 4 & CORE & Core Subsystem Fails & OR & $2.00 \mathrm{E}-03$ & 29 & gate29 & $\begin{array}{l}\text { Faulty Chiller Oil Pumps } \\
\text { Motor Bearings }\end{array}$ & OR & $2.00 \mathrm{E}-03$ \\
\hline 5 & OIL & $\begin{array}{l}\text { Oil Insulation Subsystem } \\
\text { Fails }\end{array}$ & OR & $1.80 \mathrm{E}-02$ & 30 & Gate30 & $\begin{array}{ll}\text { Impaired Insulation } \\
\text { Medium }\end{array}$ & OR & $3.00 \mathrm{E}-03$ \\
\hline 6 & CHILLER & Chiller Subsystem Fails & OR & $1.00 \mathrm{E}-02$ & 31 & Gate31 & Impaired Bushing Leads & OR & $2.00 \mathrm{E}-03$ \\
\hline 7 & OLTC & $\begin{array}{lll}\text { On-Load Tap } & \text { Changer } \\
\text { Subsystem Fails }\end{array}$ & OR & $5.00 \mathrm{E}-03$ & 32 & Gate32 & Oil Material Short-circuit & OR & $2.00 \mathrm{E}-03$ \\
\hline 8 & CISTERN & Cistern Subsystem Fails & OR & $1.40 \mathrm{E}-02$ & 33 & Gate33 & $\begin{array}{lr}\text { Oil } & \text { Temperature } \\
\text { Indication } & \text { System } \\
\text { Collapses } & \\
\end{array}$ & OR & $3.00 \mathrm{E}-03$ \\
\hline 9 & CASING & Casing Subsystem Fails & OR & $5.00 \mathrm{E}-03$ & 34 & Gate34 & $\begin{array}{l}\text { Oil Level Gauge System } \\
\text { Collapses }\end{array}$ & OR & $3.00 \mathrm{E}-03$ \\
\hline 10 & Gate10 & Oil Insulation Fails & OR & $1.80 \mathrm{E}-02$ & 35 & Gate35 & Chiller Subsystem Fails & OR & $1.00 \mathrm{E}-02$ \\
\hline 11 & Gate11 & Coil Element Injures & OR & $2.00 \mathrm{E}-03$ & 36 & gate36 & Impaired Chiller Fans & OR & $3.00 \mathrm{E}-03$ \\
\hline 12 & Gate12 & Paper Insulation Fails & OR & $1.60 \mathrm{E}-02$ & 37 & gate37 & $\begin{array}{l}\text { Impaired Chiller } \\
\text { Circulatory System }\end{array}$ & OR & $4.00 \mathrm{E}-03$ \\
\hline 13 & gate13 & Oil Material Short-circuit & OR & $2.00 \mathrm{E}-03$ & 38 & gate38 & $\begin{array}{l}\text { Impaired Chiller Oil } \\
\text { Pumps }\end{array}$ & OR & 3.00E-03 \\
\hline 14 & gate14 & $\begin{array}{lr}\text { Oil } & \text { Temperature } \\
\text { Indication } & \text { System } \\
\text { Collapses } & \\
\end{array}$ & OR & $3.00 \mathrm{E}-03$ & 39 & gate39 & $\begin{array}{l}\text { Faulty Fans Motor } \\
\text { Bearings }\end{array}$ & OR & $2.00 \mathrm{E}-03$ \\
\hline 15 & gate15 & $\begin{array}{l}\text { Oil Level Gauge System } \\
\text { Collapses }\end{array}$ & OR & $3.00 \mathrm{E}-03$ & 40 & gate40 & $\begin{array}{lll}\text { Faulty } & \text { Fans } & \text { Motor } \\
\text { Bearings } & & \\
\end{array}$ & OR & $2.00 \mathrm{E}-03$ \\
\hline 16 & gate16 & Chiller Subsystem Fails & OR & $1.00 \mathrm{E}-02$ & 41 & Gate41 & Impaired Chiller Fans & OR & $3.00 \mathrm{E}-03$ \\
\hline 17 & gate17 & Impaired Chiller Fans & OR & $3.00 \mathrm{E}-03$ & 42 & Gate42 & $\begin{array}{l}\text { Impaired Chiller } \\
\text { Circulatory System }\end{array}$ & OR & $4.00 \mathrm{E}-03$ \\
\hline 18 & gate18 & $\begin{array}{l}\text { Impaired Chiller } \\
\text { Circulatory System }\end{array}$ & OR & $4.00 \mathrm{E}-03$ & 43 & Gate43 & $\begin{array}{lll}\text { Impaired } & \text { Chiller } & \text { Oil } \\
\text { Pumps }\end{array}$ & OR & $3.00 \mathrm{E}-03$ \\
\hline 19 & gate19 & $\begin{array}{l}\text { Impaired Chiller Oil } \\
\text { Pump }\end{array}$ & OR & $3.00 \mathrm{E}-03$ & 44 & gate44 & $\begin{array}{lll}\begin{array}{l}\text { Faulty } \\
\text { Bearings }\end{array} & \text { Fans } & \text { Motor } \\
\end{array}$ & OR & $2.00 \mathrm{E}-03$ \\
\hline 20 & gate20 & $\begin{array}{lll}\text { Faulty } & \text { Fans } & \text { Motor } \\
\text { Bearings } & & \\
\end{array}$ & OR & $2.00 \mathrm{E}-03$ & 45 & gate45 & $\begin{array}{l}\text { Faulty Pumps Motor } \\
\text { Bearings }\end{array}$ & OR & $2.00 \mathrm{E}-03$ \\
\hline 21 & gate21 & $\begin{array}{ll}\text { Faulty Pumps Motor } \\
\text { Bearings }\end{array}$ & OR & $2.00 \mathrm{E}-03$ & 46 & Gate46 & $\begin{array}{l}\text { Impaired Pressure Relief } \\
\text { Machine }\end{array}$ & OR & $5.00 \mathrm{E}-03$ \\
\hline 22 & gate 22 & Chiller Subsystem Fails & OR & $1.00 \mathrm{E}-02$ & 47 & Gate47 & Cistern Materials Damage & OR & $2.00 \mathrm{E}-03$ \\
\hline 23 & gate23 & $\begin{array}{l}\text { Faulty Coil Temperature } \\
\text { Indication System }\end{array}$ & OR & $3.00 \mathrm{E}-03$ & 48 & Gate48 & $\begin{array}{l}\text { Impaired Buchholz Relay } \\
\text { Device }\end{array}$ & OR & $7.00 \mathrm{E}-03$ \\
\hline 24 & gate24 & Contaminated Paper & OR & $2.00 \mathrm{E}-03$ & 49 & Gate49 & $\begin{array}{l}\text { Machine } \\
\text { Corrosion }\end{array}$ & OR & $2.00 \mathrm{E}-03$ \\
\hline 25 & gate25 & Impaired Chiller Fans & OR & $3.00 \mathrm{E}-03$ & 50 & Gate50 & Insulation & OR & $3.00 \mathrm{E}-03$ \\
\hline
\end{tabular}

Table 4.2a below resulted MCS's of the constructed power transformer fault tree Gates with corresponding probability of occurrences respectively. All gates implemented in the fault tree construction resulted "OR". Assuming each of the basic events has equal probability of occurrence at 0.001 (fault chance of 1 in 1000 hours), Power transformer failure being the top event (Gate1) has occurrence probability of 0.095 , which mean a failure chance of 1 in $11 \mathrm{hrs}$. The power transformer fault tree resulted occurrence probabilities of 8 subsystems components including Coil Subsystem and Gate2 (0.036 or 1 in 28hrs), Bushing Subsystem and Gate3 (0.005 or 1 in $200 \mathrm{hrs})$, Core Subsystem and Gate4 (0.002 or 1 in $500 \mathrm{hrs})$, Oil Insulation Subsystem and Gate5 (0.018 or 1 in 56hrs), Chiller Subsystem and Gate6 (0.010 or 1 in $100 \mathrm{hrs}$ ), OLTC Subsystem and Gate7 (0.005 or 1 in 200 hrs), Cistern Subsystem and Gate8 (0.014 or 1 in $71 \mathrm{hrs})$, and Casing Subsystem and Gate9 (0.005 or 1 in $200 \mathrm{hrs}$ ). The results of bottom components associated with the main subsystems components listed above are also revealed in Table 4.2a. In failure occurrence probability of the 8 power transformer subsystems, the coil subsystem ranked the most with 0.036 , whereas, the Core subsystem ranked the least with 0.002. The results consequently depict the Coil Subsystem as the most susceptible part, while the Core Subsystem is the most resistant part in terms of being 


\begin{tabular}{|c|c|c|c|c|c|c|c|}
\hline $\begin{array}{l}\text { Ran } \\
\mathbf{k}\end{array}$ & $\begin{array}{l}\text { CutSets } \\
\text { probabilit } \\
\text { y }\end{array}$ & $\begin{array}{l}\text { Event } \\
\text { code }\end{array}$ & Event Description & $\begin{array}{l}\text { Ran } \\
\mathbf{k}\end{array}$ & $\begin{array}{l}\text { CutSets } \\
\text { probabili } \\
\text { ty }\end{array}$ & Event code & Event Description \\
\hline 1 & $1.00 \mathrm{E}-03$ & event38 & Sub-optimal transformer motion & 49 & $1.00 \mathrm{E}-03$ & event5 & Faulty temperature sensor \\
\hline 2 & $1.00 \mathrm{E}-03$ & event39 & Circulatory issues & 50 & $1.00 \mathrm{E}-03$ & event6 & Faulty temperature control switch \\
\hline 3 & $1.00 \mathrm{E}-03$ & event41 & Lowered efficiency & 51 & $1.00 \mathrm{E}-03$ & event7 & Faulty temperature calibrator \\
\hline 4 & $1.00 \mathrm{E}-03$ & event1 & Normal wear and tear & 52 & $1.00 \mathrm{E}-03$ & event9 & Faulty oil level control switch \\
\hline 5 & $1.00 \mathrm{E}-03$ & event 40 & $\begin{array}{l}\text { Concentrated temperature } \\
\text { increase }\end{array}$ & 53 & $1.00 \mathrm{E}-03$ & event10 & Faulty oil level calibrator \\
\hline 6 & $1.00 \mathrm{E}-03$ & event23 & Impaired OLTC control device & 54 & $1.00 \mathrm{E}-03$ & event8 & Faulty oil level sensor \\
\hline 7 & $1.00 \mathrm{E}-03$ & event24 & Impaired OLTC drive mechanism & 55 & $1.00 \mathrm{E}-03$ & event1 & Normal wear and tear \\
\hline 8 & $1.00 \mathrm{E}-03$ & event 25 & Faulty OLTC electric motor & 56 & $1.00 \mathrm{E}-03$ & event20 & Sabotage \\
\hline 9 & $1.00 \mathrm{E}-03$ & event26 & $\begin{array}{l}\text { Damaged OLTC tap selection } \\
\text { knob }\end{array}$ & 57 & $1.00 \mathrm{E}-03$ & event1 & Normal wear and tear \\
\hline 10 & $1.00 \mathrm{E}-03$ & event11 & Electrical signal loss & 58 & $1.00 \mathrm{E}-03$ & event19 & Careless handling \\
\hline 11 & $1.00 \mathrm{E}-03$ & event11 & Electrical signal loss & 59 & $1.00 \mathrm{E}-03$ & event20 & Sabotage \\
\hline 12 & $1.00 \mathrm{E}-03$ & event32 & Faulty BRD pressure balance & 60 & $1.00 \mathrm{E}-03$ & event5 & Faulty temperature sensor \\
\hline 13 & $1.00 \mathrm{E}-03$ & event33 & Faulty BRD sensor system & 61 & $1.00 \mathrm{E}-03$ & event6 & Faulty temperature control switch \\
\hline 14 & $1.00 \mathrm{E}-03$ & event34 & Faulty BRD sensor bellows & 62 & $1.00 \mathrm{E}-03$ & event7 & Faulty temperature calibrator \\
\hline 15 & $1.00 \mathrm{E}-03$ & event35 & Faulty BRD control switch & 63 & $1.00 \mathrm{E}-03$ & event17 & Detritus in paper \\
\hline 16 & $1.00 \mathrm{E}-03$ & event36 & Faulty BRD control crifice & 64 & $1.00 \mathrm{E}-03$ & event18 & Foreign liquids in paper \\
\hline 17 & $1.00 \mathrm{E}-03$ & event 37 & Faulty BRD control bellows & 65 & $1.00 \mathrm{E}-03$ & event1 & Normal wear and tear \\
\hline 18 & $1.00 \mathrm{E}-03$ & event27 & Faulty PRM control switch & 66 & $1.00 \mathrm{E}-03$ & event11 & Electrical signal loss \\
\hline 19 & $1.00 \mathrm{E}-03$ & event 28 & Faulty PRM valves & 67 & $1.00 \mathrm{E}-03$ & event1 & Normal wear and tear \\
\hline 20 & $1.00 \mathrm{E}-03$ & event29 & Faulty PRM disc & 68 & $1.00 \mathrm{E}-03$ & event16 & Impaired lubricant \\
\hline 21 & $1.00 \mathrm{E}-03$ & event30 & Faulty PRM sensor & 69 & $1.00 \mathrm{E}-03$ & event12 & Tiny cs oil nozzles \\
\hline 22 & $1.00 \mathrm{E}-03$ & event31 & Faulty PRM Spring & 70 & $1.00 \mathrm{E}-03$ & event13 & Faulty cs valves \\
\hline 23 & $1.00 \mathrm{E}-03$ & event 1 & Normal wear and tear & 71 & $1.00 \mathrm{E}-03$ & event14 & cs pipes leakages \\
\hline 24 & $1.00 \mathrm{E}-03$ & event19 & Careless handling & 72 & $1.00 \mathrm{E}-03$ & event15 & cs pipes blockages \\
\hline 25 & $1.00 \mathrm{E}-03$ & event16 & Impaired lubricant & 73 & $1.00 \mathrm{E}-03$ & event16 & Impaired lubricant \\
\hline 26 & $1.00 \mathrm{E}-03$ & event1 & Normal wear and tear & 74 & $1.00 \mathrm{E}-03$ & event1 & Normal wear and tear \\
\hline 27 & $1.00 \mathrm{E}-03$ & event11 & Electrical signal loss & 75 & $1.00 \mathrm{E}-03$ & event11 & Electrical signal loss \\
\hline 28 & $1.00 \mathrm{E}-03$ & event12 & Tiny cs oil nozzles & 76 & $1.00 \mathrm{E}-03$ & event1 & Normal wear and tear \\
\hline 29 & $1.00 \mathrm{E}-03$ & event13 & Faulty cs valves & 77 & $1.00 \mathrm{E}-03$ & event2 & Poor joining \\
\hline 30 & $1.00 \mathrm{E}-03$ & event14 & cs pipes leakages & 78 & $1.00 \mathrm{E}-03$ & event3 & Detritus in oil \\
\hline 31 & $1.00 \mathrm{E}-03$ & event15 & cs pipes blockages & 79 & $1.00 \mathrm{E}-03$ & event4 & Foreign liquids in oil \\
\hline 32 & $1.00 \mathrm{E}-03$ & event11 & Electrical signal loss & 80 & $1.00 \mathrm{E}-03$ & event5 & Faulty temperature sensor \\
\hline 33 & $1.00 \mathrm{E}-03$ & event11 & Normal wear and tear & 81 & $1.00 \mathrm{E}-03$ & event6 & Faulty temperature control switch \\
\hline 34 & $1.00 \mathrm{E}-03$ & event16 & Impaired lubricant & 82 & $1.00 \mathrm{E}-03$ & event7 & Faulty temperature calibrator \\
\hline 35 & $1.00 \mathrm{E}-03$ & event 21 & Mechanical faults & 83 & $1.00 \mathrm{E}-03$ & event8 & Faulty oil level sensor \\
\hline 36 & $1.00 \mathrm{E}-03$ & event22 & DC magnetic induction collapses & 84 & $1.00 \mathrm{E}-03$ & event9 & Faulty oil level control switch \\
\hline 37 & $1.00 \mathrm{E}-03$ & event1 & Normal wear and tear & 85 & $1.00 \mathrm{E}-03$ & event10 & Faulty oil level calibrator \\
\hline 38 & $1.00 \mathrm{E}-03$ & event16 & Impaired lubricant & 86 & $1.00 \mathrm{E}-03$ & event1 & Normal wear and tear \\
\hline 39 & $1.00 \mathrm{E}-03$ & event11 & Electrical signal loss & 87 & $1.00 \mathrm{E}-03$ & event16 & Impaired lubricant \\
\hline 40 & $1.00 \mathrm{E}-03$ & event12 & Tiny cs oil nozzles & 88 & $1.00 \mathrm{E}-03$ & event11 & Electrical signal loss \\
\hline 41 & $1.00 \mathrm{E}-03$ & event13 & Faulty cs valves & 89 & $1.00 \mathrm{E}-03$ & event12 & Tiny cs oil nozzles \\
\hline 42 & $1.00 \mathrm{E}-03$ & event14 & cs pipes leakages & 90 & $1.00 \mathrm{E}-03$ & event13 & Faulty cs valves \\
\hline 43 & $1.00 \mathrm{E}-03$ & event15 & cs pipes blockages & 91 & $1.00 \mathrm{E}-03$ & event14 & cs pipes leakages \\
\hline 44 & $1.00 \mathrm{E}-03$ & event11 & Electrical signal loss & 92 & $1.00 \mathrm{E}-03$ & event15 & ca pipes blockages \\
\hline 45 & $1.00 \mathrm{E}-03$ & event16 & Impaired lubricant & 93 & $1.00 \mathrm{E}-03$ & event11 & Electrical signal loss \\
\hline 46 & $1.00 \mathrm{E}-03$ & event1 & Normal wear and tear & 94 & $1.00 \mathrm{E}-03$ & event1 & Normal wear and tear \\
\hline 47 & $1.00 \mathrm{E}-03$ & event3 & Detritus in oil & 95 & $1.00 \mathrm{E}-03$ & event16 & Impaired lubricant \\
\hline 48 & $1.00 \mathrm{E}-03$ & event4 & Foreign liquids in oil & & & & \\
\hline
\end{tabular}


Table 4.2c: List of Power Transformer Subsystems' Minimal CutSets

\begin{tabular}{|c|c|c|c|c|}
\hline No. & Subsystems & $\begin{array}{c}\text { Minimal Cut Sets } \\
\text { (MCS's) }\end{array}$ & $\begin{array}{c}\text { Number } \\
\text { of } \\
\text { Single } \\
\text { Basic } \\
\text { Events } \\
\text { of } \\
\text { MCS's } \\
\end{array}$ & $\begin{array}{c}\text { Number } \\
\text { of } \\
\text { Double } \\
\text { Basic } \\
\text { Events } \\
\text { of } \\
\text { MCS's } \\
\end{array}$ \\
\hline 1 & Coil & $\begin{array}{l}\text { Event3, Event4, } \\
\text { Event5, Event6, } \\
\text { Event7, Event8, } \\
\text { Event9, Event10, } \\
\text { Event11, Event12, } \\
\text { Event13, Event14, } \\
\text { Event15, Event11, } \\
\text { Event1, Event16, } \\
\text { Event1, Event16, } \\
\text { Event1, Event2, } \\
\text { Event1, Event1, } \\
\text { Event12, Event13, } \\
\text { Event14, Event15, } \\
\text { Event11, Event1, } \\
\text { Event16, Event16, } \\
\text { Event1, Event5, } \\
\text { Event6, Event7, } \\
\text { Event17, Event18 }\end{array}$ & 16 & 20 \\
\hline 2 & Bushing & $\begin{array}{l}\text { Event1, Event19, } \\
\text { Event20, Event1, } \\
\text { Event20 }\end{array}$ & 5 & 0 \\
\hline 3 & Core & Event21, Event22 & 2 & 0 \\
\hline 4 & $\begin{array}{l}\text { Oil } \\
\text { Insulation }\end{array}$ & $\begin{array}{l}\text { Event3, Event4, } \\
\text { Event5, Event6, } \\
\text { Event7, Event8, } \\
\text { Event9, Event10, } \\
\text { Event11, Event12, } \\
\text { Event13, Event14, } \\
\text { Event15, Event11, } \\
\text { Event11, Event1, } \\
\text { Event16, Event16, } \\
\text { Event1 }\end{array}$ & 18 & 0 \\
\hline 5 & Chiller & $\begin{array}{l}\text { Event11, Event12, } \\
\text { Event13, Event14, } \\
\text { Event15, Event11, } \\
\text { Event16, Event1, } \\
\text { Event1, Event16 }\end{array}$ & 10 & 0 \\
\hline 6 & OLTC & $\begin{array}{l}\text { Event23, Event24, } \\
\text { Event25, Event26, } \\
\text { Event11 }\end{array}$ & 5 & 0 \\
\hline 7 & Cistern & $\begin{array}{l}\text { Event27, Event28, } \\
\text { Event29, Event30, } \\
\text { Event31, Event1, } \\
\text { Event } 19, \text { Event11, } \\
\text { Event32, Event33, } \\
\text { Event34, Event35, } \\
\text { Event36, Event37 }\end{array}$ & 14 & 0 \\
\hline 8 & Casing & $\begin{array}{l}\text { Event38, Event39, } \\
\text { Event40, Event41, } \\
\text { event } 1\end{array}$ & 5 & 0 \\
\hline
\end{tabular}

responsible for power transformer failure. Also, in Table $4.2 \mathrm{~b}$ above, based on the assumption that each of the basic elements has equal occurrence probability of 0.001 , the MCS's resulted event38 - sub-optimal transformer motion - as the topmost in ranking of the 95 basic events, whereas, event16 - impaired lubricant - ranks bottommost. It means paying much attention on the power transformer core at both the design and construction stages to take cognizance of the impact of vibrations during shipping and operational instances.

Similarly, Table $4.2 \mathrm{c}$ below documents the list of minimal cut sets of power transformer.
Table 4.2d: The Analysis of Qualitative Importance of Subsystems

\begin{tabular}{|l|l|l|l|l|l|}
\hline No. & Subsystems & $\begin{array}{l}\text { Number } \\
\text { of } \\
\text { Single } \\
\text { Basic } \\
\text { Events } \\
\text { of } \\
\text { MCS's }\end{array}$ & $\begin{array}{l}\text { Number } \\
\text { of } \\
\text { Double } \\
\text { Basic } \\
\text { Events } \\
\text { of } \\
\text { MCS's }\end{array}$ & $\begin{array}{l}\text { Minimal } \\
\text { Cut Sets } \\
\text { (MCS's) }\end{array}$ & $\begin{array}{l}\text { Occ. } \\
\text { Prob. }\end{array}$ \\
\hline 1 & Coil & 16 & 20 & 36 & 0.036 \\
\hline 2 & Bushing & 5 & 0 & 5 & 0.005 \\
\hline 3 & Core & 2 & 0 & 2 & 0.002 \\
\hline 4 & $\begin{array}{l}\text { Oil } \\
\text { Insulation }\end{array}$ & 18 & 0 & 18 & 0.018 \\
\hline 5 & Chiller & 10 & 0 & 10 & 0.010 \\
\hline 6 & OLTC & 5 & 0 & 5 & 0.005 \\
\hline 7 & Cistern & 14 & 0 & 14 & 0.014 \\
\hline 8 & Casing & 5 & 0 & 5 & 0.005 \\
\hline
\end{tabular}

2) Analysis of the Qualitative Components Importance In the assessment of Qualitative Components Importance, rise in frequency of basic events in MCS's is proportional to reduction in the MCS's contribution to the chance of the top event, and vice versa. The Qualitative Components Importance results that are shown in the Table $4.2 \mathrm{~d}$ below reveal the following analysis.

Supposing the chances of basic events at pal with one another and below 0.001, the Qualitative Components Importance rankings fault trees is deduced as follows:

A. Coil subsystem has 36 basic events with 0.036 happening chances.

B. Bushing subsystem has 5 basic events with 0.005 happening chances.

C. Core subsystem has 2 basic events with 0.002 happening chances.

D. Oil insulation subsystem has 18 basic events with 0.018 happening chances.

E. Chiller Subsystem has 10 basic events with 0.010 happening chances.

F. OLTC subsystem has 5 basic events with 0.005 happening chances.

G. Cistern subsystem has 14 basic events with 0.014 happening chances.

H. Casing subsystem has 5 basic events with 0.005 happening chances.

Also, the analyses of the results of the Ranking of Qualitative Component Importance of Power Transformer main subsystem components in Table 4.2e below presented Circulatory System and Buchholz Relay Device both of which are components of the Coil and Cistern Subsystems respectively rank the most with occurrence probabilities of 0.008 and 0.007 respectively. It means that good attention needed to be given to these components at both the design and construction stages. 
Table 4.2e: The Ranking of Qualitative Component Importance of Power Transformer

\begin{tabular}{|c|c|c|c|c|c|}
\hline No. & Subsystems & Component Name & $\begin{array}{c}\text { Number } \\
\text { of } \\
\text { Single } \\
\text { Basic } \\
\text { Event } \\
\text { of } \\
\text { MCS's }\end{array}$ & $\begin{array}{c}\text { Number } \\
\text { of } \\
\text { Double } \\
\text { Basic } \\
\text { Event } \\
\text { of } \\
\text { MCS's }\end{array}$ & $\begin{array}{l}\text { Occur. } \\
\text { Probs. }\end{array}$ \\
\hline \multirow{9}{*}{1} & \multirow{9}{*}{ Coil } & $\begin{array}{l}\text { Oil Insulation } \\
\text { Material }\end{array}$ & 2 & 0 & 0.002 \\
\hline & & $\begin{array}{l}\text { Oil temperature } \\
\text { indicator }\end{array}$ & 3 & 0 & 0.003 \\
\hline & & $\begin{array}{l}\text { Oil Level Gauge } \\
\text { Indicator }\end{array}$ & 3 & 0 & 0.003 \\
\hline & & Fan & 0 & 6 & 0.006 \\
\hline & & Circulatory System & 0 & 8 & 0.008 \\
\hline & & Oil Pump & 0 & 6 & 0.006 \\
\hline & & Coil Element & 2 & 0 & 0.002 \\
\hline & & $\begin{array}{l}\text { Coil Temperature } \\
\text { Indicator }\end{array}$ & 3 & 0 & 0.003 \\
\hline & & Paper material & 3 & 0 & 0.003 \\
\hline \multirow{2}{*}{2} & \multirow{2}{*}{ Bushing } & Insulation Medium & 3 & 0 & 0.003 \\
\hline & & Bushing Lead & 2 & 0 & 0.002 \\
\hline \multirow{2}{*}{3} & \multirow{2}{*}{ Core } & $\begin{array}{l}\text { DC Magnetic } \\
\text { Induction }\end{array}$ & 1 & 0 & 0.001 \\
\hline & & Mechanical & 1 & 0 & 0.001 \\
\hline \multirow{4}{*}{4} & \multirow{4}{*}{$\begin{array}{l}\text { Oil } \\
\text { insulation }\end{array}$} & $\begin{array}{l}\text { Oil Insulation } \\
\text { Material }\end{array}$ & 2 & 0 & 0.002 \\
\hline & & Fan & 3 & 0 & 0.003 \\
\hline & & Circulatory System & 4 & 0 & 0.004 \\
\hline & & Oil Pump & 3 & 0 & 0.003 \\
\hline \multirow{3}{*}{5} & \multirow{3}{*}{ Chiller } & Fan & 3 & 0 & 0.003 \\
\hline & & Circulatory System & 4 & 0 & 0.004 \\
\hline & & Oil Pump & 3 & 0 & 0.003 \\
\hline \multirow{5}{*}{6} & \multirow{5}{*}{ OLTC } & Control Device & 1 & 0 & 0.001 \\
\hline & & Drive Mechanism & 1 & 0 & 0.001 \\
\hline & & Electric Motor & 1 & 0 & 0.001 \\
\hline & & Tap Selection Knob & 1 & 0 & 0.001 \\
\hline & & Electric Signal & 1 & 0 & 0.001 \\
\hline \multirow{3}{*}{7} & \multirow{3}{*}{ Cistern } & $\begin{array}{l}\text { Pressure Relief } \\
\text { Machine }\end{array}$ & 5 & 0 & 0.005 \\
\hline & & Cistern Material & 2 & 0 & 0.002 \\
\hline & & $\begin{array}{l}\text { Buchholz Relay } \\
\text { Device }\end{array}$ & 7 & 0 & 0.007 \\
\hline \multirow[t]{2}{*}{8} & \multirow[t]{2}{*}{ Casting } & $\begin{array}{l}\text { Machine Driven } \\
\text { Corrosion }\end{array}$ & 2 & 0 & 0.002 \\
\hline & & Insulation Material & 3 & 0 & 0.003 \\
\hline
\end{tabular}

3) Summary of the Results of the Qualitative FTAs Assessment of Power Transformer Reliability

The required circumstance for the collapse of power transformer to happen is deduced by the minimum cut sets. The study result of the MCS's in Table 4.2a reveals 75 MCS's having one basic event, and 20 MCS's having two basic events. There are several chances of the happening of basic events collapse that consequently culminate in happening of the top event of the power transformer structure. Whichever chance of the MCS's will expressly tally the top event happening, simply described as power transformer fails to transform low current to high current, and vice-visa. From the result of ranking of the Qualitative Components Importance of the power transformer subsystems, coil subsystem with 36 basic events MCS's and a corresponding 0.036 happening chances is a reflection that coil subsystem is the highest ranking in Qualitative Components Importance. Consequently, the deduction reveals the coil subsystem as the weakness point in the power transformer structure. Conversely, the core subsystem is the strongest point in the power transformer structure, having the lowest ranking in Qualitative Components Importance with 2 basic events MCS's and a corresponding 0.002 happening chances. Supposing that each of the components of the power transformer subsystems is independent as shown in table $4.2 \mathrm{c}$, the more the single basic events of minimal cut sets constituted in any component, the more the vital involvement to the happening of the top event.

\section{Discussion}

The study result based on the SPSS analysis shows that the failure statistics of the Nigerian electric industry is high; that is, due to the numerous causes of power transformers failures. The SPSS entailed interviews, qualitative studies, and quantitative research. The study results reveal that component data seems to point most conclusively at the distinct causes of failure for which we have it, and as such this analysis will focus primarily on those. The transformers in the study were all relatively young, making it difficult to say for certain that the age of the transformers played a factor. The average age of the transformers in the study was around 7.9 years. Considering the fact that most transformers are projected to function for anywhere from 30-40 years [55], it would not be profitable to examine the age of the transformers too closely. Nor does examining the manufacturer of the transformer prove especially illuminating. A litany of manufacturers provides the transformers for the region, with none with products especially prone to failure. Additionally, without complete data on the number of transformers each manufacturer provides to the whole of Nigeria, it would be difficult to generalize the results of the study to the entire nation and say for certain that one manufacturer's transformer was more likely than others to fail. Other factors prove less useful as well. Considering the fact that transformers appear just as likely to fail across both of the two climatic seasons put in the weather for consideration, as it is seen from the practical statistical analysis that the summer or wet season contributed $70.1 \%$ of power transformer failures, whereas the winter or dry season was responsible for $29.9 \%$ failures. No, the factor with the most distinction across categories is the specific failure component, although examining that is not without its challenges. The largest cause of power failure in the Abuja Transmission Sub-Region is "Other auxiliary Components other than the main subsystems (such as Protection, Control \& Metering Components, etc)", a nonspecific designation that may refer to a previously unknown component of transformer systems or, more likely, a novel combining of components that caused failure. With this is 
mind, it is difficult to say for certain that any one component causes the majority of failures in power transformers in the Abuja transmission sub-region. However, examining this data does provide evidence as to the second and third largest causes of failure by component in the region, from which we can make specific recommendations.

The "Coils" category clocked in at 9\%, having caused 111 of 1196 of the failures noted in the region. It is assumed that had the "Other" category been more detailed, that "Coils" would have also prevailed as the number one cause of failure in the region, however without more information that is difficult to show for certain. These results were moderately surprising given that bushings are often found to be the most frequent cause of failure. Although they proved significant in this investigation, they occurred almost $60 \%$ less than coil failures. These results may remain true in further investigations as to the causes of power transformer failures in Abuja, and in Nigeria at large. Alternatively, further study may reflect another component as the major cause of power transformer failures in Abuja. Considering the large number of non-component- specific results, it becomes hard to predict this with a level of certainty. Also surprising, as previously mentioned, was the lack of specific data as to the actual component failures. More concise results were expected, however the data derived was enough to draw conclusions and make further extrapolations based on these.

On the other hand, the study result shows that the outcome of the qualitative assessment of the power transformer fault tree are minimal cut sets (MCS's) and qualitative component importance. The deduction of what mixtures of events that resulted in the top event occurrence is achieved by the appliance of qualitative fault tree analysis. The beauty of this qualitative analysis technique is that it can be executed before inputting any maintenance or collapse information in the fault tree properties' events. The minimal cut sets of top event's qualitative analysis are deduced using logic gates. The FTA facilitated precise analysis of the transformer failure, identification of the qualitative deductions and minimum cut sets. The fault tree analysis is a visual representation of the direction of failure from the smallest component [10]. The technique helps professionals to determine the estimate the reliability of a unit and cause of a fault. In FTA, the Boolean logic used to review the undesired state of a system. The logic data includes using instructions such as "OR", "AND", and, "NOR", "X-OR" and "X-NOR" on low-level events. In most cases, FTA used in reliability and safety engineering; that is, the technique helps formulate a risk management plan; or mitigate effects of a science problem. In this case, the analysis involves dividing the complex power system into sub-units and using logic gate symbols to represent the flow of events [68]. The research also utilized the event trees as an analysis tool. In this case, the strategy helps to identify the initiator, which is power transformer subsystem component failure with the series of system activities affected by the fault. Each event is a new node with the probability of several split branches. The event symbols in FTA include the conditioning; undeveloped; external and essential events. The primary activity is an error in a unit; in this case, it is the failure of transformer parts such as the core, oil insulation, casing, or bushings, etc. The external event is an operation that usually happens. An example is the operation of the Buchholz relay in transformers. On the other hand, the undeveloped event is an activity which the researcher has insufficient data concerning it. Also, the game lacks any consequence; in this case, the business is transmission cables connecting the electric grid. The conditioning activity is the event which influences or restricts the logic gates; an example is the optimum mode of operation for transformers. The Boolean gates play a pivotal role in FTA analysis.

The cut set symbol is the collection of activities such as component failures causing a fault in the entire system. Ideally, the minimum cut set is the number of events which cannot eliminate without affecting the top function; that is, power supply. In this case, the strategy helps to identify the initiator that is power transformer failure and the series of system activities affected by the fault. The validation of subsystems fault trees is achieved with the aid of MCS's, to verify that the particular event is responsible for the top event occurrence. For systems with small fault trees the resolution of minimum cut sets can be achieved with mere visual assessments. But for systems with large fault trees it becomes realistically impossible to visually assess the minimum cut sets. Hence, the needs evolved for the creation of computer algorithms to automatically produce cut sets. Sundry techniques for the assessment of minimum cut sets of fault trees are available, including: MOCUS, ZBDD and MISCUP, which meanings are method of obtaining cut sets employing a top-down technique [19], [20], [71], [72], [79], [80] - [85]; zero-suppressed binary decision diagram [71]; and minimum cut sets upward respectively - employing a bottom-up technique [72]. In the year 1972, Fussell and Vesely suggested the implementation of MOCUS that employs a top-down technique dependent upon the examination that AND gates multiply the size of the cut sets, whereas, the OR gates add the number of cut sets. In this case, this technique contemporarily known as Relex software alongside other FTA assessment apparatus was applied [19], [20], [71], [72], [79], [80] - [85].

The results of both the SPSS and FTA analyses depict consistently that it is imperative to beam attention on the coil subsystem of the power transformer as the most contributory subsystem to its unreliability. This deduction is in agreement with the universally deduced weak point of the power transformer [21], [73], and [74]. As connection errors are mostly man-made, detailed correction protocols are recommended to protect the coils from this cause of machinedriven wear and tear. Transformer shifting, as it relates directly to the age of the composite materials like cellulose, is less of a factor given the specific mean age of the transformers in this data set. However, it should not be disregarded entirely, as many transformers in the study were around seven years old. The average age that a transformer begins to show issues is age 14 [31], so these were already at the midpoint of their healthy lifespan. Defective insulation mediums can be directly addressed through careful monitoring of areas of concentrated temperature increases. These in turn can be mitigated by special attention placed on the quality of the oil that runs through the power transformer [32]. Additionally, build-ups of copper sulfide should be 
closely monitored as so not to become a further source of defective insulation medium.

Furthermore, the study interview resulted one of the approaches to improve power transformer reliability is regular repair and maintenance. It also revealed that majority of the transformer failures emanate from "ignorance" of the technician and operators. An example is the cooling and cistern subsystem failures. The systems require consistent inspection, repair of damaged parts and replacement of transformer parts such as the Buchholz Relay, Coils, Casing, Core, and Pressure Relief Subsystems components. Incontrovertibly, the study results depicted the consistently perceived approach is an accurate assessment using contemporary smart technologies [75]. The active monitoring helps technicians to correct faults fast; this prolongs the operation of the transformers and therefore improves the reliability of the power system.

\section{1) Improving the Reliability of the Power System}

Seeing as the specific component most prone to cause power transformer failure is the coil, the most advantageous area of focus would be eliminating the underlying causes of coil failure, or at least addressing them directly. Shoddy construction can be eliminated at the outset of a power transformer's life. If special care is taken in the choosing of materials and subsequent combinations of them, many coil failures due to machine wear and tear can likely be avoided. Similarly, as voltages that regularly go over capacity are another major driver of machine wear and tear, special care could be taken to protect the coils from extreme weather events such as lightning, perhaps through advanced detection systems and specific protocols put in place.

\section{SUMMARY, CONCLUSIONAND RECOMMENDATIONS}

\section{A. Summary}

With the aim of getting to the core of the problem, this thesis assessed power transformer conditions while using the SPSS and FTA combination approach. This helped in obtaining the probability of component failure that usually leads to power transformer failure [62], [63], [64], [76], and [77], as well as the causes and effects of various power transformers faults. In fact, this method helped in determining a policy of maintenance as well as operation. Also, analyzing the condition, and causes and effects of faults of power transformer using this brand new assessment technique helped the researcher to understand the failure sequences[78]. For example, the use of FTA minimal cut sets method made qualitative evaluation much easier. More so, the study acquired and generated all information that is necessary as far as power transformers faults are concerned. Through the interviews, the researcher collected data on component failure, repair, and maintenance information, human error related data to mention but a few. In this perspective, the study documented the causes and effects of power transformer faults at the Transmission Company of Nigeria, Abuja Sub-Region.

\section{B. Conclusion}

The study attempted to ascertain the reliability of the power transformer systems in Abuja, utilizing data collection and fault tree analysis in order to do so. It also aimed to provide specific recommendations as to best practices with regards to reducing power transformer failures utilizing this data. Through these methods, the research concluded that the major specified component cause of power transformer failure was coils. Additionally, that these failures could be reduced through regular maintenance and focused inspections of component parts whose failure is likely to result in coil failures, namely circuitry insulation and underlying functioning. This study also provided a brief overview of the history of the Nigerian power grid, and various attempts by researchers to ascertain the exact causes of its various failures. It also detailed a fault tree analysis and subsequent qualitative deductions for each of the major component systems of a power transformer system, and documented cause and effect relationships at each level of the subsystem. Finally and most importantly, the study described a better way of improving the reliability of the Nigerian electricity industry by reducing the incessant power transformers failures through the implementation of the advanced monitoring and diagnostic methods of power transformer faults including the change from conventional diagnostic methods to the online prognostic approaches to forestall breakdown. Hence, this study drew conclusions of and made recommendations for future work, policy implementation and study.

\section{Recommendations for Future Works}

The following topics for future researches are recommended based on our study in this thesis:

i. The qualitative FTA assessment of power transformers reliability can be validated by the implementation of a practical quantitative FTA reliability assessment method on power transformers,

ii. The power transformer's reliability can most effectively be improved by enacting strict monitoring and maintenance standards. Because coil failures have multiple causes and can result from relatively minor complications, and because they are a major cause of power transformer failure in the sub-region, many transformer failures could be prevented through better maintenance protocols. These include preparations for extreme weather events like lighting, regular oil filtration to prevent concentrated areas of high heat which could damage the insulation medium, avoidance of low-quality construction materials, and monitoring of the various components as the transformers age. Additionally, copper sulphide monitoring is recommended, and

iii. Beyond the above recommendations, greater detail should be taken to account for the various component failures of the power transformer systems. This data is crucial in ascertain the exact causes of power system failures and is invaluable in determining how to prevent them. Specific sensors for each of the component parts are recommended. 


\section{ACKNOWLEDGMENT}

But for the assistance and motivation of several dignified personalities, I would not have ascended to the peak of the thesis and consequently the degree. At this juncture, I launch out to giving some credence to all the efforts put in by these great gems.

My first expression of unalloyed appreciation goes to Engr. Dr. Stephen Oodo and to Engr. Dr. Abubakar Sadiq Umar both of which are my co-authors, for their enthusiastic motivation, perseverant direction and vital criticisms of this thesis work. Indeed, this thesis would never have been accomplished if not for their pertinent inputs and motivation. Truly, both of you offer me an unusual opportunity to access wealth of experiences and to penetrate the globe through learning in the University of Abuja, as well as garnering of some more experiences in the hall of intercontinental academic world.

My second and deep appreciation is channeled to Engr. Dr. Evans C. Ashigwuike and my departmental head; Engr. Dr. Emmanuel Eronu and my departmental postgraduate studies coordinator; and all of my departmental lecturers amongst whom are Engr. Dr. Muhammad Uthman, Engr. Douglas Uke, Engr. Obinna Ozoemena, as well as the visiting lecturers in persons of Engr. Dr. Jonas Emechebe, Engr. Dr. David Ejor, Prof. Jimoh and Prof. James Katende for their prestigious recommendations and assistance to sustain my academic progress on schedule. Your insights, contributions and elaborate comments are of great value to me, sirs.

My third expression of gratitude goes to Engr. Prof. O. B. Oloche and faculty dean, Engr. Dr. E. E. Ndububa and faculty deputy dean, Engr. Dr. (Mrs.) K. O. Adeyemi and Mechanical Engineering departmental head, Engr. Dr. Audu Taiwo and Civil Engineering departmental head, Engr. Dr. A. M. Avuti and Chemical Engineering departmental head, and Engr. Dr. Ibrahim and senior lecturer in Mechanical Engineering Department, for their constructive criticisms and academic mentoring inputs, as well as their relationship and welcome throughout my learning period in the faculty.

My fourth and candid expression of appreciation is to all my course-mates for their high spirit of cooperation and kindness that motivated me in the course of my study in University of Abuja.

\section{REFERENCES}

[1]. K. R. Ajao, H. Ajimotokan, T. Popoola, H. Akande, "Electric Energy Supply in Nigeria, Decentralized Energy Approach", Cogeneration and Distributed Generation Journal. 24 10.1080/15453660909595149. (2009).

[2]. K. Bacha, S. Souahlia and M. Gossa, "Power transformer fault diagnosis based on dissolved gas analysis by support vector machine", Electric Power Systems Research, vol. 83, no. 1, pp. 73-79, 2012.

[3]. B. Castro, G. Clerice, C. Ramos, A. Andreoli, F. Baptista, F. Campos and J. Ulson, "Partial Discharge Monitoring in Power Transformers Using Low-Cost Piezoelectric Sensors", Sensors, vol. 16, no. 8, p. 1266, 2016.

[4]. B. Ward, "A survey of new techniques in insulation monitoring of power transformers", IEEE Electrical Insulation Magazine, vol. 17, no. 3, pp. 16-23, 2001.

[5]. J. Singh, Y. Sood and R. Jarial, "Condition Monitoring of Power Transformers - Bibliography Survey", IEEE Electrical Insulation Magazine, vol. 24, no. 3, pp. 11-25, 2008
[6]. R. Liao, J. Bian, L. Yang and S. Grzybowski, "Cloud modelbased failure mode and effects analysis for prioritization of failures of power transformer in risk assessment", International Transactions on Electrical Energy Systems, vol. 23, no. 7, pp. 1172-1190, 2012.

[7]. M. Verma, A. Kumar and Y. Singh, "Power System Reliability Evaluation Using Fault Tree Approach Based on Generalized Fuzzy Number", Journal of Fuzzy Set Valued Analysis, vol. 2012, pp. 1-13, 2012.

[8]. R. Kavin, T. Kesavan and S. Anbumani, "A Smart Monitoring of Faults in Power Transformers and Maintenance Based on WiFi", International Journal of Engineering Research, vol. 6, no. 8 , p. 382, 2017

[9]. F. Peng, "Study on Transformer Fault Diagnosis Based on Dynamic Fault Tree", Journal of Electrical and Electronic Engineering, vol. 3, no. 5, p. 133, 2015.

[10]. S.D. Fabiyi, A.O. Abdulmalik, H.A. Tiamiu, "Dwindling Electrical Power Supply in Nigeria: Causes and Possible Solutions", International Journal of Science and Research (ISJR).6.14 (2013).

[11]. O. Onohaebi, "Power Outages in the Nigeria Transmission Grid", Research Journal of Applied Sciences, 4: 1-9, 2009

[12]. R. Uhunmwagho and E. Kenneth, "Issues and Challenges in the Nigerian Electricity Industry: Case of Benin Electricity Distribution Company", Academic Journal of Interdisciplinary Studies, 2013.

[13]. E. Vincent and S. Yusuf, "Integrating Renewable Energy and Smart Grid Technology into the Nigerian Electricity Grid System", Smart Grid and Renewable Energy, vol. 05, no. 09, pp 220-238, 2014.

[14]. V. Behjat, A. Vahedi, A. Setayeshmehr, H. Borsi and E. Gockenbach, "Diagnosing Shorted Turns on the Coils of Power Transformers Based Upon Online FRA Using Capacitive and Inductive Couplings", IEEE Transactions on Power Delivery, vol. 26, no. 4, pp. 2123-2133, 2011

[15]. M. Judd, O. Farish, S. McArthur and J. McDonald, "Intelligent condition monitoring and asset management: Partial discharge monitoring for power transformers", Power Engineering Journal, vol. 16 , no. 6, pp. 297-304, 2002

[16]. "Wireless Condition Monitoring Technique of Power Transformer and Formulation of Health Index", International Journal of Science and Research (IJSR), vol. 5, no. 3, pp. 222 226, 2016.

[17]. M. Jabloski and E. Napieralska-Juszczak, "Internal faults in power transformers", IET Electric Power Applications, vol. 1, no. 1, p. 105, 2007.

[18]. A. Sahebi and H. Samet, "Efficient method for discrimination between inrush current and internal faults in power transformers based on the non-saturation zone", IET Generation, Transmission \& Distribution, vol. 11, no. 6, pp. 1486-1493, 2017.

[19]. International Electrotechnical Commission, International Standard,

Std 60076-1, Edition 2.1 2000-04, Reference number IEC 60076-1:1993 + A1 .

[20]. An American National Standard, "Standard for Probabilistic risk assessment for Nuclear Power Plant Applications", ASME RA-S2002. (2002)

[21]. M.Wang, A.J. Vandermaar, K.D.Srivastava,"Review of condition assessment of power transformers in services," IEEE Electrical Insulation Magazine, Vol.18.(2002)

[22]. IEEE Standard Terminology for Power and Distribution Transformers. IEEE Std C57.12.80. (2002).

[23]. J. E. Mack, T. Shoemaker, "Chapter 15 - Distribution Transformers", The Lineman's and Cableman's Handbook (11th ed.) McGraw-Hill. pp. 15-1 to 15-22.ISBN 0-07-1467890. (2006, New York).

[24]. US Department of the interior bureau of reclamation: Transformer Maintenance, facilities instructions, standards, and techniques. FIST Volume 3-30", Denver, Colorado. (2000)

[25]. U.S. Army Corps of Engineers :Transformer Condition Assessment, Hydro Plant Risk Assessment Guide. Hydro Quebec, and Bonneville Power Administration. (2006)

[26]. R. Heywood, J. Lapworth, L. Hall, Z. Richardson,” Transformer lifetime performance: Managing the risk," 3rd IEE International 
Conference on Reliability of Transmission and Distribution Networks, p.309-313.(2005)

[27]. Z.Weizheng, Y.Li, L.yang,Z.Wang, J.Zhang, B.Hu, K.Shi, “ Study on Life management of Power Transformer", Proceeding of the 5th WSEAS Int. Conf. on Instrumentation, Measurement, Circuits and Systems, Hangzhou, pp. 175-179, China April 2006.

[28]. I.A. Metwally, "Failures, monitoring, and new trends of power transformers," IEEE Potentials, IEEE, Vol.30, p. 36-43. (2011)

[29]. L.M. Geldenhuis, "Power transformer life management," 18th International Conference on Electricity Distribution, Turin , 6-9 June. (2005)

[30]. IEEE Standard Requirements for Liquid-Immersed Distribution Substation Transformers. IEEE Std C57.12.36. (2007)

[31]. Y. Oue, T. Koyabashi, "Life management of transformers in Japan," IEEE, Transmission and Distribution Conference and Exhibition, Asia Pacific. (2002)

[32] M. Darveniza, et al., "Investigations into effective methods for assessing the condition of insulation in aged power transformers," IEEE Trans. Power Delivery,Vol.13,No.4, p.1214-1223.(1998)

[33]. T. Kohda, "Accident analysis of protective systems based on system control concepts," Reliability and Maintainability Symposium.(2007)

[34]. M. Fischer, S. Tenbohlen, M. Schafer, R. Haug, 'Determining power transformers sequence of maintenance and repair in power grids", IEEE International Symposium on. (2010)

[35]. IEEE C57.125-1991 "IEEE Guide for Failure Investigation, Documentation, and Analysis for Power Transformers and Shunt Reactors", Transformer Committee of the IEEE Powe Engineering Society, Copyright 1992 by the Institute of Electrical and Electronics Engineers, Inc., ISBN 1-55937-160-9

[36]. "Dwindling Electrical Power Supply in Nigeria: Causes and Possible Solutions", International Journal of Science and Research (IJSR), vol. 5, no. 5, pp. 635-639, 2015.

[37]. A. Ashrafian, M. Rostami and G. Gharehpetian, "Hyperbolic Stransform-based method for classification of external faults, incipient faults, inrush currents and internal faults in power transformers", IET Generation, Transmission \& Distribution, vol. 6 , no. 10 , p. 940,2012

[38]. A. Kumar, S. Kumar, H. Zakir, "Root-cause analysis of transformer failure scenario at power sub-station", Adv Environ AgricSci 2015:265-70

[39]. C. Etukudor, A. Abdulkareem, O. Ayo. "The Daunting Challenges of the Nigerian Electricity Supply Industry", Journal of Energy Technologies and Policy. 5. 25-33. (2015)

[40]. O. Somefun, "The Erratic Electric Power Supply in Nigeria: Causes and Remedy" 10.13140/RG.2.1.4755.8008. (2015)

[41]. A. Oluwole, O. Samuel, O. Festus, O. Olatunji, "Electrical Power Outage in Nigeria: History, Causes and Possible Solutions", Journal of Energy Technologies and Policy. 2(6)

[42]. CIGRE Working Group 12.8, "Guidelines for life Management Techniques for Power Transformers," CIGRE Brochure No.227, June 2003

[43]. R.R. Roger, "IEEE and IEC codes to interpret incipient faults in transformers, using gas in oil analysis," IEEE Trans. Elec. Insul., Vol. 13, no. 5, pp. 349-354, (1978)

[44]. "Interpretation of the analysis of gases in transformers and other oil-filled electrical equipment in service," IEC Publication 599 (1978)

[45]. M. Duval, "Dissolved gas analysis: It can save your transformer," IEEE Electrical Insulation Mag., vol. 5, no. 6., pp. 22-27. (1989)

[46]. Inoue, Y., Suganuma, K.,Kamba, M. and Kikkawa, M., "Development of oil- dissolved gas detector for diagnosis of transformers"; IEEE Transactions on Power Delivery, Vol. 5, No. 1, pp. 226-232. (1990)

[47]. Zhang, Y., Ding, X., Liu, Y. and Griffin, P. J., "An artificia neural network approach to transformer fault diagnosis"; IEEE Transactions on Power Delivery, Vol. 11, No. 4, pp. 1836-1841. (1996)

[48]. Huang, Y. C., Yang, H. T. and Huang, C. L., "Developing a new transformer fault diagnosis system through evolutionary fuzzy logic"; IEEE Transactions on Power Delivery, Vol. 12, No. 2, pp. 761-767. (1997)

[49]. Lin, C. E.; Ling, J. M. and Huang, C. L.: "An expert system for transformer fault diagnosis using dissolved gas analysis"; IEEE
Transactions on Power Delivery, Vol. 8, No. 1, pp. 231-238 (1993)

[50]. Tomsovic, K.; Tapper, M. and Ingvarsson, T., "A fuzzy information approach to integrating different transformer diagnostic methods"; IEEE Transactions on Power Delivery, Vol 8, No. 3, pp. 1638-1646. (1993)

[51]. Cardoso, A. J. M. and Oliveira, L. M. R., "Condition monitoring and diagnostics of power transformers", International Journal of COMADEM, vol. 2, No. 3, pp. 5-11. (1999)

[52]. "Guide for the Sampling of Gases and Oil from Oil-Filled Electrical Equipment and for the Analysis of Free and Dissolved Gases," IEC Publication 567. (1992)

[53]. IEEE Guide for the Interpretation of Gases Generated in OilImmersed Transformers, IEEE Std. C57.104-1991. (1991)

[54]. T.K. Saha, "Review of Modern Diagnostics Techniques for Assessing Insulation Condition in Aged Transformers, "IEEE Transactions on Dielectrics and Electrical Insulation, Vol. 10, No. 5; October 2003

[55]. M. Salam \& Q. Rahman \& F. Wen, S. Ang, W. Voon, "Causes of transformer failures and diagnostic methods - A review", Renewable and Sustainable Energy Reviews. 10.1016/j.rser.2017.05.165. (2017)

[56]. J. Sihite and T. Kohda, "Assessing the Reliability of Powe Transformer by Quantitative Fault Tree Analysis", Advanced Materials Research, vol. 694-697, pp. 901-906, 2013.

[57]. J. Marks, D, Martin, T, Saha, O, Krause, A, AlibegovicMemisevic G, Russell, ...\& MacArthur, T. (2016, September). An analysis of Australian power transformer failure modes, and comparison with international surveys.In Power Engineering Conference (AUPEC), 2016 Australasian Universities (pp. 16). IEEE

[58]. H. Wang and K. Butler, "Modeling Transformers with Internal Incipient Faults", IEEE Power Engineering Review, vol. 22, no. 2, pp. 64-64, 2002

[59]. V. Behjat and A. Vahedi, "Analysis of internal winding short circuit faults in power transformers using transient finite element method coupling with external circuit equations", International Journal of Numerical Modelling: Electronic Networks, Devices and Fields, vol. 26, no. 5, pp. 425-442, 2013

[60]. A. Vahedi and V. Behjat, "Online monitoring of power transformers for detection of internal winding short circuit fault using negative sequence analysis", European Transactions on Electrical Power, vol. 21, no. 1, pp. 196-211, 2010.

[61]. H. Wang and K. Butler, "Modeling Transformers with Interna Incipient Faults", IEEE Power Engineering Review, vol. 22, no. 2 , pp. 64-64, 2002

[62]. J. Sihite and T. Kohda, "Assessing the Reliability of Power Transformer by Quantitative Fault Tree Analysis", Advanced Materials Research, vol. 694-697, pp. 901-906, 2013

[63]. A. Kochetkov, "Monitoring and Recording of Electric Power via the Electric Power Supply Networks", Measurement Techniques, vol. 47, no. 7, pp. 678-681, 2004

[64]. Y. Wang, X. Li, J. Ma and S. Li, "Fault diagnosis of power transformer based on fault-tree analysis (FTA)", IOP Conference Series: Earth and Environmental Science, vol. 64, p. 012099 , 2017.

[65]. M. Martins, "Condition and risk assessment of powe transformers: a general approach to calculate a Health Index", Ciência\&Tecnologia dos Materiais, vol. 26, no. 1, pp. 9-16, 2014

[66]. L. Ogunwolu, O. Ero and O. Ibidapo-Obe, "Modeling and optimization of an electric power distribution network planning system using mixed binary integer programming", Nigerian Journal of Technology, vol. 36, no. 2, p. 552, 2017.

[67]. G. Modukpe, "Failure Analysis of Distribution Transformers - A Case Study of Ughelli”, Business Unit. Vol 10, No 9,. 172 176. (2018).

[68]. G. Bastos, "An Analysis of the Increase on Transformer Failure Rate Phenomena and Measures Taken to Improve Transformers Reliability," Proceedings of the CIGRE Bienal5, Paris, 2006.

[69]. F. Bedell, "History of A-C Wave Form, Its Determination and Standardization". Transactions of the American Institute of Electrical Engineers. $61 \quad$ (12): 864.1942 doi:10.1109/TAIEE.1942.5058456

[70]. W.H. Bartley, P.E. "Keeping the Lights On: An Action Plan for America's Aging Utility Transformers." Retrieved from: 
https://www.hsb.com/thelocomotive/Story/FullStory/ST-FSTRANAGE.html

[71]. W.S. Lee, D.L. Grosh, F.A.Tillman, C.H. Lie," Fault Tree Analysis, Methods, and Application-A Review", IEEE, Transactions on Reliability vol.R- 34, No.3. (1985)

[72]. P.K.Pande, M.E.Spector, P.Chatterjee," Computerized fault tree analysis," TREEL AND MICSUP,ORC 75-3. Operation Research Center, University of California, Berkeley, April 1975.

[73]. ANSI/IEEE, Guide for loading mineral-oil-immersed transformer, Std.C57.91-1995. (1995)

[74]. IEC, Loading guide for oil-immersed power transformers, Std 60076-7. (2005)

[75]. L. Tong, "Research on Intelligent Online Monitoring and Evaluation of Power Transformer", The Open Electrical \& Electronic Engineering Journal, vol. 9, no. 1, pp. 483-489, 2015.

[76]. http://www.weibull.com/basics/fault-tree/index.htm

[77]. S. Tyagi, D. Pandey and V. Kumar, "Fuzzy Fault Tree Analysis for Fault Diagnosis of Cannula Fault in Power Transformer", Applied Mathematics, vol. 02, no. 11, pp. 1346-1355, 2011.

[78]. M. Islam, G. Lee and S. Hettiwatte, "A review of condition monitoring techniques and diagnostic tests for lifetime estimation of power transformers", Electrical Engineering, 2017.

[79]. J. Dugan, S. Bavuso and M. Boyd," Dynamic fault tree models, for fault tolerant computer systems," IEEE Transactions on Reliability, Vol. 41, No.3, September 1992, pp 363-377. (1992)

[80]. J. Pukite and P. Pukite, "Modeling for Reliability Analysis," IEEE Press. (1998)

[81]. T. Kohda, E.J. Henley, " On Diagraphs, Fault Trees, and Cut Sets”, Reliability Engineering and System Safety, 20 pp 35-61. (1988)

[82]. J.B. Fussell, E.B. henry, N.H Marshall," Mocus-a computer program to obtain minimal cut sets from fault trees," ANCR1156, Aerojet Nuclear Company, Idaho Falls, Idaho, 1974, March. (1974)

[83]. J.B. Fussell, W.E. Vesely," A new methodology for obtaining cut sets for fault trees," Trans. Amer. Nuc.Soc. Vol 15, 1972, p.262. (1972).

[84]. R. Sinnamon and J. Andreas, "Fault Tree Analysis and Binary Decision Diagrams, Proceedings of the Reliability and Maintainability Symposium, January 1996, pp 215-222. (1996)

[85]. A. Rauzy, "New Algorithms for Fault Tree Analysis, Reliability Engineering and System Safety, Vol. 40, 1993, pp 203-211. (1993)

\section{ABBREVIATIONS AND ACRONYMS}

FTA

SPSS

IEEE

PT

OLTC

ANSI

EPRI

CIGRE

$\mathrm{AC}$

DC

$\mathrm{T} / \mathrm{S}$

ACC

TR

KV

KVA

MVA

MW

$\mathrm{Hz}$

YRS
Fault Tree Analysis

Statistical Package for Social Sciences

Institute of Electrical and Electronics

Engineers

Power Transformer

On-load Tap Changer

American National Standards Institutes

Electric Power Research Institute

Conseil international des grands réseaux électriques (The International Council on Large Electric Systems)

Alternating Current

Direct Current

Transmission Station

Area Control Center

Auto Power Transformer

Kilo Volts

Kilo Volts Ampere

Mega Volts Ampere

Mega Watts

Hertz

Years

$\begin{array}{ll}\text { HRS } & \text { Hours } \\ \text { ONAN } & \text { Oil Natural - Air Natural } \\ \text { ONAF } & \text { Oil Natural - Air Forced } \\ \text { OFAF } & \text { Oil Forced - Air Forced } \\ \text { REF } & \text { Restricted Earth Fault } \\ \text { DIFF } & \text { Differential } \\ \text { SBEF } & \text { Standby Earth Fault } \\ \text { PRM } & \text { Pressure Relief Machine } \\ \text { BRD } & \text { Buchholz Relay Device } \\ \text { PLC } & \text { Programmable Logic Controller } \\ \text { BDDs } & \text { Binary Decision Diagrams } \\ \text { MCS } & \text { Minimal Cut Sets } \\ \text { IAEA } & \text { International Atomic Energy Agency } \\ \text { SBE } & \text { Single Basic Event } \\ \text { DBE } & \text { Double Basic Event } \\ \text { IEC } & \text { International Electro-technical Commission } \\ \text { IEEE } & \text { Institute of Electrical and Electronics } \\ & \text { Engineers } \\ \text { PROB } & \text { Probability } \\ \text { TCN } & \text { Transmission Company of Nigeria }\end{array}$

